\title{
Beyond lipids and smoking
}

Citation for published version (APA):

Brandenburg, V. M. (2019). Beyond lipids and smoking: the nephrologist's perspective on cardiovascular disease associated with CKD. [Doctoral Thesis, Maastricht University]. ProefschriftMaken Maastricht. https://doi.org/10.26481/dis.20190906vb

Document status and date:

Published: 01/01/2019

DOI:

10.26481/dis.20190906vb

Document Version:

Publisher's PDF, also known as Version of record

\section{Please check the document version of this publication:}

- A submitted manuscript is the version of the article upon submission and before peer-review. There can be important differences between the submitted version and the official published version of record.

People interested in the research are advised to contact the author for the final version of the publication, or visit the DOI to the publisher's website.

- The final author version and the galley proof are versions of the publication after peer review.

- The final published version features the final layout of the paper including the volume, issue and page numbers.

Link to publication

\footnotetext{
General rights rights.

- You may freely distribute the URL identifying the publication in the public portal. please follow below link for the End User Agreement:

www.umlib.nl/taverne-license

Take down policy

If you believe that this document breaches copyright please contact us at:

repository@maastrichtuniversity.nl

providing details and we will investigate your claim.
}

Copyright and moral rights for the publications made accessible in the public portal are retained by the authors and/or other copyright owners and it is a condition of accessing publications that users recognise and abide by the legal requirements associated with these

- Users may download and print one copy of any publication from the public portal for the purpose of private study or research.

- You may not further distribute the material or use it for any profit-making activity or commercial gain

If the publication is distributed under the terms of Article $25 \mathrm{fa}$ of the Dutch Copyright Act, indicated by the "Taverne" license above, 


\section{Beyond lipids and smoking - the nephrologist's perspective on cardiovascular disease associated with CKD}

\section{Vincent Matthias Brandenburg}


(C) copyright Vincent Brandenburg, Maastricht 2019

Printing: ProefschriftMaken || www.proefschriftmaken.nl

ISBN 9789463804790

All rights reserved. No part of this publication may be reproduced, stored in a retrieval system or transmitted, in any form or by any means, electronic, mechanical, photocopying, recording or otherwise, without prior permission of the author or the copyright-owning journals for previous published chapters. 


\section{Beyond lipids and smoking - the nephrologist's perspective on cardiovascular disease associated with CKD}

Dissertation

to obtain the degree of Doctor at Maastricht University, on the authority of the Rector magnificus Prof. Dr. Rianne M. Letschert in accordance with the decision of the Board of Deans, to be defended in public on Friday, September $6^{\text {th }}$ at 10.00 hours

by Vincent M. Brandenburg 
Supervisor:

Prof. Dr. H.P. Brunner-la Rocca

Co-supervisor: Dr. C. Knackstedt,

\section{Assessment Committee:}

Prof. Dr. A.W.J. van 't Hof, (chairman)

Prof. Dr. F.W. Dekker, (Leids UMC)

Prof. Dr. J.P. Kooman,

Prof. Dr.med. H. Reinecke, (Klinik fuer Kardiologie, Universitaetsklinikum

Muenster, Deutschland)

Prof. Dr. C.P.M. Reutelingsperger, 
Aan Iris, Franca, Lorenz, Thea 


\section{CONTENTS}

1. SECTION: General introduction ................................................. 1

2. SECTION: Fibroblast growth factor 23 (FGF23) and cardiovascular risk

a) Fibroblast growth factor 23 (FGF23) and mortality: the Ludwigshafen Risk and Cardiovascular Health Study (IF 4).................................. 13

b) Soluble klotho and mortality: the Ludwigshafen Risk and Cardiovascular Health Study (IF 4) ................................................ 31

c) High-Dose Ferric Carboxymaltose in Patients With HFrEF Induces Significant Hypophosphatemia (IF 19) ............................................ 51

3. SECTION: Vitamin K and cardiovascular disease..........................57

a) Calcific uraemic arteriolopathy (calciphylaxis): data from a large

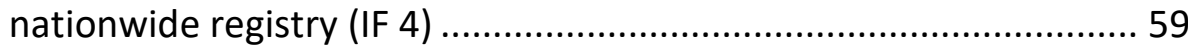

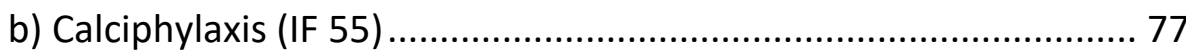

c) Slower Progress of Aortic Valve Calcification With Vitamin K Supplementation: Results From a Prospective Interventional Proof-ofConcept Study (IF 19) ................................................................ 99

4. SECTION: Additional documents ..........................................105

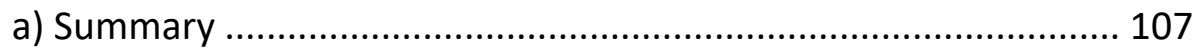

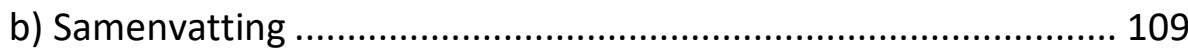

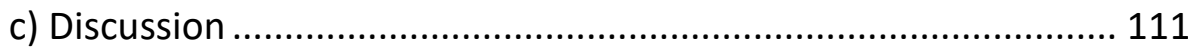

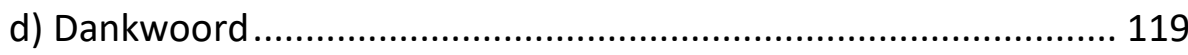

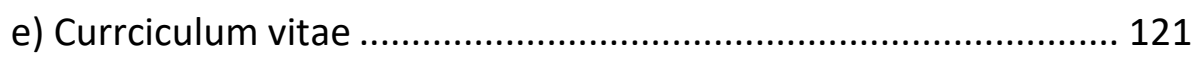

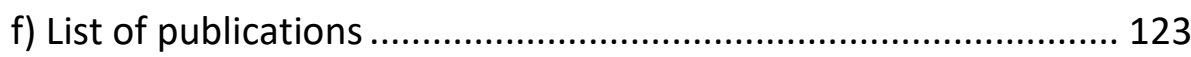

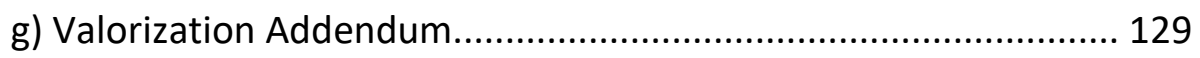

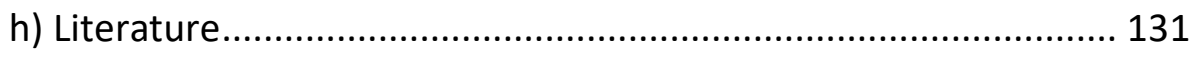




\section{SECTION: \\ General introduction}




\section{Overview on cardiovascular risk in chronic kidney disease}

Chronic kidney disease (CKD) is a significant risk factor for the development of cardiovascular disease with a major impact on disease severity and can as such be considered equivalent to diabetes mellitus (1). This association is dose-dependent, meaning that already small declines in renal function, as assessed by subnormal levels of glomerular filtration rate (GFR) or the occurrence of albuminuria, increases the risk for cardiovascular events and mortality (1). Indeed, a patient with early CKD has a risk of developing cardiovascular disease (CVD) approximately twenty times higher than the risk to ultimately require renal replacement therapy (2). In regard to the most severe form of CKD, i.e. endstage renal disease (ESRD), it has been convincingly shown that dialysis patients suffer from an exorbitantly high risk which brings likelihood of death in an 20-year-old ESRD patient within the same range as in "healthy" octogenarians $(1 ; 3)$. The reasons for the excessive cardiovascular morbidity and mortality in patients with CKD are manifold, and various risk factors in many divergent areas and disease conditions contribute to this risk (4) (Figure 1). Among the previously established risk factors, FGF23 excess/klotho deficiency as well as distubances in vitamin $\mathrm{K}$ metabolism have gained a substantial amount of scientific and clinical interest.

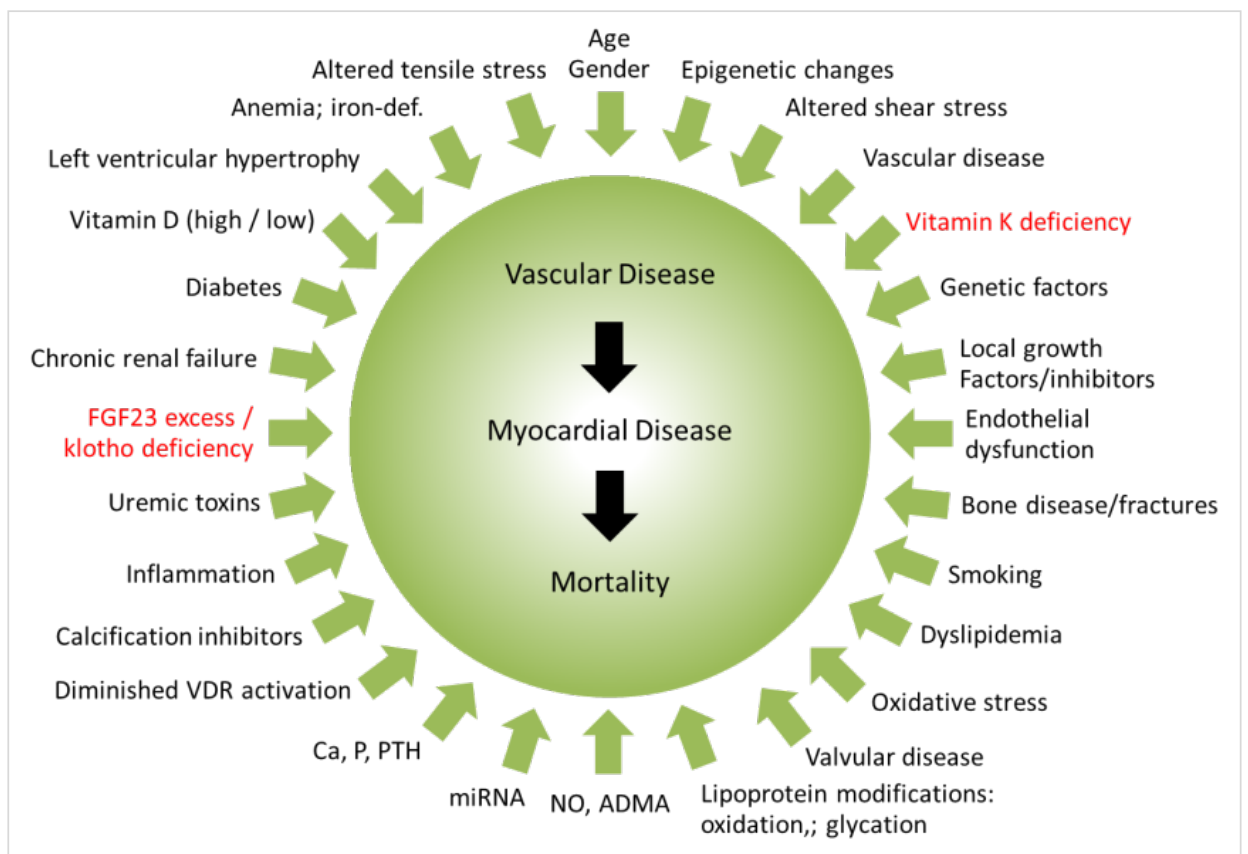

Figure 1: Schematic overview of tradional and non-traditional cardiovascular risk factors; marked in red are the topics of the present thesis 
These risk factors and predisposing conditions can be classified into several categories, e.g. disturbed mineral metabolism, deficiency of factors inhibiting ectopic (vascular) mineral deposition and chronic inflammatory states. Many of the uremia-associated cardiovascular risk factors belong to a syndrome known as chronic kidney disease - mineral and bone disorder (5). This syndrome nicely summarizes how different organs, such as the endocrine glands or the skeleton, contribute to the cardiovascular risk in CKD. Cardiovascular disease (CVD) in CKD patients differs in various ways from CVD in non-renal patient populations. These differences encompass the age of occurrence and speed of development as well as the clinical consequences. The vascular phenotype in CKD patients exhibits some specific features undetectable in the typical coronary artery disease patient with healthy kidneys. While a major proportion of the cardiovascular risk in patients without significant CKD can be attributed to the so-called traditional Framingham risk factors such as arterial hypertension and smoking, non-traditional risk factors are considered to be the major driving force behind cardiovascular risk in CKD patients (Figure 1). The complexity of CVD disease in CKD is in many ways reflected by the unsuccessful attempt to transfer wellestablished CVD-modifiying drugs such as statins into the ESRD population, whereas statins have failed to reduce mortality in these patients (6).

\section{Vascular calcification as a hallmark of CKD-associated cardiovascular disease}

Accelerated and premature vascular calcification is one of the non-traditional Framingham cardiovascular risk factors among CKD patients (7). Vascular calcification in CKD is the final common pathway of various disturbances ranging from abnormalities in local cellular functions (8) to skeletal demineralization processes (9). These demineralization processes stimulate the deposition of calcium and phosphate in the vascular wall due to the inhibited mineral buffering capacities of bone (9). Vascular calcification is not only physico-chemical precipitation but represents a regulated and cell-mediated process as well (8). All anatomical cardiovascular structures are susceptible to the development of premature and acceletared calcifications in CKD and ESRD patients. Calcifications in arteries and heart valves, which ultimately directly impair cardiovascular function such as elasticity and valvular hemodynamics, are of specific clinical importance. A specific subtype of cardiovascular calcification is a rare disease coined calciphylaxis.

\section{Calciphylaxis as an extreme variant of vascular calcification in CKD}

Calciphylaxis (calcific uremic arteriolopathy, CUA) is a life-threatening disease which is increasingly acknowledged as a challenging condition at the interface of nephrology, dermatology and cardiology (10). Calciphylaxis predominantly occurs in ESRD patients. The primary CUA diagnosis is most often made in nephrology care units because the vast majority of affected cases are detected in patients undergoing chronic hemodialysis therapy. The typical clinical cascade starts with severe pain often in initially inconspicuous skin areas and may ultimately progress to deep tissue ulcerations (10). Figure 2 depicts prototypic 
macroscopic skin findings at the lower thigh in a calciphylaxis patient. Clinically, the lesions were painful and discomfort started before lesions were visible.

Ulcer development is a severe complication with particularly high morbidity and mortality. Unfortunately, the nephrology community must lament a certain stagnancy in regard to the slow progress in our understanding of how and why CUA develops. Moreover, there are several important open issues regarding therapy that have yet to be successfully addressed (10). The pathohistological hallmarks of the disease are circumferential calcifications in small skin arterioles which contribute to endothelial shedding and luminal thrombosis (10).

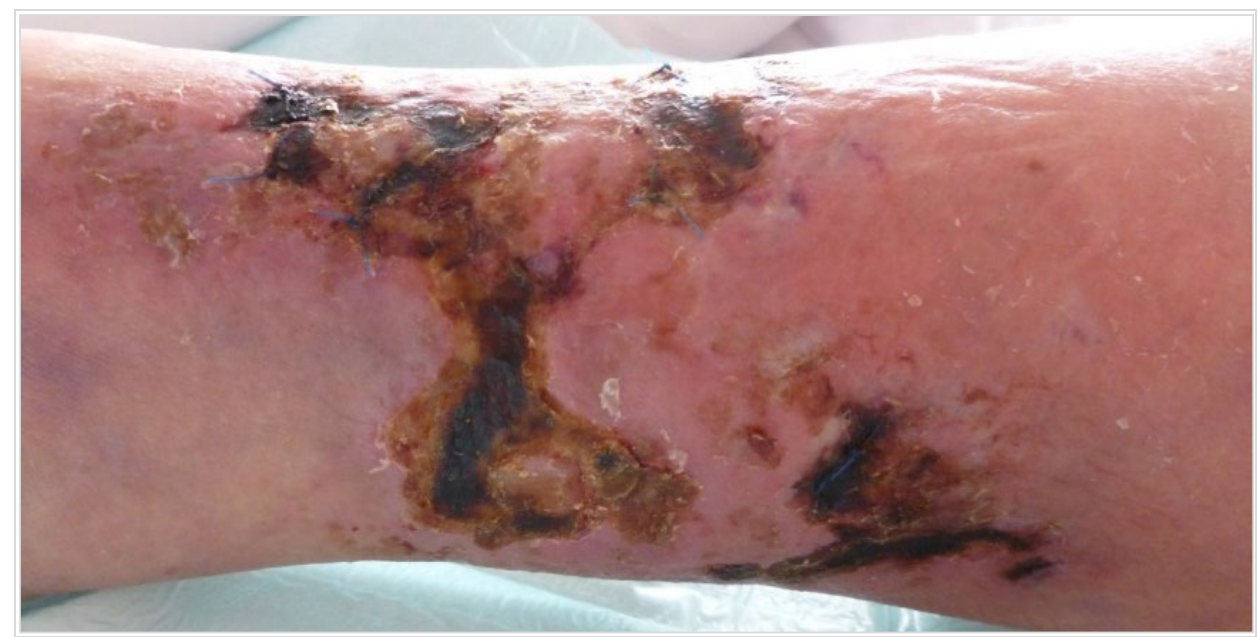

Figure 2: Macroscopic appearance of calciphylaxis at the lower thigh.

A major risk factor for calciphylaxis is previous vitamin $\mathrm{K}$ antagonist treatment such as warfarin or phenprocoumon (11). Application of vitamin $\mathrm{K}$ antagonists apparently predisposes the vascular wall to the development of calcification $(12 ; 13)$. Vitamin $K$ deficiency is increasingly acknowledged as a risk factor that can trigger the development of vascular calcification.

Collecting and analyzing data from calciphylaxis patients is difficult due to the rare and unpredictable occurrence in these patients. In countries where centralized data storage for all incident and prevalent dialysis patients is not compulsory (as in most European countries) alterantive routes of data collection are required. A nation-wide and prospectively international internet-based registry approach is such an alternative (www.calciphylaxis.net) (14). One of the reasons EuCalNet was founded was to benefit the analysis of potential risk factors, among them VKA use which has become recongnized as a modifiable risk factor of major importance $(10 ; 15)$. 
A major goal of the present thesis is to provide epidemiological, cross-sectional data derived from a national survey on calciphylaxis in Germany based on an internet-based registry (16). These data were in part integrated into a summarizing review which gives a clinically focused update on calciphylaxis. This update is intended to represent a state-ofthe-art summary regarding etiology, pathogenesis, and clinical presentation. Moreover, therapeutic strategies (e.g. the potential benefits of VKA avoidance and vitamin K application, see below) were specifically reviewed (10).

\section{Vitamin K and its implications for cardiovascular health}

Vitamin $\mathrm{K}$ is best known as a purely hemostasiological co-factor required to activate clotting factors. However, it is also a key factor in the regulation of bone and soft tissue calcification based on the anti-calcific property of vitamin $\mathrm{K}$ due to its ability to activate matrix-Gla protein (MGP) (17). Comparable to other clotting factors, MGP needs to undergo posttranslational gamma-glutamylcarboxylation of specific protein- bound glutamate residues, for which vitamin $\mathrm{K}$ is an essential co-factor. Hence, these proteins are called vitamin K-dependent proteins (Gla-proteins) (18). Data from epidemiological studies have pointed to an important role of Vitamin $\mathrm{K}$ as a potential protective factor for cardiovascular health (19). Research investigating the role of vitamin $\mathrm{K}$ in vascular biology started some 20 years ago with a first description of the MGP knock-out animal modell. Luo and coworkers were the first to show that MGP deficiency in mice resulted in vascular calcification at the elastic lamellae of the aortic wall starting as early as two weeks after birth (20). This deficiency had a deleterious consequence: MGP-deficient animals died prematurely due to rupture of the heavily calcified aorta and internal hemorraghe (20). The next step was initiated by Price and colleagues showing that the chemical inhibition of MGP function by the vitamin K-antagonist warfarin resulted in a similar calcification phenotype (21). Hence, application of warfarin mimicks to some extent the MGP knock-out phenotype. It is important to understand that vitamin $\mathrm{K}$ exists in two subtypes, vitamin $\mathrm{K} 1$ and $\mathrm{K} 2$. Both exhibit strong overlap in biological function but do have some specificities in their mode of action with $\mathrm{K} 1$ predominantly stabilizing hepatic synthesis of active clotting factors and K2 being responsible for peripheral MGP activation in the arterial wall. Rodent experiments with warfarin as inductor of vascular calcification require some vitamin K1 application in order to avoid fatal bleeding in the animals prior to the development of calcification (13). Mutagenesis of the Glu residues into aspartate residues indeed resembled the warfarininduced calcification phenotype (22). These findings established MGP as an important inhibitor of vascular calcification, and more precisely, as a local calcification inhibitor (22). Noteworthy, the severe calcification phenotype induced by MGP deficiency or MGP inactivity could not be rescued by systemic, rather only by local arterial wall knock-in of MGP. From these data, a paradigm shift for vitamin $\mathrm{K}$ was induced. The sole function of vitamin $\mathrm{K}$ as coagulation cofactor was expanded by its novel function in protecting the vascular wall against calcification, hence contributing to vascular health (18). 


\section{Vitamin K antagonists as potential inducers of vascular calcification}

Vitamin K deficiency can occur via two routes: insufficient oral supply and / or treatment with vitamin $\mathrm{K}$ antagonists. The first evidence for a link between nutritional vitamin $\mathrm{K}$ status and vascular health was provided by the Rotterdam study (19). In this study, dietary intake of phylloquinone (vitamin $\mathrm{K}-1$ ) and menaquinone (vitamin $\mathrm{K}-2$ ) was related to aortic calcification and coronary heart disease (CHD) in 4,807 elderly subjects recruited from the general population. Risk of incident CHD, all-cause mortality, and vascular pathology (aortic calcification) was studied in relation to vitamin $\mathrm{K}$ intake. Intake of vitamin K-2 was inversely related to both cardiovascular mortality and presence of aortic calcification. Interestingly, no such benefits could be detected with respect to different levels of vitamin K-1 intake. Since the Rotterdam study (19), several additional associative cohort studies have supported the hypothesis that insufficient dietary intake of vitamin $\mathrm{K}$ is associated with increased risk of cardiovascular calcification, whereas high dietary intake of vitamin K exerts cardiovascular protection. However, these studies cannot prove causality since there might be residual confounding - e.g. vitamin $\mathrm{K}$ intake might just be a reflector of overall healthy nutrition and life style including a high intake of leafy green vegetables. Spinach and broccoli are amongst the most important vitamin $\mathrm{K}$ suppliers in the Western diet.

However, as already discussed, these epidemiological data are supported by fundamental in vitro and in vivo work demonstrating that the use of vitamin $\mathrm{K}$ antagonists (VKA) for oral anticoagulation therapy (OAT) accelerates cardiovascular calcification $(12 ; 13)$. This has significant implications for human therapeutic strategies (23) since the application of VKA is still a common finding in general practice despite the availability of alternatives, i.e. the so-called non-vitamin K antagonists (NOAKs). In animals, it has been shown that vitamin $\mathrm{K}$ application can reverse VKA-induced calcification. In rats with warfarin-induced medial elastocalcinosis, high intake of vitamin K-1 and K-2 for 6 weeks reversed calcification, indicating that the process of vascular calcification is amendable through intervention (24). In line with these increasingly available experimental findings (25), several human noninterventional studies point towards an association between OAT with VKA and amount of vascular calcification, while NOAKs promise to be a safer alternative (23;25-27). Remarkably, VKA-induced ectopic calcification in humans was first described in tracheal cartilage (28). MGP also protects cartilage from ectopic, non-physiological calcification. Importantly, clinical associations between VKA use and calcification were described for both the arterial vessel wall and heart valves (29-31). Additionally, as mentioned above, VKA use is considered a major risk factor for the development of calciphylaxis (32) (Figure 2). Major implications for health care emerge, since some degree of cardiovascular calcifications in the elderly morbid population might actually arise from usage of VKA despite alternatives for OAT. 
Several aspects regarding the association of vitamin $\mathrm{K}$ and protection against vascular calcification are under debate: First, a significant association between VKA use and cardiovascular calcification was not confirmed by all previous studies $(33 ; 34)$. Secondly, most studies do not allow true causality between VKA use and calcification to be determined since we cannot definitively exclude bias by indication. Thirdly, vascular calcification might also cause a disease condition requiring VKA use (reverse causality). In summary, while speculations about long-term VKA use (i.e. $>12$ months) as a causative factor for vascular calcification in patients are intriguing, true proof of concept in humans is still lacking. Indeed, the potential importance of VKA for anticoagulant treatment could certainly exceed arteriosclerosis development (i.e. vascular calcification in the medial layer of the vascular wall). It may also negatively affect plaque composition and therefore intimal atherosclerosis development (reviewed extensively in (35)). Warfarin use in ApoE-deficient mice provided experimental evidence that VKA-induced vascular deficiency resulted in a vulnerable plaque phenotype (36). Human randomized controlled studies are an adequate tool to close the gaps of knowledge:

Another major goal of the present work is to present data about the usefulness of vitamin $K$ supplementation in the setting of calcific aortic stenosis in which a slower progression rate of valvular calcification was the primary endpoint (37).

The issue of acelerated cardiovascular calcification by VKA compared to NOAK application is covered by an ongoing trial that will present data from an interim analysis in 2019 (23).

\section{Left ventricular hypertrophy in CKD}

Besides vascular calcification, another cardiovascular pathology, actually myocardial pathology, is a hallmark of CKD patients, i.e. left-ventricular hypertrophy (LVH) (38). The pathophysiology of CKD-associated LVH is complex and multifactorial, and LVH occurs even in the absence of severe and long-standing uncontrolled arterial hypertension or aortic valvular disease in CKD patients. Instead, increased vascular stiffness (which relates to a significant extent to vascular calcification), anemia, hypervolamia, activation of the reninangiotensin and sympathetic nervous system as well as direct toxic effects of uremiaassociated circulating factors (uremic toxins) also contribute to the development of LVH in the setting of CKD (38). Among the latter, fibroblast growth factor 23 (FGF23) is a candidate that is currently undergoing intense debate. 


\section{Fibroblast growth factor 23 (FGF23)}

An important milestone in our understanding of cardiovascular disease in CKD and in determing how skeletal and mineral disturbances relate to this increased risk was the discovery of the profound metabolic, specifically mineral effects of FGF23 (39). FGF23 is a $32 \mathrm{kDa}$ bone-derived potent regulator of vitamin $\mathrm{D}$ and phosphorus metabolism. Circulating FGF23 is mainly produced by osteocytes and osteoblasts. FGF23 primarily targets the renal tubular and parathyroid cells (40). These canonical effects of FGF23 (i.e. regulating phosphate, vitamin D metabolism and PTH) rely upon its interaction with FGF23 receptors and its obligate renal co-receptor alpha-klotho. In renal tubular cells, upon binding to the FGF-receptor and alpha-klotho, FGF23 (1) stimulates the excretion of phosphate, (2) reduces the activation of calcidiol to calcitriol and (3) increases the degradation of the latter $(40 ; 41)$.

FGF23 was originally identified less than 20 years ago as phosphaturic hormone in renal phosphate wasting syndromes such as oncogenic osteomalacia (42). Shortly thereafter, it was found that plasma concentration of FGF23 rises dramatically with increasing severity of CKD (43), and moreover, it is independently associated with poorer outcome among nondialysis CKD patients as well as dialysis patients (44). Soon, FGF23 left the nephrology niche and proved to be of particular interest also for the cardiology community, since the dismal association between high FGF23 levels and poor prognosis is also detectable in patients selected primarily via cardiac disorders (45). Abundant cohort studies followed, all pointing towards the same direction - a morbid association between elevated FGF23 levels and fatal outcome (mortality and morbidity) (46). The next evolutionary step in our FGF23 understanding was the transfer from association towards causality. In addition to the above-mentioned epidemiological and associative studies, recent experimental data have established a causal pathway and linked extra-cardiac FGF-23 directly to the development of cardiovascular pathologies, specifically cardiomyopathy (47). However, even this point of view is again moving forward as evidence grows that the cardiovascular system itself may be able to modulate and even influence FGF23 levels with potential, yet to be determined, local and systemic effects (48). Much of the previous FGF23-related work in cohort studies is based on the assumption that the predictive power of FGF23 is comparable between the two forms, intact (iFGF23) and c-terminal FGF23 (c-term FGF23) (44).

We sought to investigate whether c-term FGF23 can independently predict outcome (cardiovascular events and mortality) in a cohort of patients included by virtue of the need to undergo coronary angiography due to a recent onset of acute coronary syndrome (LURIC cohort) (49).

Much less data is available as to whether a comparable association exists between the circulating part of the obligate FGF23 coreceptor klotho (soluble klotho) and outcome. Hence, we analyzed the same cohort also with regard to s-klotho (50). 


\section{FGF23 with specific focus upon iron metabolism and anemia}

Another interesting aspect of FGF23 is the close association of anemia, inflammation and iron deficiency with substantially increasing levels of FGF23, especially the c-term FGF23 form $(51 ; 52)$. An increasing level of evidence points towards the fact that FGf23 production and release are not only dependent on phosphate intake and serum phosphate levels $(53 ; 54)$., but also upon systemic inflammation, anemia and hypoxia.

Of particular interest, and also of practical importance, is the association between anemia and FGF23. Iron deficiency and anemia associate with high levels of FGF23 in both directions meaning that anemia causes FGF23 increases and high levels of FGf23 aggravate anemia (54-56). While anemia correction and iron replenishment lower FGF23 levels in the long run, very recently a novel disease entity came to the attention of physicians: i.v. iron-associated osteomalacia (57). Apparently, some i.v. formulations cause a transient sharp rise in intact FGF23 levels which cause renal phosphate wasting, hypopshosphatemia and finally, in some at risk patients, induce osteomalacia with an increased risk for Looser's fractures (58). The latter complication was described after repetitive usage over several months to years of i.v. iron. This potential side effect of i.v. iron upon phosphate metabolism has direct clinical implications since iron replenishment is increasingly recommended for various disease conditions with heart failure as a prominent example (59). However, uncertainties exist about the true dimension of the problem and the exact etiology since detailed investigations of FGF23 metabolism shortly after i.v. iron administration have not been performed. Moreover, i.v. iron-associated osteomalacia has not yet been investigated in heart failure patients (rather predominantly in patients with underlying chronic bowel disease (57)) despite the fact that heart failure patients are at risk for osteoporosis which might further increase with widespread usage of i.v. iron (60).

Hence, we identified an unsolved question concerning the issue if and why i.v. iron in heart failure patients could induce hypophosphatemia, and we sought to investiage the exact role of FGF23 metabolism in this setting (61). 


\section{Aim of this thesis}

As shown above, FGF23 excess and vitamin K deficiency are prototypic examples of factors representing the so-called bone-heart-kidney axis. This term describes a condition in which various organs interact and multiply the deleterious effects induced by reduced kidney function. The major aim of the research summarized in the present thesis is an in-depth description of how FGF23 excess and vitamin K deficiency contribute to cardiovascular risk in specific patient cohorts. Importantly, the underlying work addresses not only descriptional data but also focuses upon potential therapeutic influence, i.e. can FGF23 levels be modified and how does vitamin $\mathrm{K}$ replenishment influence vascular calcification processes.

The specific focus of this thesis was addressed in the following workpackages:

- Section A, Chapter 1 presents a cross-sectional description of data on calciphylaxis (incidence, clinical presentation, potential risk factors) in Germany with a focus on the association between calciphylaxis and VKA usage.

- Section A, Chapter 2 is a state-of-the-art review about calciphylaxis.

- Section A, Chapter 3 summarizes data from a human pilot interventional study regarding the efficacy of vitamin $\mathrm{K}$ application to slow the progression of valvular calcification.

- Section B, Chapter 1 and 2 show results from an investigation of the association between circulating FGF23 levels as well as soluble klotho levels and the outcome in an observational prospective cohort study (LURIC) including patients with acute coronary syndrome.

- Section B, Chapter 3 presents data on the impact of iron replenishment upon FGF23 metabolism in heart failure patients in order to gain information about the threat of hypopshosphatemia development. 


\section{SECTION: \\ Fibroblast growth factor 23 (FGF23) and cardiovascular risk}





\section{a)}

Fibroblast growth factor 23 (FGF23) and mortality: the Ludwigshafen Risk and Cardiovascular Health Study (IF 4)

Fibroblast growth factor 23 (FGF23) and mortality: the Ludwigshafen Risk and Cardiovascular Health Study.

Brandenburg VM, Kleber ME, Vervloet MG, Tomaschitz A, Pilz S, Stojakovic T, Delgado G, Grammer TB, Marx N, März W, Scharnagl H. Atherosclerosis. 2014 Nov; 237 (1): 53-9. 


\section{Abstract}

Background: Fibroblast growth factor 23 (FGF23) is an important regulatory hormone in phosphate and vitamin D metabolism. Here, we investigated the associations of FGF23 with traditional cardiovascular risk factors and with bone metabolism parameters as well as the impact of FGF23 upon long-term mortality in a large cohort of patients referred for coronary angiography.

Methods: We examined whether c-term FGF23 concentrations at baseline were associated with cardiovascular and total mortality in 2974 patients from the Ludwigshafen Risk and Cardiovascular Health Study (LURIC). We investigated if these associations were independent from established cardiovascular risk factors as well as from other mineral regulating factors and bone biomarkers such as calcium, parathyroid hormone (PTH), alkaline phosphatase (AP), vitamin D, and serum phosphate.

Results: Mean age of participants was $63 \pm 10$ years; median c-term FGF23 serum levels were 54 (40 - 78) RU/ml. During a median follow-up of 9.9 years, 884 deaths (30\%) occurred, $545(18 \%)$ of which were cardiovascular. FGF23 significantly and inversely correlated with eGFR. AP, phosphate, and PTH increased in parallel with quartiles of FGF23. Age- and sexadjusted hazard ratios (HRs) in the fourth quartile compared to the first quartile of FGF23 were $2.54(95 \% \mathrm{Cl}, 2.09-3.09 ; \mathrm{p}<0.001)$ for all cause and $2.56(95 \% \mathrm{Cl}, 1.99-3.28 ; \mathrm{p}<$ 0.001 ) for cardiovascular mortality. These associations remained significant after additional adjustments for cardiovascular risk factors and bone biomarkers (calcium, PTH, AP, vitamin $\mathrm{D}$, and phosphate): Adjusted HRs were $1.38(95 \% \mathrm{Cl}, 1.26-1.52 ; \mathrm{p}<0.001)$ for all-cause and $1.35(95 \% \mathrm{Cl}, 1.20-1.52 ; \mathrm{p}<0.001)$ for cardiovascular mortality for each increase by one standard deviation of c-term FGF23.

Conclusions: In patients undergoing coronary angiography baseline c-term FGF23 levels predict the risk for all-cause and cardiovascular mortality over 9.9 years of follow-up. These associations were independent of established cardiovascular risk factors and serum phosphate. 


\section{Introduction}

Fibroblast growth factor 23 (FGF23) was initially described as a hormone synthesized by osteocytes with stimulating effects upon renal phosphate excretion and down-regulation of 1.25 dihydroxyvitamin D synthesis. ${ }^{1}$ However, FGF23 activities reach beyond mineral metabolism. Both increased FGF23 concentrations, elevated serum phosphate, and low vitamin $D$ negatively influence cardiovascular health in various patient populations. ${ }^{2,3}$ While the negative effects of high serum phosphate and high FGF23 were originally detected in patients with severely impaired renal function, ${ }^{4,5}$ more recent data also point to dismal effects of elevated serum phosphate and FGF23 in cohorts without overt renal insufficiency ${ }^{6,7}$ In the Heart and Soul study patients in the highest FGF23 tertile revealed a hazard ratio of $2.07(95 \% \mathrm{Cl}, 1.36 \mathrm{e} .13)$ for overall mortality during prospective follow-up as compared to patients in the lowest FGF23 tertile. ${ }^{7}$ The vast majority of previously published data confirm an independent risk of high FGF23 levels for increased cardiovascular morbidity, events and mortality effects in the investigated cohorts. ${ }^{7-13}$ This is of particular interest given the fact that FGF23 helps controlling serum phosphate levels which per se contribute to cardiovascular risk. ${ }^{2}$ Since FGF23 is in the center of complex bone and mineral regulatory systems such as phosphate, alkaline phosphatase, vitamin $D$ or PTH careful adjustments need to be made for possible confounding. Moreover, it is incompletely understood how the association between FGF23 concentrations and outcome is influenced by the background cardiovascular risk and might be different between population-based cohorts compared to those selected for elevated cardiovascular risk or previous events. In the present study we analyzed data from the LURIC (the Ludwigshafen Risk and Cardiovascular Health Study) study including long-term outcome in patients who had been referred for coronary angiography and underwent long-term follow-up. Thorough adjustments for confounders were performed in order to study the independent role of FGF23 in cardiovascular events in this population at intermediate to high risk.

\section{Methods}

2.1. Participants, study design, and definition of comorbidities

The baseline examination of the LURIC study was performed between 1997 and 2000 at a coronary care tertiary referral center (Herzzentrum Ludwigshafen). Overall 3316 patients with coronary angiogram at baseline were included. All patients were Caucasians and were required to be in clinical stable conditions except for acute coronary syndromes. Indications for coronary angiogram were cardiac chest pain, acute coronary syndrome or cardiac ischemia as suspected with non-invasive testing. The patients gave written and informed consent. A diagnosis of coronary artery disease (CAD) was established if at least one stenosis of at least one out of 15 coronary arterial segments according to visual estimation of the maximal luminal narrowing _ $20 \%$ was present. The severity of CAD was quantified with the Friesinger score. ${ }^{14}$ Acute myocardial infarction (MI) was defined as a $\mathrm{MI}$ that had occurred within the four weeks prior to enrollment. A definite STsegment elevation MI (STEMI) was diagnosed if typical ECG changes were present along with prolonged chest pain, refractory to sublingual nitrates and/or enzyme or troponin $T$ 
Brandenburg VM, Kleber ME, Vervloet MG et al. Fibroblast growth factor 23 (FGF23) and mortality: the Ludwigshafen Risk and Cardiovascular Health Study. Atherosclerosis. 2014 Nov; 237(1): 53-9.

elevations (>0.1 mg/L). Non-ST elevation MI (NSTEMI) was diagnosed, if symptoms and/or troponin T criteria weremet without STEMI ECG criteria. Diabetes mellitus was diagnosed by the previous prescription of antidiabetic medication, or fasting blood glucose levels greater than $7.0 \mathrm{mmol} / \mathrm{l}$, or if $\mathrm{HbA} 1 \mathrm{c}$ was $>6.5 \%$. Arterial hypertension was present if the mean blood pressure in one out of five measurements exceeded either $140 \mathrm{~mm} \mathrm{Hg}$ systolic or $90 \mathrm{mmHg}$ diastolic.

Alternatively, current prescription of antihypertensive drugs confirmed the diagnosis of arterial hypertension. Details about participants, recruitment, comorbidities and baseline examinations have been previously described. ${ }^{15}$

\subsection{Outcome assessment during follow-up}

FGF23, lipid, and vitamin D measurements were available in 2974 individuals with coronary angiograms ( $90 \%$ of the entire cohort). During a median follow-up time of 9.9 years 884 $(30 \%)$ of the patients died. No patient was lost to follow-up. Death certificates were missing in 18 decedents who were included in the analysis for total mortality, but excluded from analysis of cardiovascular mortality. Two physicians without knowledge of FGF23 levels and baseline characteristics of the study participants classified causes of death by reviewing hospital records and death certificates. Cardiovascular deaths included sudden cardiac death (SCD), fatal myocardial infarction, deaths due to heart failure, death after intervention to treat CAD, stroke, and other deaths due to heart disease. SCD was defined as a sudden unexpected death either within $1 \mathrm{~h}$ of symptom onset or within $24 \mathrm{~h}$ of having been observed alive and symptom free.

\subsection{Laboratory analyses}

Standard laboratory measurements were performed as previously described. ${ }^{15}$ In brief, venous blood was drawn in the morning before coronary angiography and standard laboratory parameters were immediately determined. Serum and plasma was harvested according to standard procedures and was snap frozen for further determinations and stored at $-80^{\circ} \mathrm{C}$ until further analysis. FGF23 (c-term) was measured by enzyme-linked immunosorbent assay (ELISA, Immundiagnostik AG, Bensheim, Germany), intra- and interassay coefficient of variation were 2.4 and $3.1 \%$, respectively. Intact PTH, and N-terminal pro-B-type natriuretic peptide (NT-pro-BNP) were determined by ElectroChemiLuminescence (ECL) on an Elecsys 2010 (Roche Diagnostics, Mannheim, Germany). Serum concentrations of 25-hydroxyvitamin $D$ were measured by a radioimmunoassay (Dia-Sorin Antony, France; Stillwater, USA) with an intra- and inter-assay coefficient of variation of 8.6 and 9.2\%, respectively. 1.25-dihydroxyvitamin $D$ was measured by radioimmunoassay (Nichols Institute Diagnostika GmbH, Bad Nauheim, Germany) using a multicrystal counter (Berthold LB2014, Dia- Sorin, SA, USA). Estimated glomerular filtration rate (eGFR) was calculated according to the CKD-EPI study equation. ${ }^{16,17}$

\subsection{Statistical analysis}

FGF23 concentration quartiles were generated according to the values of the entire study cohort. Baseline characteristics were analyzed by FGF23 quartiles. Depending on their distribution, continuous parameters are either presented as means \pm standard deviation (normally distributed variables) or as medians with interquartile range (skewed variables). 
Brandenburg VM, Kleber ME, Vervloet MG et al. Fibroblast growth factor 23 (FGF23) and mortality: the Ludwigshafen Risk and Cardiovascular Health Study. Atherosclerosis. 2014 Nov; 237(1): 53-9.

Categorical data are shown as proportions. All skewed continuous parameters were logarithmically transformed before use in parametric procedures. Comparisons across FGF quartiles were carried out by analysis of variance (ANOVA) with $p$ for trend for continuous parameters and by X2-test with $\mathrm{p}$ for linear-by-linear test for categorical variables. For allcause and cardiovascular mortality, KaplaneMeier curves followed by a log-rank test were calculated to show the differences in event-free survival between FGF23 quartiles. Hazard ratios (HRs) with $95 \%$ confidence intervals $(95 \% \mathrm{Cl}$ ) for all-cause and cardiovascular mortality were calculated with Cox proportional hazard models both according to quartiles of FGF23 and per increase of 1 SD. To test for interaction of FGF23 with BMI and eGFR we used Cox proportional hazard models allowing for interaction. Finally, the predictive value of multivariate models with and without FGF23 for total and cardiovascular mortality was calculated using receiver operating characteristic (ROC) curves, net reclassification improvement (NRI) and integrated discrimination improvement (IDI). A p-value below 0.05 was considered statistically significant and all statistical tests were two-sided. Data were analyzed using the SPSS 15.0 statistical package (SPSS Inc., Chicago, IL, USA).

\section{Results}

\subsection{Patient characteristics}

A total of 2974 patients with available FGF23, vitamin D, and lipid levels at baseline were included in the present cohort study (68.7\% male, mean age $63 \pm 10$ years). 648 patients (21.8\%) were free of coronary artery disease. Reduced renal function (defined as an eGFR $<60 \mathrm{ml} / \mathrm{min}$ ) was present in 405 patients (13.6\%). Details regarding patients' characteristics, baseline demographic data and laboratory data of the entire cohort are listed in Table 1. During a median follow-up of 9.9 years 884 (30\%) patients had died. Among these 545 (18\%) deaths were due to cardiovascular reasons. Cardiovascular risk factors, demographic data, and laboratory data were compared between patients with GFR $<60 \mathrm{ml} / \mathrm{min}$ and those with GFR $>60 \mathrm{ml} / \mathrm{min}$ (Table 1).

3.2. Associations between FGF23 levels and cardiovascular risk factors and cardiovascular status and markers of mineral and bone metabolism

Between group comparisons revealed the following statistically significant differences in FGF23 levels between patient subgroups (Table 2): Higher FGF23 levels were detected in female patients compared to male, younger patients compared to elderly patients, those without lipid-lowering drugs compared to those with such medication, those with diabetes compared to non-diabetics, and smokers compared to non-smokers. FGF23 rose constantly in parallel to decreasing renal function (Table 2). There was an almost linear decrease of FGF23 levels detectable with increasing quartiles of HDL-cholesterol, LDL-cholesterol, and triglycerides. We examined markers of mineral and bone metabolism according to quartiles of FGF23 concentrations (first quartile: $n=742,<40.2 \mathrm{RU} / \mathrm{ml}$; second quartile: $n=743,40.2$ - $54.1 \mathrm{RU} / \mathrm{ml}$; third quartile: $\mathrm{n} 1 / 4=745,54.2$ - $78.0 \mathrm{RU} / \mathrm{ml}$; fourth quartile: $\mathrm{n}=743,>78$ $\mathrm{RU} / \mathrm{ml}$ ) (Table 3). Levels of AP, phosphate, and PTH showed linear and clinically meaningful increases with increasing quartiles of FGF23. 1.25-dihydroxyvitamin D levels constantly decreased from the lowest to the highest FGF23 quartile (Table 3). 


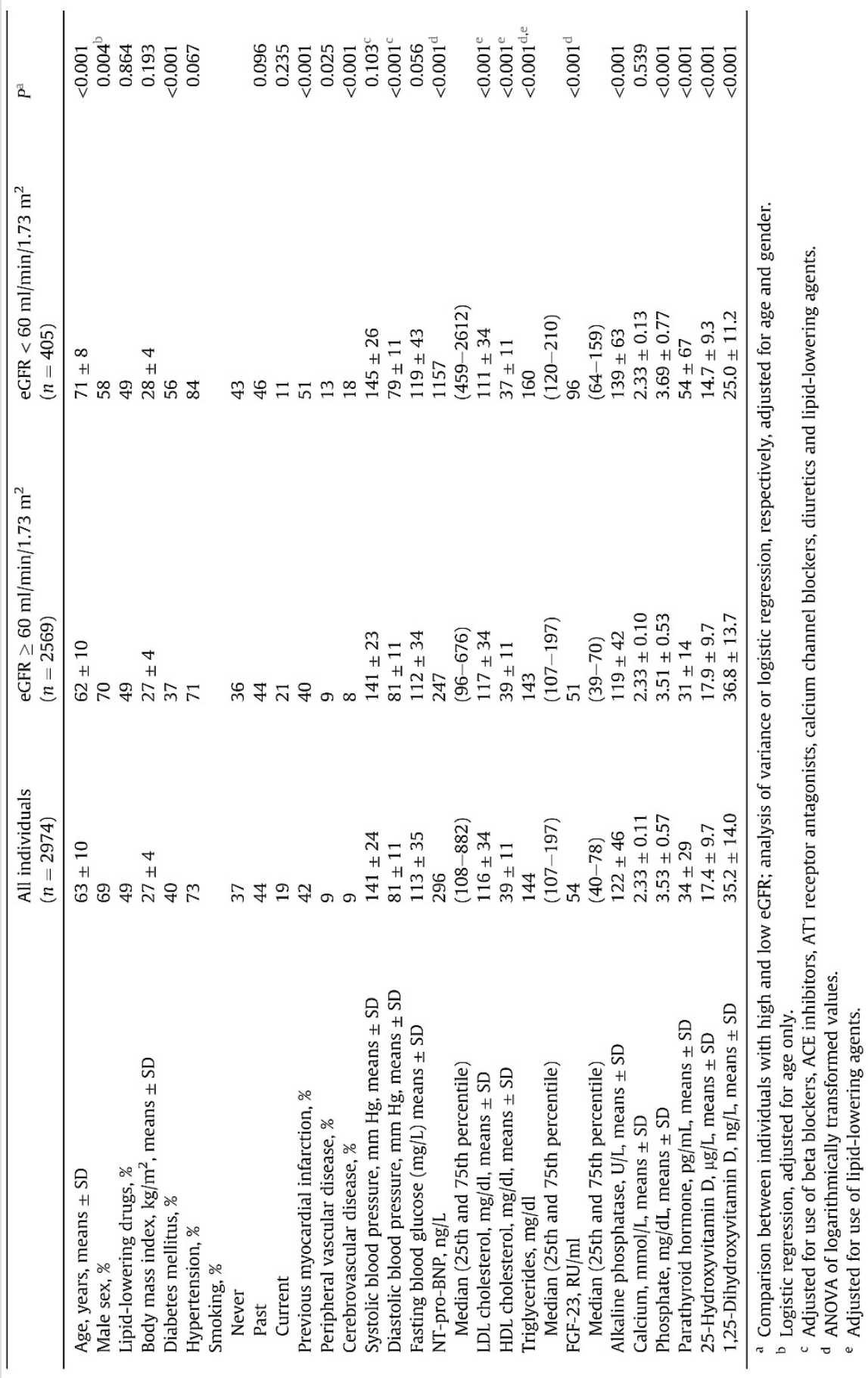

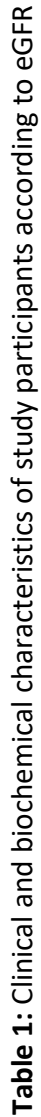




\begin{tabular}{|c|c|c|c|c|}
\hline & $n$ & FGF-23 (ng/mL) & $\begin{array}{l}\text { Difference } \\
(\%)^{b}\end{array}$ & $P^{\mathrm{b}}$ \\
\hline \multicolumn{5}{|l|}{ Gender } \\
\hline Men & 2042 & $59.3(57.6-61.1)$ & & \\
\hline Women & 932 & $63.1(60.3-66)$. & +6.4 & 0.028 \\
\hline \multicolumn{5}{|l|}{ Age (years) } \\
\hline$<60$ & 1079 & $66.0(63.2-68.9)$ & & \\
\hline $60-70$ & 1085 & $57.6(55.4-59.9)$ & -12.6 & $<0.001$ \\
\hline$>70$ & 810 & $57.5(54.7-60.3)$ & -12.9 & $<0.001$ \\
\hline \multicolumn{5}{|l|}{ Lipid-lowering drugs } \\
\hline No & 1508 & $62.1(60.0-64.3)$ & & \\
\hline Yes & 1466 & $58.9(56.8-60.9)$ & -5.3 & 0.033 \\
\hline \multicolumn{5}{|l|}{ Coronary artery disease } \\
\hline None & 648 & $60.2(57.0-63.6)$ & & \\
\hline Stable CAD & 1380 & $61.3(59.2-63.4)$ & +1.8 & 0.596 \\
\hline $\begin{array}{l}\text { Unstable CAD } \\
\text { (Troponin T-) }\end{array}$ & 573 & $60.0(56.9-63.2)$ & -0.4 & 0.923 \\
\hline $\begin{array}{l}\text { Unstable CAD } \\
\text { (Troponin T+) }\end{array}$ & 373 & $58.7(54.9-62.9)$ & -2.5 & 0.595 \\
\hline \multicolumn{5}{|l|}{ Friesinger Score } \\
\hline 1st quartile (0-1) & 614 & $57.8(54.2-61.7)$ & & \\
\hline 2nd quartile (2-4) & 675 & $62.5(59.6-65.6)$ & +8.1 & 0.054 \\
\hline 3rd quartile (5-8) & 976 & $60.0(57.5-62.6)$ & +3.8 & 0.390 \\
\hline 4th quartile $(9-15)$ & 709 & $61.6(58.6-64.8)$ & +6.6 & 0.171 \\
\hline \multicolumn{5}{|l|}{ Body mass index $\left(\mathrm{kg} / \mathrm{m}^{2}\right)$} \\
\hline$<26$ or $27^{c}$ & 1400 & $61.8(59.7-63.9)$ & & \\
\hline$>26$ or $27^{c}$ & 1574 & $59.3(57.5-61.3)$ & -4.0 & 0.092 \\
\hline \multicolumn{5}{|l|}{ Type 2 Diabetes mellitus } \\
\hline None & 1799 & $57.7(55.9-59.4)$ & & \\
\hline Diabetes mellitus & 1175 & $65.0(62.6-67.6)$ & +12.7 & $<0.001$ \\
\hline \multicolumn{5}{|l|}{ Hypertension } \\
\hline No & 807 & $61.9(59.1-64.9)$ & & \\
\hline Yes & 2167 & $59.9(58.3-61.6)$ & -3.2 & 0.252 \\
\hline \multicolumn{5}{|l|}{ Smoking } \\
\hline Never & 1089 & $56.9(54.7-59.3)$ & & \\
\hline Former & 1311 & $61.6(59.4-63.9)$ & +8.2 & 0.006 \\
\hline Current & 574 & $64.8(61.3-68.6)$ & +13.9 & $<0.001$ \\
\hline \multicolumn{5}{|l|}{$\mathrm{eGFR}\left(\mathrm{ml} / \mathrm{min} / 1.73 \mathrm{~m}^{2}\right)^{\mathrm{d}}$} \\
\hline$>60$ & 2569 & $55.1(53.7-56.5)$ & & \\
\hline $30-59$ & 359 & $94.3(88.0-101.2)$ & 71.3 & $<0.001$ \\
\hline$<30$ & 46 & 337.6 (279.5-407.9) & 512.9 & $<0.001$ \\
\hline \multicolumn{5}{|l|}{ LDL cholesterol (mg/dL) } \\
\hline 1st quartile $(<94)$ & & $64.3(61.3-67.6)$ & & \\
\hline 2nd quartile (94-113) & & $59.1(56.4-61.9)$ & -8.1 & 0.013 \\
\hline 3rd quartile (114-137) & & $60.0(57.3-62.9)$ & -6.7 & 0.045 \\
\hline 4 th quartile $(>138)$ & & $58.7(56.0-61.5)$ & -8.8 & 0.009 \\
\hline
\end{tabular}




\begin{tabular}{|c|c|c|c|c|}
\hline & $n$ & FGF-23 (ng/mL) & $\begin{array}{l}\text { Difference } \\
(\%)^{b}\end{array}$ & $P^{\mathrm{b}}$ \\
\hline \multicolumn{5}{|l|}{ HDL cholesterol (mg/dL) } \\
\hline 1 st quartile $(<32)$ & & $66.0(62.9-69.3)$ & & \\
\hline 2nd quartile (32-37) & & $61.4(58.7-64.3)$ & -6.9 & 0.033 \\
\hline 3rd quartile (38-44) & & $58.7(56.0-61.6)$ & -11.0 & 0.001 \\
\hline 4th quartile $(>44)$ & & $56.2(53.5-59.0)$ & -14.9 & $<0.001$ \\
\hline \multicolumn{5}{|l|}{ Triglycerides (mg/dL) } \\
\hline 1st quartile $(<109)$ & & $64.0(61.0-67.2)$ & & \\
\hline 2nd quartile (109-145) & & $59.7(57.1-62.6)$ & -6.7 & 0.039 \\
\hline 3rd quartile (146-199) & & $58.7(56.0-61.5)$ & -8.2 & 0.035 \\
\hline 4th quartile ( $>199)$ & & $59.6(56.8-62.6)$ & -6.9 & 0.036 \\
\hline
\end{tabular}

a Estimated marginal means and 95\% confidence intervals obtained in a general linear model (ANOVA), adjusted for each of the other factors, whereby age, body mass index, eGFR, LDL cholesterol, HDL cholesterol and triglycerides (log transformed), were included as continuous rather than categorial covariables.

b Compared to the first category of each variable.

c Thresholds of 26 and $27 \mathrm{~kg} / \mathrm{m}^{2}$ apply to males and females, respectively.

d eGFR was calculated on the basis of the equation of the CKD-EPI (Chronic Kidney Disease Epidemiology Collaboration).

Table 2: Association of FGF-23 with cardiovascular risk factors and coronary artery disease 
Brandenburg VM, Kleber ME, Vervloet MG et al. Fibroblast growth factor 23 (FGF23) and mortality: the Ludwigshafen Risk and Cardiovascular Health Study. Atherosclerosis. 2014 Nov; 237(1): 53-9.

3.3. Associations between FGF23 levels and cardiovascular or allcause mortality

The hazard ratios for all cause mortality increased with increasing quartiles of FGF23 concentration (Table 4A). Compared to the lowest quartile, the unadjusted hazard ratios (HRs) for death from all causes in the second, third, and fourth quartile were $1.20(95 \% \mathrm{Cl}$ : 0.96 - 1.50), 1.53 (95\% Cl: 1.23 - 1.89), and 3.22 (95\% Cl: 2.66 - 3.91), respectively (Table $4 \mathrm{~A}$, model 1). In the multiple adjusted model (including cardiovascular risk factors, phosphate, AP, calcium, PTH, and 25-hydroxyvitamin D) the HR in the highest compared to the lowest FGF23 quartile was 1.72 (95\% Cl: 1.38 - 2.14). An increase of one SD in FGF23 concentration was associated with a HR for all-cause and cardiovascular mortality of 1.38 (95\% Cl: $1.26-1.52)$ and 1.35 (1.20 - 1.52), respectively, in the multiple adjusted model. We obtained similar results for the association of FGF23 with cardiovascular mortality (Table 4B). HRs per increase of one SD were 1.84 (95\% Cl: 1.69 - 1.99) in the unadjusted model and 1.35 (95\% Cl: 1.20 - 1.52) in the multiple adjusted model, respectively (Table 4B, model 1 and model 5). Additional inclusion of NTproBNP as covariate only slightly decreased the HRs for both, total and cardiovascular mortality (Table 4A and B, model 6). Figure 1 shows the KaplaneMeier curve analyses for total (left panel) and cardiovascular mortality (right panel) according to quartiles of FGF-23. Increasing FGF23 concentration was significantly associated with increased death from all causes ( $\log$ rank $p<0.001$ ) and cardiovascular causes (log rank $p<0.001$ ) during a median follow-up period of 9.9 years. We analyzed the effect of the interaction of BMI and FGF23 on clinical outcomes (total and cardiovascular mortality). Cox proportional hazard model allowing for interaction of these parameters revealed that the interaction was not significant. The significant association between increasing FGF23 concentration expressed as quartiles or as increasing SD was not substantially modified by renal function, i.e. eGFR. Table 5 (Suppl. Material) indicates that HRs for all cause and cardiovascular mortality were similar after stratifying patients at an eGFR threshold of $60 \mathrm{ml} / \mathrm{min}$. Further, statistical models allowing for interaction of FGF23 and eGFR did not reveal any significant interaction. 


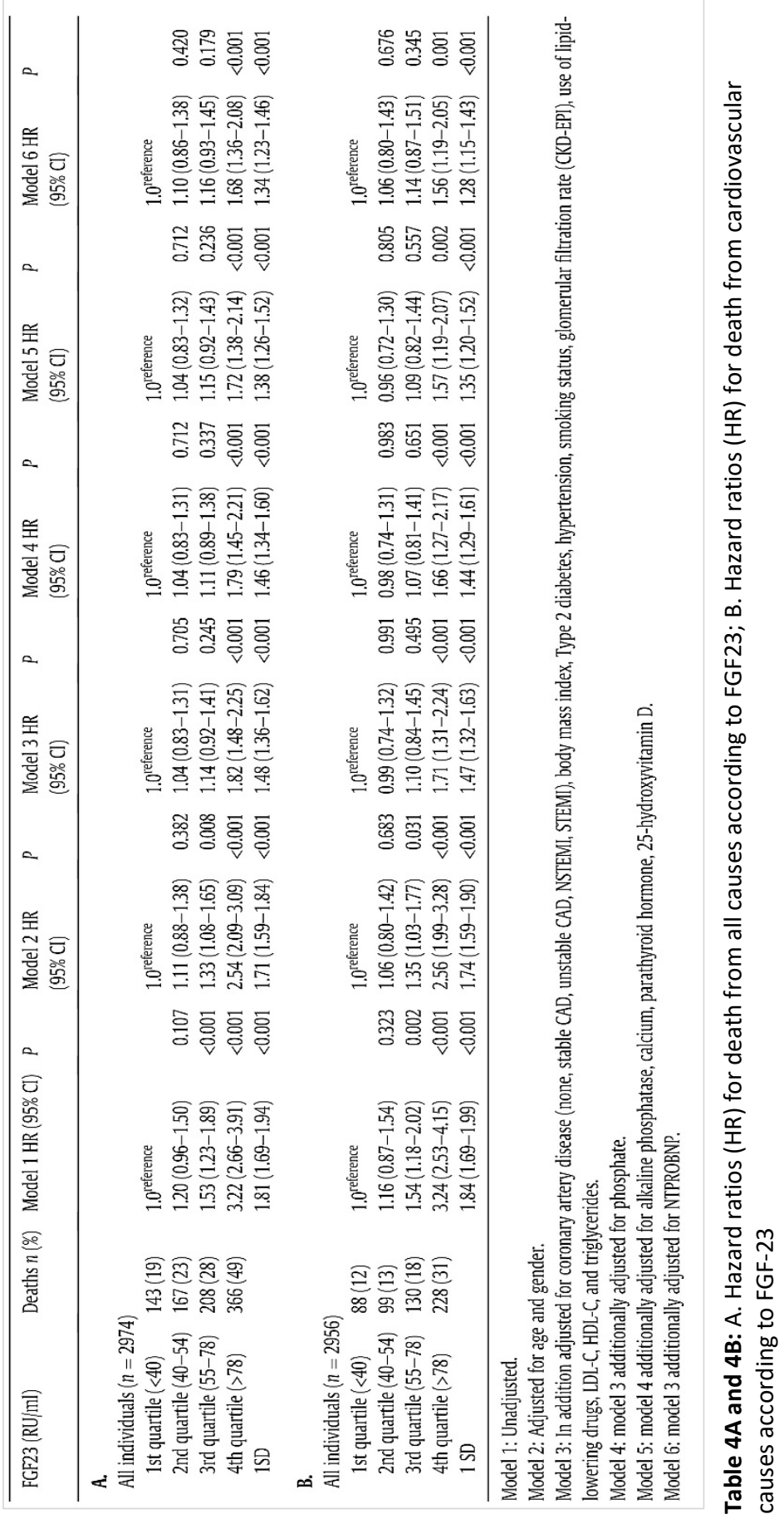


Brandenburg VM, Kleber ME, Vervloet MG et al. Fibroblast growth factor 23 (FGF23) and mortality: the Ludwigshafen Risk and Cardiovascular Health Study. Atherosclerosis. 2014 Nov; 237(1): 53-9.

\begin{tabular}{|c|c|c|c|c|c|c|}
\hline Total mortality & \multicolumn{2}{|c|}{$\begin{array}{l}\text { all individuals } \\
(\mathrm{n}=2974)\end{array}$} & \multicolumn{2}{|c|}{$\begin{array}{c}\text { eGFR } \geq 60 \mathrm{ml} / \mathrm{min} / 1.73 \mathrm{~m}^{2} \\
(\mathrm{n}=2569)\end{array}$} & \multicolumn{2}{|c|}{$\begin{array}{c}\text { eGFR }<60 \mathrm{ml} / \mathrm{min} / 1.73 \\
\mathrm{~m}^{2} \\
(\mathrm{n}=405)\end{array}$} \\
\hline Deaths, n (\%) & \multicolumn{2}{|c|}{$884(30)$} & \multicolumn{2}{|c|}{$640(25)$} & \multicolumn{2}{|c|}{$244(60)$} \\
\hline & HR per 1SD & $P$ & HR per 1SD & $P$ & HR per 1SD & $P$ \\
\hline Model 1 & $\begin{array}{c}1.81(1.69- \\
1.94)\end{array}$ & $<0.001$ & $\begin{array}{c}1.67(1.51- \\
1.85)\end{array}$ & $<0.001$ & $\begin{array}{c}1.47(1.31- \\
1.65)\end{array}$ & $<0.001$ \\
\hline Model 2 & $\begin{array}{c}1.71(1.59- \\
1.84)\end{array}$ & $<0.001$ & $\begin{array}{c}1.59(1.43- \\
1.77)\end{array}$ & $<0.001$ & $\begin{array}{c}1.55(1.38- \\
1.74)\end{array}$ & $<0.001$ \\
\hline Model 3 & $\begin{array}{c}1.48(1.36- \\
1.62)\end{array}$ & $<0.001$ & $\begin{array}{c}1.48(1.32- \\
1.66)\end{array}$ & $<0.001$ & $\begin{array}{c}1.37(1.19- \\
1.59)\end{array}$ & $<0.001$ \\
\hline Model 4 & $\begin{array}{c}1.46(1.34- \\
1.60)\end{array}$ & $<0.001$ & $\begin{array}{c}1.47(1.30- \\
1.64)\end{array}$ & $<0.001$ & $\begin{array}{c}1.42(1.22- \\
1.65)\end{array}$ & $<0.001$ \\
\hline Model 5 & $\begin{array}{c}1.38(1.26- \\
1.52)\end{array}$ & $<0.001$ & $\begin{array}{c}1.40(1.25- \\
1.58)\end{array}$ & $<0.001$ & $\begin{array}{c}1.37(1.17- \\
1.61)\end{array}$ & $<0.001$ \\
\hline $\begin{array}{l}\text { Cardiovascular } \\
\text { mortality }\end{array}$ & \multicolumn{2}{|c|}{$\begin{array}{c}\text { all individuals } \\
(\mathrm{n}=2956)\end{array}$} & \multicolumn{2}{|c|}{$\begin{array}{c}\text { eGFR } \geq 60 \mathrm{ml} / \mathrm{min} / 1.73 \mathrm{~m}^{2} \\
(\mathrm{n}=2556)\end{array}$} & \multicolumn{2}{|c|}{$\begin{array}{c}\text { eGFR }<60 \mathrm{ml} / \mathrm{min} / 1.73 \\
\mathrm{~m}^{2}\end{array}$} \\
\hline Deaths, n (\%) & \multicolumn{2}{|c|}{545 (18) } & \multicolumn{2}{|c|}{$383(15)$} & \multicolumn{2}{|c|}{$162(40)$} \\
\hline & HR per 1SD & $P$ & HR per 1SD & $P$ & HR per 1SD & $P$ \\
\hline Model 1 & $\begin{array}{c}1.84(1.69- \\
1.99)\end{array}$ & $<0.001$ & $\begin{array}{c}1.69(1.48- \\
1.92)\end{array}$ & $<0.001$ & $\begin{array}{c}1.47(1.27- \\
1.69)\end{array}$ & $<0.001$ \\
\hline Model 2 & $\begin{array}{c}1.74(1.59- \\
1.90)\end{array}$ & $<0.001$ & $\begin{array}{c}1.62(1.41- \\
1.86)\end{array}$ & $<0.001$ & $\begin{array}{c}1.53(1.33- \\
1.76)\end{array}$ & $<0.001$ \\
\hline Model 3 & $\begin{array}{c}1.47(1.32- \\
1.63)\end{array}$ & $<0.001$ & $\begin{array}{c}1.49(1.29- \\
1.73)\end{array}$ & $<0.001$ & $\begin{array}{c}1.35(1.13- \\
1.62)\end{array}$ & 0.001 \\
\hline Model 4 & $\begin{array}{c}1.44(1.29- \\
1.61)\end{array}$ & $<0.001$ & $\begin{array}{c}1.47(1.26- \\
1.70)\end{array}$ & $<0.001$ & $\begin{array}{c}1.40(1.17- \\
1.69)\end{array}$ & $<0.001$ \\
\hline Model 5 & $\begin{array}{c}1.35(1.20- \\
1.52)\end{array}$ & $<0.001$ & $\begin{array}{c}1.39(1.19- \\
1.63)\end{array}$ & $<0.001$ & $\begin{array}{c}1.33(1.09- \\
1.61)\end{array}$ & 0.004 \\
\hline
\end{tabular}

MODEL 1: UNADJUSTED

MODEL 2: ADJUSTED FOR AGE AND GENDER

MODEL 3: IN ADDITION ADJUSTED FOR CORONARY ARTERY DISEASE (NONE, STABLE CAD, UNSTABLE CAD, NSTEMI, STEMI), BODY MASS INDEX, TYPE 2 DIABETES, HYPERTENSION, SMOKING STATUS, GLOMERULAR FILTRATION RATE (CKD-EPI), USE OF LIPID-LOWERIMG DRUGS, LDL-C, HDL-C, AND TRIGLYCERIDES MODEL 4: MODEL 3 ADDITIONALLY ADJUSTED FOR PHOSPHATE MODEL 5: MODEL 4 ADDITIONALLY ADJUSTED FOR ALKALINE PHOSPHATASE, CALCIUM, PARATHYROID HORMONE, 25-HYDROXYVITAMIN D

Table 5: Hazard ratios (HR) for total and cardiovascular mortality according to FGF23 in subgroups with eGFR above and below $60 \mathrm{ml} / \mathrm{min} / 1.73 \mathrm{~m}^{2}$ 

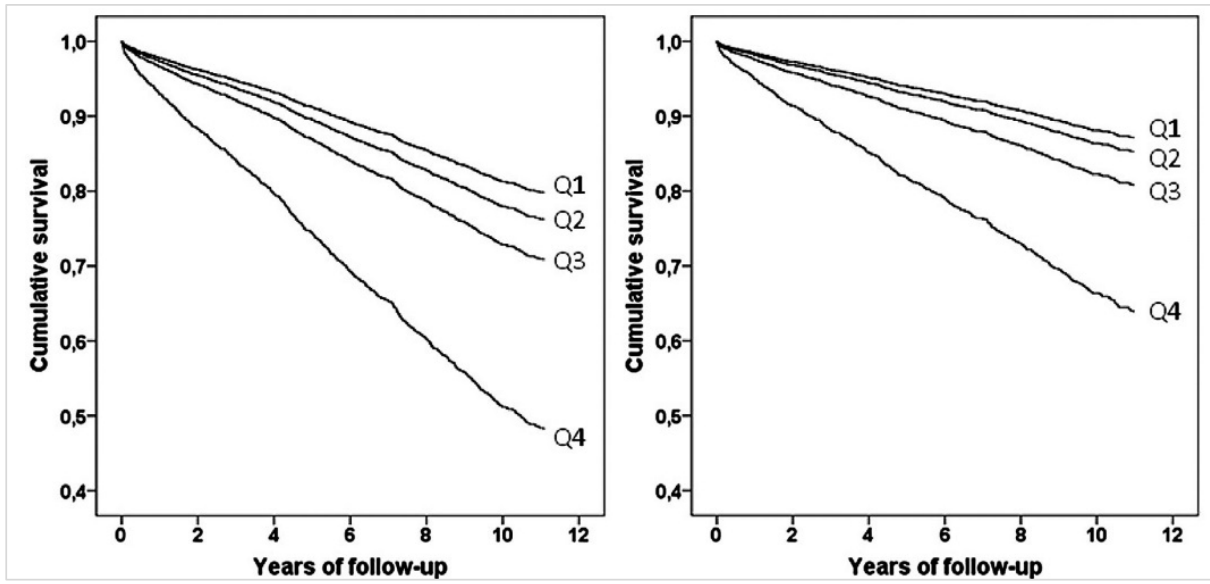

Figure 1: Kaplan-Meier curve for total (left panel, log rank $p<0.001$ ) and cardiovascular mortality (right panel, log rank $\mathrm{p}<0.001$ ) according to quartiles of FGF-23. For hazard ratios and confidence intervals, see Table $4 A$ and $B$ (model 1 )

\subsection{Reclassification analysis}

The predictive value of FGF23 for total and cardiovascular mortality was assessed using ROC and reclassification analysis (Table 6; Suppl Material). The addition of FGF23 to a model consisting of cardiovascular risk factors including eGFR did not significantly increase the area under the ROC curve for total mortality (0.772 vs. 0.785) and cardiovascular mortality (0.748 vs. 0.756), respectively. However, reclassification analysis revealed significant improvement of the predictive model on addition of FGF23. The net reclassification improvement (NRI) for total mortality was $30.1 \%(95 \% \mathrm{Cl}: 22.2-37.9$, $\mathrm{p}<$ $0.001)$, the integrated discrimination improvement (IDI) was $0.020(95 \% \mathrm{Cl}: 0.014-0.027$, $\mathrm{p}<0.001)$. Similar results were obtained for cardiovascular death: NRI was $21.9 \%(95 \% \mathrm{Cl}$ : 12.7 - 31.2, $\mathrm{p}<0.001)$, IDI was 0.010 (95\% Cl: $0.004-0.014, \mathrm{p}=0.002)$. 
Brandenburg VM, Kleber ME, Vervloet MG et al. Fibroblast growth factor 23 (FGF23) and mortality: the Ludwigshafen Risk and Cardiovascular Health Study. Atherosclerosis. 2014 Nov; 237(1): 53-9.

\begin{tabular}{|l|c|c|c|c|c|c|}
\hline & \multicolumn{3}{|c|}{ Total mortality } & \multicolumn{3}{c|}{ Cardiovascular mortality } \\
\cline { 2 - 7 } & Model 1 & Model 2 & P & Model 1 & Model 2 & P \\
\hline AUC & 0.772 & 0.785 & ns & 0.748 & 0.756 & ns \\
& $(0.754-$ & $(0.768-$ & & $(0.726-$ & $(0.735-$ & \\
& $0.790)$ & $0.803)$ & & $0.770)$ & $0.777)$ & \\
\hline NRI, \% (95\% Cl) & $30.1(22.2-37.9)$ & $<0.001$ & $21.9(12.7-31.2)$ & $<0.001$ \\
\hline IDI (95\% Cl) & $0.020(0.014-0.027)$ & $<0.001$ & $0.010(0.004-0.014)$ & 0.002 \\
\hline
\end{tabular}

Model 1: cardiovascular risk factors including age, sex, BMI, hypertension, HDL- and LDL-cholesterol, triglycerides, smoking, coronary artery disease, type 2 diabetes mellitus, eGFR (CKD-EPI)

Model 2: model 1 plus FGF-23

AUC indicates area under the receiver-operating characteristic (ROC) curves; NRI, net reclassification improvement; IDI, integrated discrimination improvement; NS, not significant

Table 6: ROC and reclassification analysis for total and cardiovascular mortality

\section{Discussion}

The major finding of the present study is the independent association of FGF23 at baseline with future cardiovascular and allcause mortality in patients from the LURIC cohort, which includes Caucasian patients who underwent coronary angiography with comprehensive long-term prospective follow-up. These significant associations proved to be independent from kidney function at baseline and remained stable also after adjustments for levels of potentially confounding markers of bone and mineral metabolism (calcium, vitamin $D$, alkaline phosphatase, and PTH). Remarkably, also adjustments for serum phosphate did not substantially mitigate the association between FGF23 and outcome, suggesting that GF23 is not just a proxy for phosphate, or other markers of mineral metabolism, in predicting risk for mortality. Important characteristics of LURIC patients are their clinical homogeneity as high risk patients for future cardiovascular events based on the previous clinical indication for coronary angiography and the high proportion of patients with documented CAD. Thus, the current work is a valuable extension to previous ones indicating that FGF23 qualifies as a marker for increased mortality risk in future. $5,7,8,11,12,18$ However, despite the consistency of clinical observations, there is less certainty as to the exact mechanism underlying the impact of higher FGF23 concentrations. Several studies demonstrated that higher FGF23 levels are associated with an increased risk for prevalent and incident left-ventricular hypertrophy and dysfunction. This association was found in patients with and without severely impaired renal function. ${ }^{11,19,20}$ In a set of elegant in vivo and in vitro experiments Faul and coworkers showed that FGF23 directly induces cardiomyocyte hypertrophy..$^{19}$ We also would like to emphasize that when we added NTproBNP as a marker of left-ventricular dysfunction to our prognostic models the predictive power of FGF23 was only slightly attenuated suggesting an independent contribution of FGF23 to allcause and cardiovascular mortality. In this context it may be important to mention that classical atherosclerotic disease conditions such as peripheral arterial disease are only moderately associated with higher FGF23 levels ${ }^{21}$ while leftventricular hypertrophy revealed a strong association. ${ }^{22}$ It has been speculated that the presence of CKD modifies the association between FGF23 and outcome. ${ }^{23}$ Indeed, median FGF23 were about twice as high in patients with GFR below $60 \mathrm{ml} / \mathrm{min}$ compared to those 
Brandenburg VM, Kleber ME, Vervloet MG et al. Fibroblast growth factor 23 (FGF23) and mortality: the Ludwigshafen Risk and Cardiovascular Health Study. Atherosclerosis. 2014 Nov; 237(1): 53-9.

with GFR above $60 \mathrm{ml} / \mathrm{min}$. However, the presence of CKD as defined with an eGFR below $60 \mathrm{ml} / \mathrm{min}$ did not substantiallymodify FGF23 effects uponmortality, norwas there any indication for a significant interaction between FGF23 and eGFR. The LURIC cohort allows for the first time analyzing the effects of FGF23 elevations upon cardiovascular outcomes in a very high risk CAD population, since the LURIC cohort is not a populationbased screening cohort. ${ }^{7,9,11}$ The currently most similar cohort study for LURIC is the Californian Heart and Soul study. ${ }^{7}$ However, the LURIC and the Heart and Soul study reveal important differences in various aspects including the threefold larger sample size of the LURIC study. Moreover, in contrast to LURIC, the patient selection in Heart and Soul was based on the historic diagnosis of confirmed and presumed CAD and in contrast to LURIC the baseline visit was not timely related to the qualifying event. After multivariate adjustment in Heart and Soul the third tertile of FGF23 was associated with a HR of 2.07 (95\% Cl $1.36-3.13$ ) for all-cause mortality. Thus our data extend these previous findings ${ }^{7}$ by several essential aspects. Among these novel aspects special attention is warranted on the ability to analyze separately all-cause and cardiovascular mortality, and most importantly, the ability to adjust for important potentially confounding bone and mineral metabolism factors. All of these bone biomarkers may independently influence cardiovascular events: High levels of PTH, alkaline phosphatases, and phosphate ${ }^{6,24}$ and low levels of vitamin $D^{25}$ have been previously identified as risk factors for increased morbidity and mortality. Moreover, these bone biomarkers and FGF23 are closely interrelated and part of a complex feed-back loop underlining the need for adjustments in order to avoid confounding. ${ }^{1,3}$ So the particular strength of the LURIC database is the homogenous character of the cohort and the comprehensive adjustments that put substantial and unique strength to the core result: FGF23 baseline levels predict independently future cardiovascular and especially all-cause mortality in patients referred to coronary angiography. However, the exact impact of FGF23 in predicting future cv events and also its contribution to risk stratification remains to be clarified. Our study faces some limitations. The results are cohortdependent and generalizability to cohorts with lower cv risk is limited. We could not assess the impact of time-averaged FGF23 concentrations since only single spot measurements were obtained. Data upon urinary phosphate excretion e.g. are not available. Moreover, it is unclear if coronary angiography and the acute clinical setting itself could influence individual FGF23 levels. A recent study in patients with acute heart failure and cardiogenic shock showed significantly elevated FGF23 levels upon admission in the intensive care unit ${ }^{26}$ and therefore reverse causality ${ }^{27}$ cannot be excluded.

\section{Conclusion}

In summary, the present large-scale prospective cohort data clearly indicate that the risk for all-cause and cardiovascular mortality increases significantly and independently with increasing baseline levels of FGF23 in persons at the time of, or at risk for an acute coronary ischemic event, even after adjustments for a large array of confounders of bone metabolism. 
Brandenburg VM, Kleber ME, Vervloet MG et al. Fibroblast growth factor 23 (FGF23) and mortality: the Ludwigshafen Risk and Cardiovascular Health Study. Atherosclerosis. 2014 Nov; 237(1): 53-9.

\section{Author contributions}

W.M. designed the study, contributed to the interpretation of the results and reviewed the manuscript. V.B. contributed to data analysis and interpretation and wrote the manuscript. M.K. was responsible for sample handling and database management and supported writing of the manuscript. T.S. and H.S. organized and supervised the FGF23 measurements. H.S. conducted the statistical analyses. All co-authors contributed to the interpretation of the results and reviewed and edited the manuscript. All authors have read and approved the final version of the manuscript as submitted.

\section{Sources of funding}

This work was supported by the Jubilaeumsfond der Oesterreichischen Nationalbank (No. 15179 to H.S.). LURIC has received funding through the 6th Framework Program (integrated project loodomics, grant LSHMCT-2004-503485), from the 7th Framework Program (integrated projects Atheroremo, Grant Agreement Number 201668 and RiskyCAD, grant agreement number 305739) of the European Union and from the INTERREG IV Oberrhein Program (Project A28, Genetic mechanisms of cardiovascular diseases) with support from the European Regional Development Fund (ERDF) and the Wissenschaftsoffensive TMO. Sponsors had no involvement in the design and conduct of the study; collection, management, analysis, and interpretation of the data; and preparation, review, or approval of the manuscript.

\section{Disclosure/conflict of interest}

The authors have no conflict of interest to declare.

\section{Acknowledgments}

The authors thank the patients of the LURIC study for their willing to participate in data collection and assessment. We also thank the LURIC study team either temporarily or permanently involved in patient recruitment and sample and data handling, the laboratory staff at the Ludwigshafen General Hospital, and the Universities of Freiburg, UIm, Graz and Heidelberg. We also thank and the German registration offices and local public health departmentsfor their assistance.

\section{Appendix A. Supplementary data}

Supplementary data related to this article can be found at http://dx.doi.org/10.1016/j.atherosclerosis.2014.08.0

37 


\section{References}

1. Silver J, Naveh-Many T. FGF-23 and secondary hyperparathyroidism in chronic kidney disease. Nat Rev Nephrol 2013; 9(11): 641e9.

2. Brandenburg VM, Vervloet MG, Marx $\mathrm{N}$. The role of vitamin $\mathrm{D}$ in cardiovascular disease: from present evidence to future perspectives. Atherosclerosis 2012; 225(2): $253 e 63$.

3. Wolf M. Update on fibroblast growth factor 23 in chronic kidney disease. Kidney Int 2012; 82(7): 737e47.

4. Block GA, Klassen PS, Lazarus JM, Ofsthun N, Lowrie EG, Chertow GM. Mineral metabolism, mortality, and morbidity in maintenance hemodialysis. J Am Soc Nephrol 2004; 15(8): 2208e18.

5. Gutierrez OM, Mannstadt M, Isakova T, Rauh-Hain JA, Tamez $H$, Shah A, et al. Fibroblast growth factor 23 and mortality among patients undergoing hemodialysis. N Engl J Med 2008; 359(6): 584e92.

6. Tonelli M, Sacks F, Pfeffer M, Gao Z, Curhan G. Relation between serum phosphate level and cardiovascular event rate in people with coronary disease. Circulation 2005; 112(17): 2627e33.

7. Parker BD, Schurgers LJ, Brandenburg VM, Christenson RH, Vermeer C, Ketteler M, et al. The associations of fibroblast growth factor 23 and uncarboxylated matrix Gla protein with mortality in coronary artery disease: the Heart and Soul study. Ann Intern Med 2010; 152(10): 640e8.

8. Scialla JJ, Xie H, Rahman M, Anderson AH, Isakova $T$, Ojo A, et al. Fibroblast growth factor-23 and cardiovascular events in CKD. J Am Soc Nephrol 2013 Feb; 25(2): 349e60.

9. Plischke M, Neuhold S, Adlbrecht C, Bielesz B, Shayganfar S, Bieglmayer C, et al. Inorganic phosphate and FGF-23 predict outcome in stable systolic heart failure. Eur J Clin Invest 2012; 42(6): 649e56.

10. Ix JH, Katz R, Kestenbaum BR, de Boer IH, Chonchol M, Mukamal KJ, et al. Fibroblast growth factor-23 and death, heart failure, and cardiovascular events in communityliving individuals: CHS (Cardiovascular Health study). J Am Coll Cardiol 2012; 60(3): $200 \mathrm{e} 7$.

11. Seiler S, Cremers B, Rebling NM, Hornof F, Jeken J, Kersting S, et al. The phosphatonin fibroblast growth factor 23 links calcium-phosphate metabolism with left-ventricular dysfunction and atrial fibrillation. Eur Heart J 2011; 32(21): 2688 e96.

12. Arnlov J, Carlsson AC, Sundstrom J, Ingelsson E, Larsson A, Lind L, et al. Serum FGF23 and risk of cardiovascular events in relation to mineral metabolism and cardiovascular pathology. Clin J Am Soc Nephrol 2013; 8(5): 781e6.

13. Taylor EN, Rimm EB, Stampfer MJ, Curhan GC. Plasma fibroblast growth factor 23, parathyroid hormone, phosphorus, and risk of coronary heart disease. Am Heart J 2011; 161(5): 956e62.

14. Friesinger GC, Page EE, Ross RS. Prognostic significance of coronary arteriography. Trans Assoc Am Physicians 1970; 83: 78e92.

15. Winkelmann BR, Marz W, Boehm BO, Zotz R, Hager J, Hellstern P, et al. Rationale and design of the LURIC studyea resource for functional genomics, pharmacogenomics 
Brandenburg VM, Kleber ME, Vervloet MG et al. Fibroblast growth factor 23 (FGF23) and mortality: the Ludwigshafen Risk and Cardiovascular Health Study. Atherosclerosis. 2014 Nov; 237(1): 53-9.

and long-term prognosis of cardiovascular disease. Pharmacogenomics 2001; 2(1 Suppl. 1): S1e73.

16. Stevens LA, Schmid CH, Greene T, Zhang YL, Beck GJ, Froissart M, et al. Comparative performance of the CKD epidemiology collaboration (CKD-EPI) and the modification of diet in renal disease (MDRD) study equations for estimating GFR levels above 60 $\mathrm{ml} / \mathrm{min} / 1.73 \mathrm{~m}^{2}$. Am J Kidney Dis 2010; 56(3): 486e95.

17. Levey AS, Stevens LA, Schmid CH, Zhang YL, Castro III AF, Feldman HI, et al. A new equation to estimate glomerular filtration rate. Ann Intern Med 2009; 150(9): 604e12.

18. Gutierrez OM, Wolf M, Taylor EN. Fibroblast growth factor 23, cardiovascular disease risk factors, and phosphorus intake in the health professionals followup study. Clin J Am Soc Nephrol 2011; 6(12): 2871 e8.

19. Faul C, Amaral AP, Oskouei B, Hu MC, Sloan A, Isakova T, et al. FGF23 induces left ventricular hypertrophy. J Clin Invest 2011; 121(11): 4393e408.

20. Gutierrez OM, Januzzi JL, Isakova T, Laliberte K, Smith K, Collerone G, et al. Fibroblast growth factor 23 and left ventricular hypertrophy in chronic kidney disease. Circulation 2009; 119(19): 2545e52.

21. Garimella PS, Ix JH, Katz R, Chonchol MB, Kestenbaum BR, de Boer IH, et al. Fibroblast growth factor 23, the ankle-brachial index, and incident peripheral artery disease in the Cardiovascular Health study. Atherosclerosis 2014; 233(1): 91e6.

22. Jovanovich A, Ix JH, Gottdiener J, McFann K, Katz R, Kestenbaum B, et al. Fibroblast growth factor 23, left ventricular mass, and left ventricular hypertrophy in community-dwelling older adults. Atherosclerosis 2013; 231(1): 114e9.

23. Westerberg PA, Tivesten A, Karlsson MK, Mellstrom D, Orwoll E, Ohlsson C, et al. Fibroblast growth factor 23, mineral metabolism and mortality among elderly men (Swedish MrOs). BMC Nephrol 2013; 14: 85.

24. Pilz S, Tomaschitz A, Drechsler C, Ritz E, Boehm BO, Grammer TB, et al. Parathyroid hormone level is associated with mortality and cardiovascular events in patients undergoing coronary angiography. Eur Heart J 2010; 31(13): 1591e8.

25. Brondum-Jacobsen $P$, Benn M, Jensen GB, Nordestgaard BG. 25-hydroxyvitamin d levels and risk of ischemic heart disease, myocardial infarction, and early death: population-based study and meta-analyses of 18 and 17 studies. Arterioscler Thromb Vasc Biol 2012; 32(11): 2794e802.

26. Poss J, Mahfoud F, Seiler S, Heine GH, Fliser D, Bohm M, et al. FGF-23 is associated with increased disease severity and early mortality in cardiogenic shock. Eur Heart J Acute Cardiovasc Care 2013; 2(3): 211e8.

27. Mirza MA, Larsson A, Melhus H, Lind L, Larsson TE. Serum intact FGF23 associate with left ventricular mass, hypertrophy and geometry in an elderly population. Atherosclerosis 2009; 207(2): 546e51. 


\section{b)}

\section{Soluble klotho and mortality: the Ludwigshafen Risk and Cardiovascular Health Study (IF 4)}

Soluble klotho and mortality: the Ludwigshafen Risk and Cardiovascular Health Study.

Brandenburg VM, Kleber ME, Vervloet MG, Larsson TE, Tomaschitz A, Pilz S, Stojakovic T, Delgado G, Grammer TB, Marx N, März W, Scharnagl H. Atherosclerosis. 2015 Oct; 242(2): 483-9. 


\section{Abstract}

Background: Experimental evidence suggests that soluble klotho (s-klotho), a co-receptor for fibroblast growth factor 23 (FGF23), may modulate cardiovascular risk through multiple mechanisms. However, the predictive value of s-klotho in patients remains unclear. Therefore, the present study examined in a large cohort of patients referred for coronary angiography whether s-klotho is associated with cardiovascular and total mortality.

Methods: The longitudinal associations between baseline s-klotho and FGF23 concentrations and mortality were evaluated in 2948 participants of the Ludwigshafen Risk and Cardiovascular Health Study (LURIC), referred for coronary angiography.

Results: Mean age of participants was: $63 \pm 10$ years. Patients with diabetes mellitus ( $n=1136)$ had elevated s-klotho: [440 (430 - 449) versus $414(406-421) \mathrm{pg} / \mathrm{ml}, \mathrm{p}<0.001$ ]. S-klotho decreased in parallel to glomerular filtration rate (GFR) and increased in parallel to FGF23. During a median follow-up of 9.9 years, 874 deaths (30\%) occurred, 539 (18\%) of which were cardiovascular. After adjustment for cardiovascular risk factors, the hazard ratios in the fourth quartile compared to the first quartile of sklotho were $1.14(95 \% \mathrm{Cl}, 0.94$ - 1.38; $p=0.187)$ for all-cause mortality and $1.03(95 \% \mathrm{Cl}, 0.80-1.31 ; \mathrm{p}=0.845)$ for cardiovascular mortality. Excess mortality prediction by high levels of baseline FGF23 was not modified by adjustment for baseline s-klotho levels.

Conclusions: Klotho does not add predictive power to cardiovascular and mortality risk assessment in patients with normal renal function. 


\section{Introduction}

Klotho was first identified as a protein involved in aging-like processes and reduced lifespan detectable in klotho-deficiency models, whereas an extended life span was seen when klotho was over-expressed. ${ }^{1,2}$ Close interactions between fibroblast growth factor 23 (FGF23) and klotho exist, since classical FGF23 signal transduction requires membraneklotho to increase binding affinity to FGF receptors. ${ }^{3}$ FGF23 increases renal phosphate excretion and decreases $1 \mathrm{e} 25$ dihydroxyvitamin D synthesis. ${ }^{4}$ Additionally, klotho-FGF23 is strongly involved in cardiovascular (patho-) physiology. Studies in various patient populations have consistently shown that high levels of FGF23 are associated with dismal outcome and elevated cardiovascular event rates. ${ }^{5-12}$ In vivo FGF23 application directly leads to myocardial hypertrophy in murine models. ${ }^{13}$ The klotho gene encodes a singlepass transmembrane protein with a large extracellular domain, which is synthesized predominantly in the kidney. ${ }^{1}$ The extracellular domain of klotho can be cleaved and released into extracellular fluids including plasma, ${ }^{14}$ where soluble klotho (s-klotho) is detectable via ELISA techniques. ${ }^{15}$ Circulating klotho is considered to be involved in preservation of endothelial function and arterial wall integrity and hence may be protective against endothelial dysfunction and arteriosclerosis, ${ }^{16}$ reduced vascular elasticity or calcification. ${ }^{17,18}$ Recent in vivo findings point towards direct cardioprotective effects of sklotho. ${ }^{19,20}$ A small human study showed that decreased klotho was an independent determinant of arterial stiffness as measured by pulsewave velocity. ${ }^{21} \mathrm{It}$ is noteworthy that klotho also interacts with calcium and phosphate homeostasis which per se influences cardiovascular health. ${ }^{16}$ Moreover, it is intriguing to speculate about the presence of reciprocal effects between klotho and FGF23. This hypothesis of concerted klotho-FGF23 action is fueled by recent experimental in vivo work showing that high FGF23 concentration positively correlated with cardiac remodeling only in a klothodeficient state but not in a klotho-replete state. ${ }^{22}$ So klotho deficiency in humans might mediate at least in part FGF23associated mortality excess. However, recent longitudinal cohort studies in pre-dialysis and dialysis patients did not detect any significant relationship between s-klotho and cardiovascular outcome. ${ }^{23,24}$ Notably, since renal failure is a condition of severely mpaired klotho-FGF23-mineral-metabolism with remarkable GF23 excess these previous negative human study results ${ }^{23,24}$ re presumably not generalizable to patients with preserved renal unction. Therefore, we explored the predictive value of s-klotho in large cohort comprising patients with (close to) normal kidney unction by analyzing the Ludwigshafen Risk and Cardiovascular Health Study (LURIC), i.e. patients identified via referral for coronary angiography.

\section{Methods}

\subsection{Participants, study design, and definition of comorbidities}

The LURIC study is a prospective cohort study. The baseline examinationwas performed between 1997 and 2000 in south-west Germany at a coronary care tertiary referral center (Herzzentrum Ludwigshafen). Details about participants, recruitment, comorbidities and baseline examinations have been described previously. ${ }^{25}$ Overall 3316 patients with coronary angiogram at baseline were included. All patients were Caucasians and were 
required to be in clinical stable conditions except for acute coronary syndromes. Indications for coronary angiography were cardiac chest pain, acute coronary syndrome or cardiac ischemia as suspected with non-invasive testing. Chest pain with non-cardiac origin was an exclusion criterion as well as the predominance of any noncardiac disease and malignancy within the previous 5 years. Kidney function was not relevant for inclusion. The patients gave written and informed consent. The study protocol was designed according to the Declaration of Helsinki. The Ärztekammer Rheinland-Pfalz was the responsible ethics committee, which approved the study. We diagnosed coronary artery disease (CAD) based on at least one stenosis of at least one out of 15 coronary arterial segments according to visual estimation of the maximal luminal narrowing $>20 \%$. Myocardial infarction (MI) was classified as acute if the event was within the four weeks prior to enrolment. A definite STsegment elevation MI (STEMI) was diagnosed if typical ECG changes were present along with prolonged chest pain, refractory to sublingual nitrates and/or enzyme or troponin $\mathrm{T}$ elevations (>0.1 mg/L). Non-ST elevation MI (NSTEMI) was diagnosed, if symptoms and/or troponin T criteria were met in the absence of ECG criteria defining STEMI. The diagnosis diabetes mellitus was based on at least one of the following findings: the (previous) prescription of antidiabetic medication, fasting blood glucose levels greater than 7.0 $\mathrm{mmol} / \mathrm{l}, \mathrm{HbA} 1 \mathrm{c}$ was $>6.5 \%$, or if the $2 \mathrm{~h}$ blood glucose level exceeded $11.1 \mathrm{mmol} / \mathrm{L}$ in an oral glucose tolerance test. Arterial hypertension was diagnosed if the mean systolic and systolic blood pressure exceeded either $140 \mathrm{mmHg}$ systolic or $90 \mathrm{mmHg}$ diastolic in three consecutive measurements at the upper arm. Alternatively, current prescription of antihypertensive drugs confirmed the diagnosis. Cerebrovascular disease (CVD) was defined clinically by documented history of a previous cerebrovascular event or by documented carotid plaques ( $>50 \%$ luminal obstruction).

\subsection{Outcome assessment during follow-up}

S-klotho measurements were available in 2948 patients representing $89 \%$ of the entire LURIC cohort. Median follow-up time was 9.9 years. Death certificates were missing in 18 decedents who were included in the analysis for total mortality, but excluded from analysis of cardiovascular mortality. Information on survival status was obtained from local person registries. Two physicians blinded to baseline characteristics of the study participants classified causes of death by reviewing hospital records and death certificates. Cardiovascular deaths included sudden cardiac death (SCD), fatal myocardial infarction, deaths due to heart failure, death after intervention to treat CAD, stroke, and other deaths due to heart disease. SCD was defined as a sudden unexpected death either within $1 \mathrm{~h}$ of symptom onset or within $24 \mathrm{~h}$ of having been observed alive and symptom free. Persons whose sudden death was most likely attributable to a non-cardiac disease and patients who suffered from any predominant non-cardiac and terminal disease (e.g. cancer) so that their death was not unexpected were not classified as having died due to SCD. In the case of disagreement about classification, the final decision was made by one of the principal LURIC investigators after appropriate review of the data.

\subsection{Laboratory analyses}

Standard laboratory measurements were performed as previously described. ${ }^{25}$ In brief, venous blood was drawn in the morning before coronary angiography and standard 
laboratory parameters were immediately determined. Serum and plasma was harvested according to standard procedures and was snap frozen for further determinations and stored at _80_C until further analysis. Soluble klotho levels were assessed by human soluble alpha-klotho assay, Immuno-Biological Laboratories Ltd. (Japan). Within the LURIC analysis the assay revealed an intra- and interassay coefficient of variation of 3.4 and $4.9 \%$, respectively. FGF23 (c-terminal) was measured by enzyme-linked immunosorbent assay (ELISA, Immundiagnostik AG, Bensheim, Germany), intraand inter-assay coefficient of variation were 2.4 and $3.1 \%$, respectively. Intact $\mathrm{PTH}$, and $\mathrm{N}$-terminal pro-B-type natriuretic peptide (NT-pro-BNP) were determined by ElectroChemiLuminescence (ECL) on an Elecsys 2010 (Roche Diagnostics, Mannheim, Germany). 25-hydroxyvitamin D was measured with a radioimmunoassay (DiaSorin Antony, France; Stillwater, USA) with an intra- and interassay coefficient of variation of 8.6 and $9.2 \%$, respectively. 1.25-dihydroxyvitamin D was measured by radioimmunoassay (Nichols Institute Diagnostika GmbH, Bad Nauheim, Germany) using a multicrystal counter (Berthold LB2014, Dia Sorin, SA, USA). Estimated glomerular filtration rate (GFR) was calculated according to the CKD-EPI study equation. ${ }^{26,27}$

\subsection{Statistical analysis}

Soluble klotho concentration quartiles were generated according to the values of the entire study cohort. Depending on their distribution, continuous parameters are either presented as means \pm standard deviation (normally distributed variables) or as medians with interquartile range (skewed variables). Categorical data are shown as proportions. All skewed continuous parameters were logarithmically transformed before use in parametric procedures. Characteristics of bone and kidney metabolism were analyzed by s-klotho quartiles. Comparisons across s-klotho quartiles were carried out by analysis of variance (ANOVA) with $\mathrm{p}$ for trend for continuous parameters and by $\mathrm{X}^{2}$-test with $\mathrm{p}$ for linearbylinear test for categorical variables. For all-cause and cardiovascular mortality, Hazard ratios (HRs) with $95 \%$ confidence intervals $(95 \% \mathrm{Cl}$ ) for all-cause and cardiovascular mortality were calculated with Cox proportional hazard models after negative testing for violation of the proportional hazard assumption using Cox models with time-dependent covariates. Cox proportional hazards were calculated both according to quartiles of sklotho and per increase of 1 SD (calculated from the logarithmically transformed values).We present results of different adjustment models: Model 1: unadjusted; Model 2: adjusted for age and gender; Model 3: in addition adjusted for coronary artery disease (none, stable CAD, unstable CAD, NSTEMI, STEMI), body mass index, type 2 diabetes, hypertension, smoking status, use of lipid-lowerimg drugs, LDL-C, HDL-C, triglycerides, and glomerular filtration rate (CKDEPI); Model 4: model 3 additionally adjusted for FGF23; Model 5: model 3 additionally adjusted for interaction of FGF-23 and sklotho. Additionally we performed outcome assessment with parallel analysis of s-klotho and FGF23 by stratifying patients according to the median levels of s-klotho and FGF23 into four groups: low sklotho and low FGF23, low s-klotho and high FGF23, high s-klotho and low FGF23, and high s-klotho and high FGF23, respectively. A p-value below0.05 was considered statistically significant and all statistical tests were two-sided. Data were analyzed using the SPSS 22.0 statistical package (SPSS Inc., Chicago, IL, USA). 


\section{Results}

Mean age of the LURIC participants was $63 \pm 10$ years, $69 \%$ were male and $39 \%$ were diabetics. During the median follow-up time of 9.9 years 874 (30\%) of these 2948 patients died. 539 (18\%) deaths were due to cardiovascular causes. The median s-klotho level was 419 (334 - 525) pg/ml and the median FGF23 was 54 (40 - 78) RU/ml.

3.1. Association of s-klotho with clinical data, cardiovascular risk factors, status of coronary artery disease and FGF23 (Table 1)

S-klotho was not related to age, hypertension, body mass index, and the lipid status of the patients. Women, presence of diabetes, and smokers revealed significantly higher s-klotho concentrations. There was a linear and significant trend for increasing s-klotho levels with increasing quartiles of FGF23. About $14 \%$ of all LURIC participants exhibited CKD defined as GFR $<60 \mathrm{ml} / \mathrm{min} / 1.732$. Sklotho levels declined significantly in parallel with CKD-stages: Patients with a GFR $<30 \mathrm{ml} / \mathrm{min} / 1.722$ exhibited about $15 \%$ lower s-klotho levels compared to those with a GFR $>90 \mathrm{ml} / \mathrm{min} / 1.732$ (Table 1).

3.2. Association of s-klotho levels with biomarkers of chronic kidney disease - mineral and bone disorder (CKD-MBD) (Table 2)

Persons in the highest quartile of s-klotho showed significantly higher concentrations of total serum calcium, lower phosphorus, and higher 1.25-dihydroxyvitamin D (Table 2). Alkaline phosphatase, PTH, and calcidiol were not related to s-klotho.

3.3. Associations of s-klotho with all-cause and cardiovascular mortality (Tables 3a and 3b) S-klotho levels at baseline were not associated with total and cardiovascular mortality in all models (models 2, 3, and 4). An increase of 1 SDwas associated with fully adjusted HRs for death from any cause of $1.05(0.98-1.13, p=0.142)$ and for cardiovascular death of $1.03(0.95-1.13, p=0.480)$.

3.4. Combined analysis for FGF23 plus s-klotho for mortality (Tables 4a and 4b).

We analyzed the impact of high/lows-klotho levels on mortality of FGF23 levels. Patients within the highest quartile of FGF23 revealed the highest hazard ratio for death independent of the sklotho being above or below the median. These findings were similar for all-cause and for cardiovascular mortality (Tables $4 a$ and $4 b$ ). 


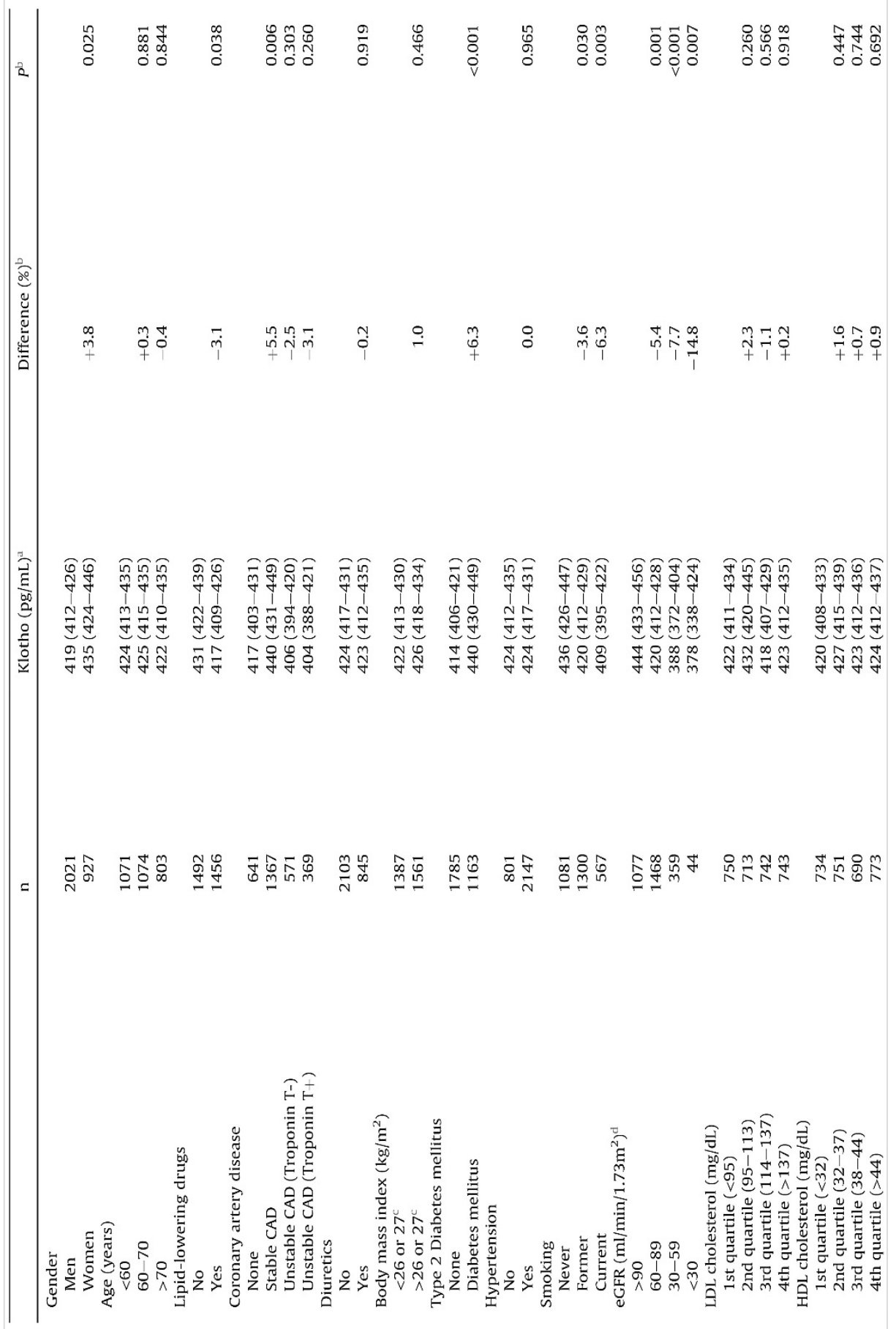




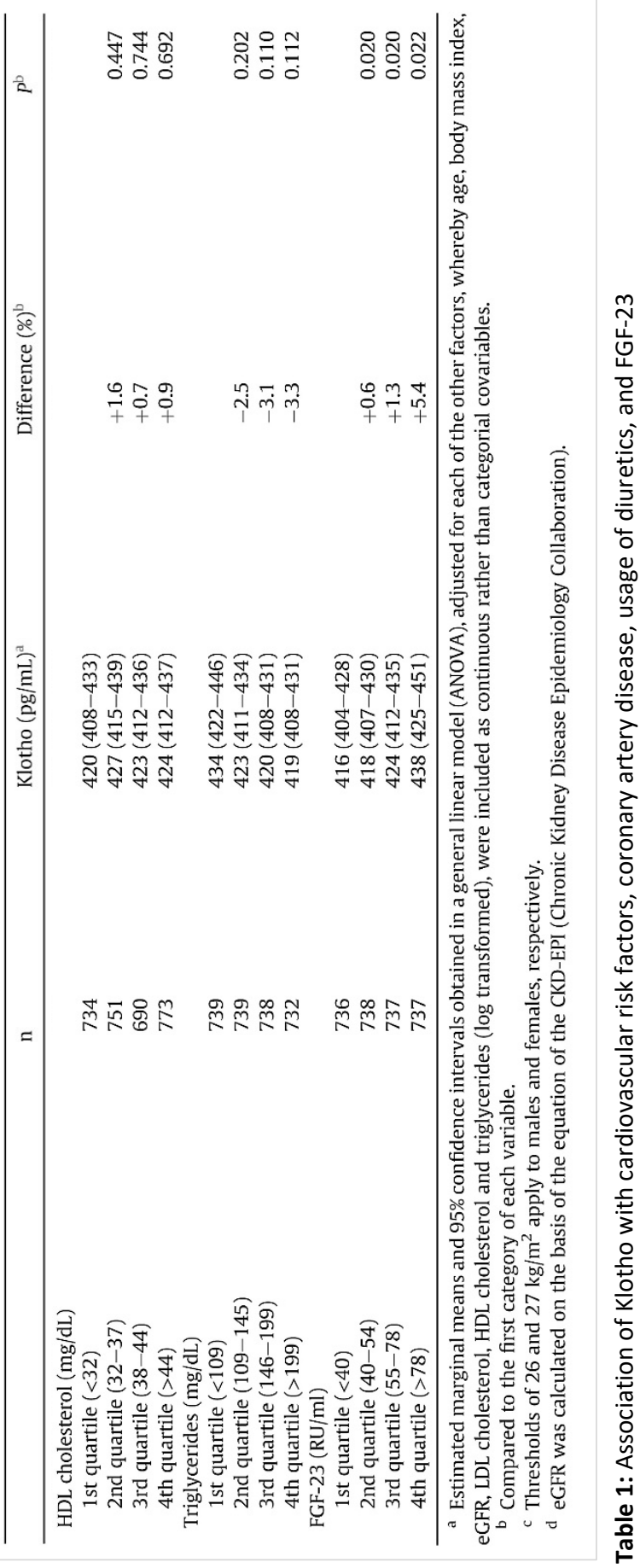




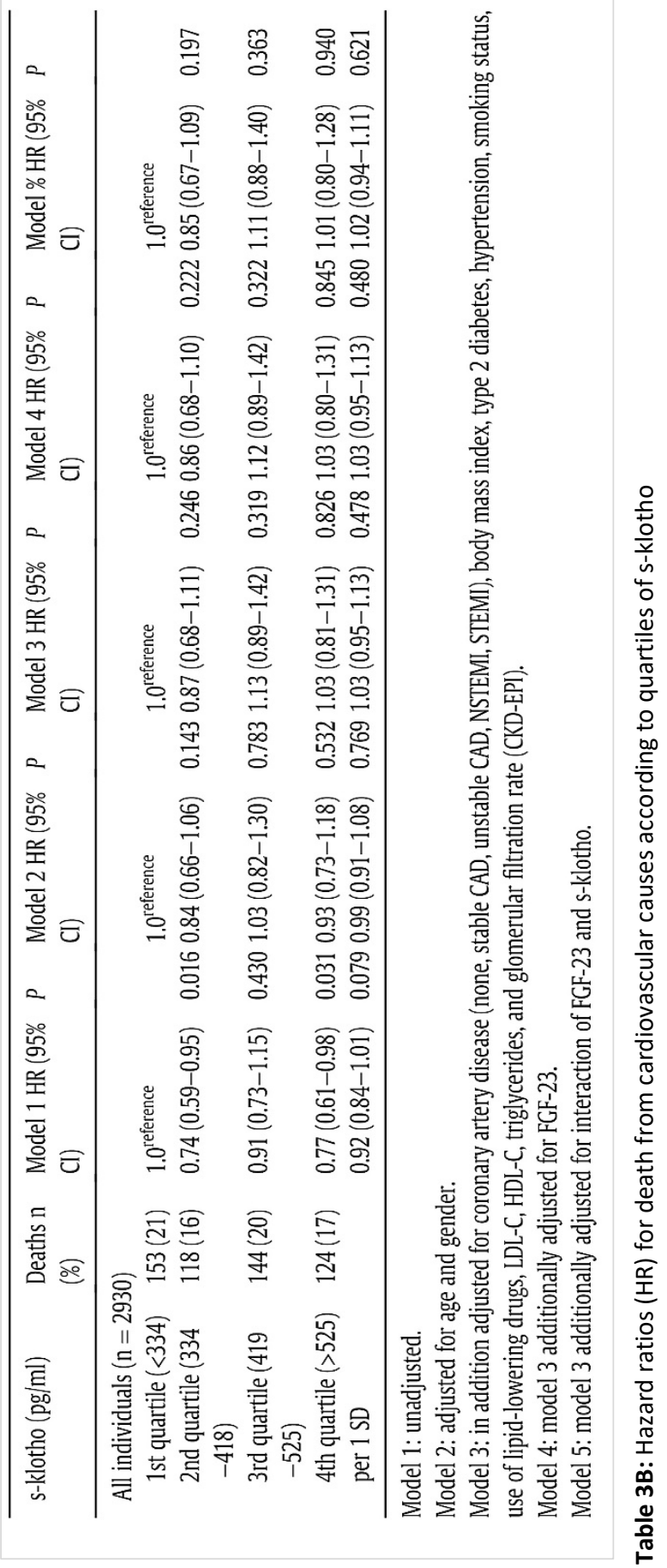




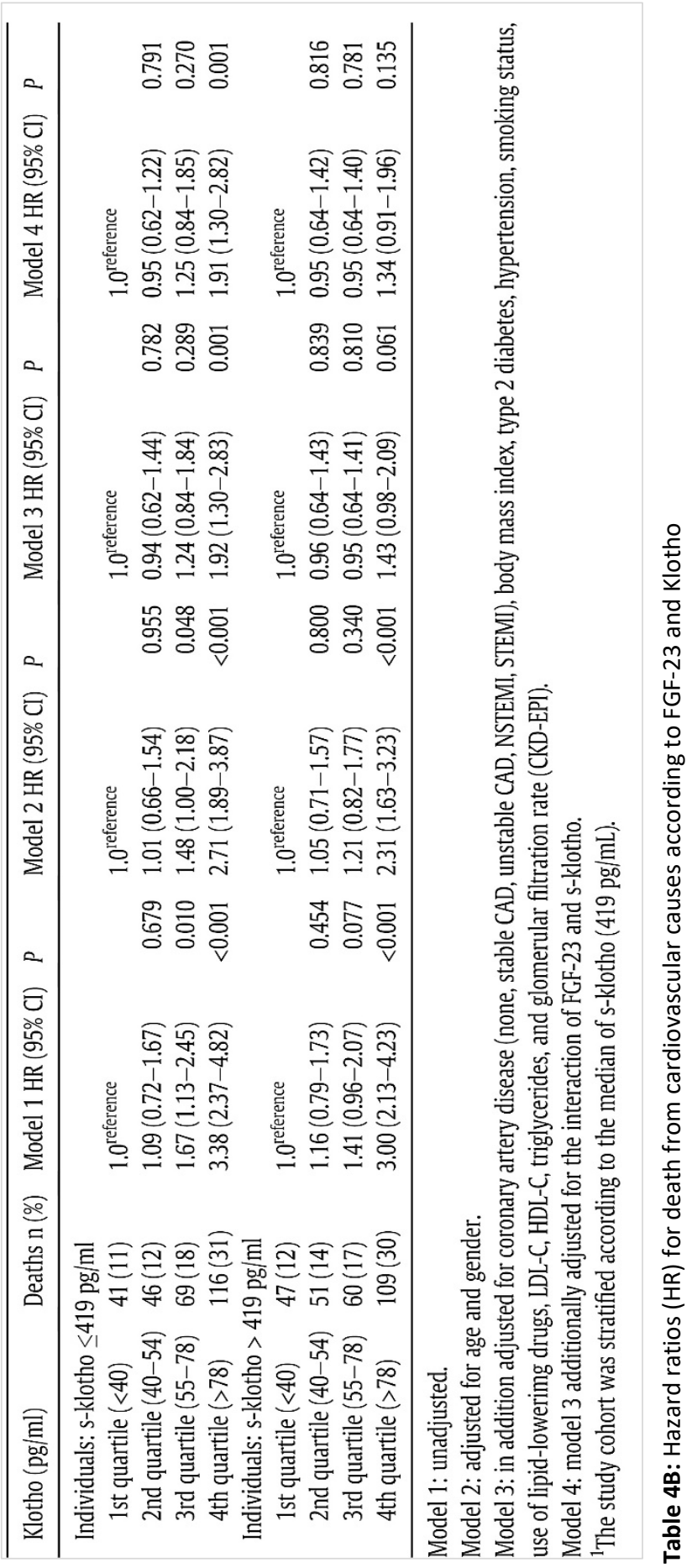




\section{Discussion}

Analyzing the impact of s-klotho upon outcome within the prospective cohort study LURIC provides two novel and important findings: First, s-klotho levels at baseline did not predict cardiovascular and all-cause mortality in a cohort with normal and mildly impaired renal function but at high risk for future cardiovascular events. Second, s-klotho did not modify the corroborated strong relationship between FGF23 and mortality. The present findings about the absence of an association between s-klotho and outcome of particular interest considering our recent publication about an independent and strong association between FGF23 serum levels and future mortality coming from the same cohort, the LURIC study (n $=2974$ patients). ${ }^{12}$ So LURIC has revealed already convincing data about a strong impact of high FGF23 with poor outcome which is perfectly in line with other prospective cohorts. ${ }^{28}$ Our previous data showed a hazard ratio of $1.34(95 \% \mathrm{Cl}, 1.23-1.46)$ for all-cause mortality [1.28 ( $95 \% \mathrm{Cl}, 1.15$ - 1.43) for cardiovascular mortality] for each standard deviation increase in baseline FGF23 concentration. Based on the strong biological interactions between FGF23 and klotho it is therefore reasonable to investigate the association between s-klotho and outcomes. Klotho is the obligatory co-receptor mediating FGF23 receptor activity especially in the kidneys e a key organ for FGF23 mediated systemic effects. ${ }^{3,29}$ Although klotho is absent in the heart in vivo experiments by $\mathrm{Hu}$ and coworkers pointed towards reciprocal klotho-FGF23 effects: Preserved klotho activity ameliorated deleterious cardiac effects associated with phosphate load, CKD, or FGF23 excess. ${ }^{22}$ The authors came to the conclusion that klotho deficiency may be a promoter and modifier of cardiomyopathy and that FGF23 excess is especially noxious to the heart only in states of klotho deficiency. ${ }^{22}$ These experimental findings are strongly supported by various human and in vivo studies indicating that s-klotho associates in a protective way with different cardiovascular surrogates such as kidney function development, aging, fibrosis, or oxidative stress. ${ }^{2,28,30}$ According to in vivo findings by Xie and coworkers ${ }^{19}$ klothodeficiency aggravated CKDinduced cardiomyopathy and restoration of soluble klotho via transgenic expression ameliorated signs of cardiomyopathy independent from phosphate and FGF23 levels. ${ }^{19}$ The lack of association between s-klotho and mortality in the LURIC cohort, in particular cardiovascular mortality, and also the non-existence of any modulatory effect of s-klotho upon FGF23 risk prediction therefore deserves careful interpretation. ${ }^{16,28}$ There may be several causes for this observation. First, it is imaginable that previously reported klotho effects, especially in isolated in vitro systems, are not clinically relevant in the context of competing risk factors. Second, most of the reported effects of klotho in animal studies were generated in various models of pronounced klotho deficiency that may not translate into similar effects in humans with (close to) normal klotho levels. In this regard, all relevant animal models of klotho deficiency (e.g. models of CKD and genetically induced klotho deficiency) are accompanied by predominant secondary alterations including high FGF23 levels that are known to elicit many of the "aging-like" phenotypes attributed to klotho deficiency. ${ }^{31}$ Finally, it remains uncertain to what extent s-klotho reflects its tissue levels and it remains elusive whether currently available s-klotho assays appropriately assess circulating s-klotho. ${ }^{28}$ Several lines of evidence suggest that such assays may suffer from limitations concerning specificity, most importantly because circulating klotho levels in 
animal CKD studies invariably are strongly decreased when measured with alternate techniques, whereas human studies provide inconsistent data on the relationship between klotho and kidney function. ${ }^{16,28,32}$ In agreement, we found only a weak correlation between eGFR and sklotho levels. The present klotho data from the LURIC cohort in terms of absence of association to mortality support two previous reports ${ }^{23,24}$ with remarkable differences in terms of patient characteristics. These two studies were performed in patients either with moderate to severe $C K D^{24}$ or end-stage renal disease ${ }^{23}$ in whom causes for morbidity and mortality are presumably different from LURIC patients. Accordingly median FGF23 levels in LURIC are much lower [median c-term FGF23 serum levels were $54(40-78) \mathrm{RU} / \mathrm{ml}$ ] compared to the Care for Home cohort [102 (64 - 164) RU/ ml] ${ }^{24}$ or especially to the ICD-2 cohort [7247 $\pm 16815 \mathrm{RU} / \mathrm{ml}] .{ }^{23}$ However, all these studies were all performed in patients with a significant degree of comorbidities such as chronic kidney disease, prevalent coronary artery disease or diabetes. Thus, our cohort does not include basically healthy individuals and LURIC is not a prototypic screening cohort. Hence, we cannot assess the potential link between s-klotho and survival in patients at very low cardiovascular risk. Analyses of the LURIC cohort comprising high-risk patients provide evidence that smoking habits (higher levels in nonsmokers), gender (higher levels in females) and diabetes status (higher levels in diabetics) associate with s-klotho levels. These associations have not yet been addressed in previous prospective cohort studies. ${ }^{23,24}$ The nature of our cohort does not allow conclusions about causality. While female gender and non-smoking are prototypic cardioprotective factors, the associated higher sklotho levels do not translate into reduced mortality in the entire cohort and thus, these findings remain of undetermined biological significance. A previous study reported comparable associations between s-klotho levels and diabetes status but this study was too small to provide conclusive evidence $\left(n=62\right.$ patients). ${ }^{33}$ Further studies are clearly needed to evaluate the potential link between smoking and s-klotho. Overall, the present data derived from LURIC extend our understanding that s-klotho concentrations are not associated with future mortality to a patient cohort which is at intermediate to high risk of cardiovascular events, but without overt chronic kidney disease. Some potential limitations of our study need to be acknowledged. Only few participants of the LURIC study are in the low GFR range (CKD stage IV was present in only 44 patients). Renal function impairment was only assessed via GFR determination, while data upon proteinuria are missing. Additionally, our data solely rely upon measurements of s-klotho, of which specificity is not firmly established. Moreover, these levels may not sufficiently reflect tissue levels of klotho which cannot be obtained and analyzed in the absence of a clinical indication for renal biopsy. Based on the inclusion criteria of the present study we can only assess the impact of s-klotho upon mortality in a diseased population (secondary prevention) while our data do not allow conclusions about cardioprotective effects of elevated s-klotho in healthy people or those at very low cardiovascular risk (primary prevention). Strenghts of the current study is its magnitude, homogeneous inclusion criteria, prospective data collection, stringent longterm follow-up and meticulous assessment of clinical endpoints. Moreover a wide range of standard cardiovascular risk factors were captured. 


\section{Conclusion}

In conclusion, higher S-klotho levels are not associated with the long-term risk of death in persons undergoing coronary angiography and it does not modify the strong and established association of FGF23 with mortality. Thus, it is unlikely that s-klotho will qualify as a novel biomarker for cardiovascular risk.

\section{Disclosure/conflict of interest}

The authors have no conflict of interest to declare.

\section{Sources of funding}

This work was supported by the Jubilaeumsfond der Oesterreichischen Nationalbank (No. 15179 to H.S.). LURIC has received funding through the 7th Framework Program (integrated projects Atheroremo, Grant Agreement Number 201668 and RiskyCAD, grant agreement number 305739) of the European Union and from the INTERREG IV Oberrhein Program (Project A28, Genetic mechanisms of cardiovascular diseases) with support from the European Regional Development Fund (ERDF) and the Wissenschaftsoffensive TMO, and from the German ministry for education and research, project e:AtheroSysMed (Systems medicine of coronary heart disease and stroke), grant number 01ZX1313A-K. The authors declare that there are no competing interests with regard to the content and the publication of the present manuscript.

Sponsors had no involvement in the design and conduct of the study; collection, management, analysis, and interpretation of the data; and preparation, review, or approval of the manuscript.

\section{Acknowledgments}

The authors thank the patients of the LURIC study for their willingness to participate in data collection and assessment. We also thank the LURIC study team either temporarily or permanently involved in patient recruitment and sample and data handling, the laboratory staff at the Ludwigshafen General Hospital, and the Universities of Freiburg, Ulm, Graz and Heidelberg. We also thank and the German registration offices and local public health departments for their assistance. 


\section{References}

1. M. Kuro-o, Y. Matsumura, H. Aizawa, H. Kawaguchi, T. Suga, T. Utsugi, Y. Ohyama, M. Kurabayashi, T. Kaname, E. Kume, H. Iwasaki, A. lida, T. Shiraki-lida, S. Nishikawa, R. Nagai, Y.I. Nabeshima, Mutation of the mouse klotho gene leads to a syndrome resembling ageing, Nature 390 (6655) (1997) 45e51.

2. H. Kurosu, M. Yamamoto, J.D. Clark, J.V. Pastor, A. Nandi, P. Gurnani, O.P. McGuinness, H. Chikuda, M. Yamaguchi, H. Kawaguchi, I. Shimomura, Y. Takayama, J. Herz, C.R. Kahn, K.P. Rosenblatt, M. Kuro-o, Suppression of aging in mice by the hormone Klotho, Science 309 (5742) (2005) 1829e1833.

3. I. Urakawa, Y. Yamazaki, T. Shimada, K. lijima, H. Hasegawa, K. Okawa, T. Fujita, S. Fukumoto, T. Yamashita, Klotho converts canonical FGF receptor into a specific receptor for FGF23, Nature 444 (7120) (2006) 770e774.

4. J. Silver, T. Naveh-Many, FGF-23 and secondary hyperparathyroidism in chronic kidney disease, Nat. Rev. Nephrol. 9 (11) (2013) 641e649.

5. J.J. Scialla, H. Xie, M. Rahman, A.H. Anderson, T. Isakova, A. Ojo, X. Zhang, L. Nessel, T. Hamano, J.E. Grunwald, D.S. Raj, W. Yang, J. He, J.P. Lash, A.S. Go, J.W. Kusek, H. Feldman, M. Wolf, Fibroblast growth factor-23 and cardiovascular events in CKD, J. Am. Soc. Nephrol. 25 (2) (2013) 349e360.

6. M. Plischke, S. Neuhold, C. Adlbrecht, B. Bielesz, S. Shayganfar, C. Bieglmayer, T. Szekeres, W.H. Horl, G. Strunk, P. Vavken, R. Pacher, M. Hulsmann, Inorganic phosphate and FGF-23 predict outcome in stable systolic heart failure, Eur. J. Clin. Invest 42 (6) (2012) 649e656.

7. J.H. Ix, R. Katz, B.R. Kestenbaum, I.H. de Boer, M. Chonchol, K.J. Mukamal, D. Rifkin, D.S. Siscovick, M.J. Sarnak, M.G. Shlipak, Fibroblast growth factor-23 and death, heart failure, and cardiovascular events in community-living individuals: CHS (cardiovascular health study), J. Am. Coll. Cardiol. 60 (3) (2012) $200 \mathrm{e} 207$.

8. B.D. Parker, L.J. Schurgers, V.M. Brandenburg, R.H. Christenson, C. Vermeer, M. Ketteler, M.G. Shlipak, M.A. Whooley, J.H. Ix, The associations of fibroblast growth factor 23 and uncarboxylated matrix Gla protein with mortality in coronary artery disease: the heart and soul study, Ann. Intern Med. 152 (10) (2010) 640e648.

9. S. Seiler, B. Cremers, N.M. Rebling, F. Hornof, J. Jeken, S. Kersting, C. Steimle, P. Ege, M. Fehrenz, K.S. Rogacev, B. Scheller, M. Bohm, D. Fliser, G.H. Heine, The phosphatonin fibroblast growth factor 23 links calcium-phosphate metabolism with left-ventricular dysfunction and atrial fibrillation, Eur. Heart J. 32 (21) (2011) $2688 \mathrm{e} 2696$.

10. J. Arnlov, A.C. Carlsson, J. Sundstrom, E. Ingelsson, A. Larsson, L. Lind, T.E. Larsson, Serum FGF23 and risk of cardiovascular events in relation to mineral metabolism and cardiovascular pathology, Clin. J. Am. Soc. Nephrol. 8 (5) (2013) 781e786.

11. E.N. Taylor, E.B. Rimm, M.J. Stampfer, G.C. Curhan, Plasma fibroblast growth factor 23, parathyroid hormone, phosphorus, and risk of coronary heart disease, Am. Heart J. 161 (5) (2011) 956e962.

12. V.M. Brandenburg, M.E. Kleber, M.G. Vervloet, A. Tomaschitz, S. Pilz, T. Stojakovic, G. Delgado, T.B. Grammer, N. Marx, W. Marz, H. Scharnagl, Fibroblast growth factor 23 
(FGF23) and mortality: the ludwigshafen risk and cardiovascular health study, Atherosclerosis 237 (1) (2014) 53e59.

13. C. Faul, A.P. Amaral, B. Oskouei, M.C. Hu, A. Sloan, T. Isakova, O.M. Gutierrez, R. Aguillon-Prada, J. Lincoln, J.M. Hare, P. Mundel, A. Morales, J. Scialla, M. Fischer, E.Z. Soliman, J. Chen, A.S. Go, S.E. Rosas, L. Nessel, R.R. Townsend, H.I. Feldman, S.M. St John, A. Ojo, C. Gadegbeku, G.S. Di Marco, S. Reuter, D. Kentrup, K. Tiemann, M. Brand, J.A. Hill, O.W. Moe, O. Kuro, J.W. Kusek, M.G. Keane, M. Wolf, FGF23 induces left ventricular hypertrophy, J. Clin. Invest 121 (11) (2011) 4393e4408.

14. A. Imura, A. Iwano, O. Tohyama, Y. Tsuji, K. Nozaki, N. Hashimoto, T. Fujimori, Y. Nabeshima, Secreted Klotho protein in sera and CSF: implication for posttranslational cleavage in release of Klotho protein from cell membrane, FEBS Lett. 565 (1e3) (2004) $143 e 147$.

15. Y. Yamazaki, A. Imura, I. Urakawa, T. Shimada, J. Murakami, Y. Aono, H. Hasegawa, T. Yamashita, K. Nakatani, Y. Saito, N. Okamoto, N. Kurumatani, N. Namba, T. Kitaoka, K. Ozono, T. Sakai, H. Hataya, S. Ichikawa, E.A. Imel, M.J. Econs, Y. Nabeshima, Establishment of sandwich ELISA for soluble alpha-Klotho measurement: agedependent change of soluble alpha-Klotho levels in healthy subjects, Biochem. Biophys. Res. Commun. 398 (3) (2010) 513e518.

16. M.G. Vervloet, A.Y. Adema, T.E. Larsson, Z.A. Massy, The role of klotho on vascular calcification and endothelial function in chronic kidney disease, Semin. Nephrol. 34 (6) (2014) $578 \mathrm{e} 585$.

17. S.M. Moe, Klotho: a master regulator of cardiovascular disease? Circulation 125 (18) (2012) 2181e2183.

18. M.C. Hu, M. Shi, J. Zhang, H. Quinones, C. Griffith, M. Kuro-o, O.W. Moe, Klotho deficiency causes vascular calcification in chronic kidney disease, J. Am. Soc. Nephrol. 22 (1) (2011) 124e136.

19. J. Xie, J. Yoon, S.W. An, O. Kuro, C.L. Huang, Soluble klotho protects against uremic cardiomyopathy independently of fibroblast growth factor 23 and phosphate, J. Am. Soc. Nephrol. 26 (5) (2015) 1150e1160.

20. K. Yang, C. Wang, L. Nie, X. Zhao, J. Gu, X. Guan, S. Wang, T. Xiao, X. Xu, T. He, X. Xia, J. Wang, J. Zhao, Klotho Protects against Indoxyl sulphate-induced myocardial hypertrophy, J. Am. Soc. Nephrol. (2015) (Epub ahead of print).

21. M. Kitagawa, H. Sugiyama, H. Morinaga, T. Inoue, K. Takiue, A. Ogawa, T. Yamanari, Y. Kikumoto, H.A. Uchida, S. Kitamura, Y. Maeshima, K. Nakamura, H. Ito, H. Makino, A decreased level of serum soluble Klotho is an independent biomarker associated with arterial stiffness in patients with chronic kidney disease, PLoS One 8 (2) (2013) e56695.

22. M.C. Hu, M. Shi, H.J. Cho, B. Adams-Huet, J. Paek, K. Hill, J. Shelton, A.P. Amaral, C. Faul, M. Taniguchi, M. Wolf, M. Brand, M. Takahashi, O. Kuro, J.A. Hill, O.W. Moe, Klotho and phosphate are modulators of pathologic uremic cardiac remodeling, J. Am. Soc. Nephrol. 26 (6) (2015) 1290e1302.

23. M.S. Buiten, M.K. de Bie, A. Bouma-de Krijger, B. van Dam, F.W. Dekker, J.W. Jukema, T.J. Rabelink, J.I. Rotmans, Soluble Klotho is not independently associated with cardiovascular disease in a population of dialysis patients, BMC Nephrol. 15 (1) (2014) 197. 
24. S. Seiler, K.S. Rogacev, H.J. Roth, P. Shafein, I. Emrich, S. Neuhaus, J. Floege, D. Fliser, G.H. Heine, Associations of FGF-23 and sKlotho with cardiovascular outcomes among patients with CKD stages 2-4, Clin. J. Am. Soc. Nephrol. 9 (6) (2014) 1049e1058.

25. B.R. Winkelmann, W. Marz, B.O. Boehm, R. Zotz, J. Hager, P. Hellstern, J. Senges, Rationale and design of the LURIC studyea resource for functional genomics, pharmacogenomics and long-term prognosis of cardiovascular disease, Pharmacogenomics 2 (1 Suppl. 1) (2001) S1eS73.

26. L.A. Stevens, C.H. Schmid, T. Greene, Y.L. Zhang, G.J. Beck, M. Froissart, L.L. Hamm, J.B. Lewis, M. Mauer, G.J. Navis, M.W. Steffes, P.W. Eggers, J. Coresh, A.S. Levey, Comparative performance of the CKD epidemiology collaboration (CKD-EPI) and the modification of diet in renal disease (MDRD) study equations for estimating GFR levels above $60 \mathrm{ml} / \mathrm{min} / 1.73 \mathrm{~m}^{2}$, Am. J. Kidney Dis. 56 (3) (2010) $486 \mathrm{e} 495$.

27. A.S. Levey, L.A. Stevens, C.H. Schmid, Y.L. Zhang, A.F. Castro III, H.I. Feldman, J.W. Kusek, P. Eggers, F. Van Lente, T. Greene, J. Coresh, A new equation to estimate glomerular filtration rate, Ann. Intern Med. 150 (9) (2009) 604e612.

28. H. Olauson, M.G. Vervloet, M. Cozzolino, Z.A. Massy, T.P. Urena, T.E. Larsson, New insights into the FGF23-klotho axis, Semin. Nephrol. 34 (6) (2014) $586 \mathrm{e} 597$.

29. H. Olauson, K. Lindberg, R. Amin, T. Jia, A. Wernerson, G. Andersson, T.E. Larsson, Targeted deletion of Klotho in kidney distal tubule disrupts mineral metabolism, J. Am. Soc. Nephrol. 23 (10) (2012) 1641e1651.

30. H.R. Kim, B.Y. Nam, D.W. Kim, M.W. Kang, J.H. Han, M.J. Lee, D.H. Shin, F.M. Doh, H.M. Koo, K.I. Ko, C.H. Kim, H.J. Oh, T.H. Yoo, S.W. Kang, D.S. Han, S.H. Han, Circulating alpha-klotho levels in CKD and relationship to progression, Am. J. Kidney Dis. 61 (6) (2013) 899e909.

31. G. Zoppellaro, E. Faggin, M. Puato, P. Pauletto, M. Rattazzi, Fibroblast growth factor 23 and the bone-vascular axis: lessons learned from animal studies, Am. J. Kidney Dis. 59 (1) (2012) 135e144.

32. H. Sakan, K. Nakatani, O. Asai, A. Imura, T. Tanaka, S. Yoshimoto, N. Iwamoto, N. Kurumatani, M. Iwano, Y. Nabeshima, N. Konishi, Y. Saito, Reduced renal alpha-Klotho expression in CKD patients and its effect on renal phosphate handling and vitamin $D$ metabolism, PLoS One 9 (1) (2014) e86301.

33. M.S. Buiten, M.K. de Bie, A. Bouma-de Krijger, B. van Dam, F.W. Dekker, J.W. Jukema, T.J. Rabelink, J.I. Rotmans, Soluble Klotho is not independently associated with cardiovascular disease in a population of dialysis patients, BMC Nephrol. 15 (2014) 197. 



\section{c)}

High-Dose Ferric Carboxymaltose in Patients

\section{With HFrEF Induces Significant Hypophosphatemia (IF 19)}

High-Dose Ferric Carboxymaltose in Patients with HFrEF Induces Significant Hypophosphatemia.

Stöhr R, Sandstede L, Heine GH, Marx N, Brandenburg V. J Am Coll Cardiol. 2018 May 15; 71(19): 2270-2271. 
Iron deficiency is a frequent comorbidity in up to $50 \%$ of patients who have heart failure with reduced ejection fraction (HFrEF). ${ }^{1}$ Intravenous iron replenishment (specifically by ferric carboxymaltose [FCM]) increases exercise tolerance and quality of life in HFrEF patients with iron deficiency. ${ }^{1} \mathrm{FCM}$ is currently graded as a Class Ila recommendation by heart failure guidelines in iron-deficient HFrEF patients. ${ }^{2,3}$ However, preliminary data have linked FCM administration to the development of hypophosphatemia. ${ }^{4}$ Since circulating fibroblast growth factor (FGF)-23 is a key regulator of phosphate and vitamin D metabolism, we sought to determine if FCM modifies FGF-23 levels and how this associates with hypophosphatemia induction. Our single-center prospective interventional pilot trial included 23 stable iron-deficient HFrEF patients (NCT03079518). Patients were divided into groups based on presence or absence of chronic kidney disease (CKD) (cut-off estimated glomerular filtration rate $\left.60 \mathrm{ml} / \mathrm{min} / 1.73 \mathrm{~m}^{2}\right)$ : group $\operatorname{HFrEF}(-) C K D(\mathrm{n}=12)$, and group $\operatorname{HFrEF}(+)$ CKD $(n=11)$. Iron deficiency was defined as ferritin $<100 \mathrm{mg} / \mathrm{dl}$ or ferritin 100 to $300 \mathrm{mg} / \mathrm{dl}$ and transferrin saturation (TSAT) $<20 \%$. Patients received a single dose of 1,000 mg FCM intravenously. We assessed FGF-23 levels by both intact FGF-23 (iFGF-23) as well as the degraded C-terminal FGF-23 (c-termFGF-23) (both by enzymelinked immunosorbent assay) over a period of 28 days. Furthermore, we measured serum phosphate, 1,25-OH vitamin $\mathrm{D}$, parathyroid hormone, tartrateresistant acid phosphatase $5 \mathrm{~b}$, and bone-specific alkaline phosphatase as well as fractional excretion of phosphate (FEPi). FCM infusion resulted in a concordant increase in ferritin and TSAT. Baseline serum phosphate, iFGF-23, c-termFGF-23, and FEPi were higher in $\operatorname{HFrEF(+)~CKD~compared~to~HFrEF(-)CKD~patients.~}$ iFGF-23 levels rose rapidly in both groups reaching their peak at day 1 (in HFrEF[+]CKD patients by a factor of 1.8; $p=N S$; in HFrEF[-]CKD patients by a factor of $11 ; p<0.001$ ). In HFrEF(-)CKD patients, iFGF23 remained significantly elevated until day 28 . c-termFGF23 levels decreased constantly toward day 28 in both groups. Serum phosphate significantly decreased only in HFrEF(-)CKD patients (nadir at day 14, mean decrease $0.33-0.2 \mathrm{mmol} / \mathrm{l}$ compared to baseline) and returned to baseline at day 28. FEPi was induced in both groups, although more in the HFrEF(-)CKD group. Transient hypophosphatemia $(<0.8 \mathrm{mmol} / \mathrm{l})$ developed in 14 of 23 patients (9 HFrEF[-]CKD patients and 5 HFrEF[+] CKD). Levels of 1.25$\mathrm{OH}$ vitamin $\mathrm{D}$ significantly decreased in both groups by more than $50 \%$ with a similar time course as serum phosphate (Table 1). Bone markers parathyroid hormone, tartrateresistant acid phosphatase $5 \mathrm{~b}$, and bone-specific alkaline phosphatase remained stable over the follow-up period (data not shown). We thus show that the currently recommended intravenous iron supplementation in HFrEF patients has a relevant hypophosphatemic effect through increased iFGF-23 with relevant drops in serum phosphate and 1.25-OH vitamin D levels lasting over several weeks in HFrEF(-)CKD patients. $\mathrm{HFrEF}(+)$ CKD patients appear partially protected from these effects, presumably caused by lower relative iFGF23 increases and assumed renal Klotho deficiency, which renders the tubular phosphate reabsorption system less responsive to FGF-23. The present findings are in line with previous reports about the hypophosphatemic actions of FCM mediated by iFGF-23 increases in females with a history of heavy uterine bleeding. ${ }^{4}$ Our data obtained in a selected HFrEF cohort are of particular interest because increased FGF-23 is associated with increased cardiovascular mortality; ${ }^{5}$ moreover, FGF-23 in itself may induce or aggravate left ventricular hypertrophy and heart failure. Long-lasting or repetitive 
hypophosphatemia and active vitamin D deficiency may further associate with the risk of osteomalacia. Our data emphasize the need to assess long-term safety of repetitive FCM administration in HFrEF patients. It must be determined if the observed derangements in FGF-23-phosphate metabolism may partly outweigh beneficial effects of FCM, particularly with repetitive dosing. Potential negative skeletal effects should also be assessed. Based on our findings, we recommend monitoring of serum phosphate for 2 to 3 weeks after highdosage FCM infusion. Further studies should investigate if these changes are formulation or dosing effects of intravenous iron. In summary, despite convincing evidence regarding a net symptomatic benefit of FCM therapy in iron-deficient HFrEF patients, we recommend a careful assessment of the (transient) phosphate-FGF-23 derangements after the administration of FCM. 

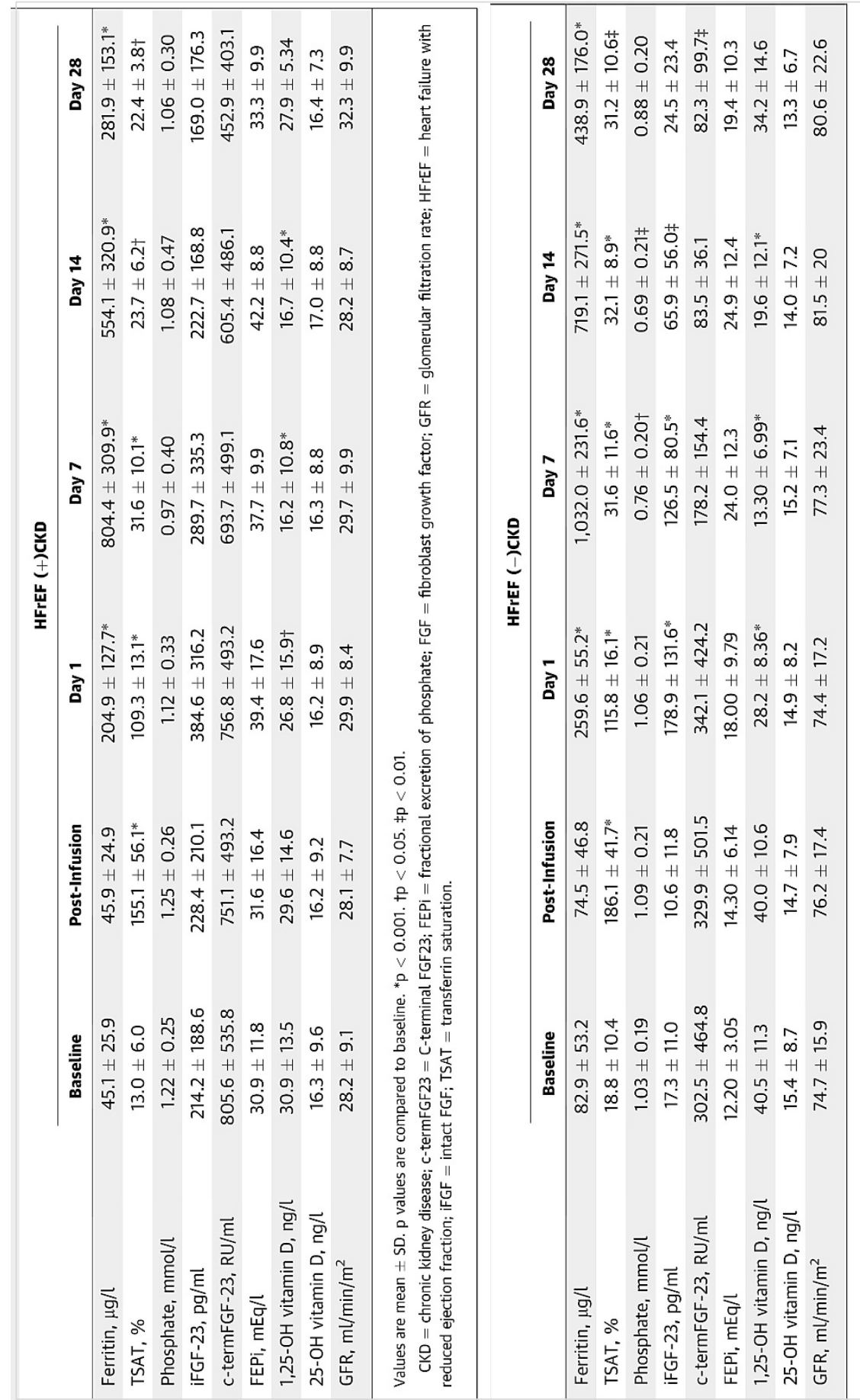

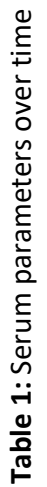




\section{References}

1. Anker SD, Comin Colet J, Filippatos G, et al. Ferric carboxymaltose in patients with heart failure and iron deficiency. N Engl J Med 2009; 361: 2436-48.

2. Ponikowski P, Voors AA, Anker SD, et al. 2016 ESC guidelines for the diagnosis and treatment of acute and chronic heart failure. Eur Heart J 2016; 37: 2129-200.

3. Yancy CW, Jessup M, Bozkurt B, et al. 2017 ACC/AHA/HFSA focused update of the 2013 ACCF/AHA guideline for the management of heart failure. J Am Coll Cardiol 2017; 70: 776-803.

4. Wolf M, Koch TA, Bregman DB. Effects of iron deficiency anemia and its treatment on fibroblast growth factor 23 and phosphate homeostasis in women. J Bone Miner Res 2013; 28: 1793-803.

5. Qin Z, Liu X, Song M, et al. Fibroblast growth factor 23 as a predictor of cardiovascular and all-cause mortality in prospective studies. Atherosclerosis 2017; 261: 1-11. 



\section{SECTION:}

Vitamin $\mathrm{K}$ and cardiovascular disease 



\section{a)}

\section{Calcific uraemic arteriolopathy (calciphylaxis): data from a large nationwide registry (IF 4)}

Calcific uraemic arteriolopathy (calciphylaxis): data from a large nationwide registry.

Brandenburg VM, Kramann R, Rothe $\mathrm{H}$, Kaesler $\mathrm{N}$, Korbiel J, Specht P, Schmitz S, Krüger T, Floege J, Ketteler M. Nephrol Dial Transplant. 2017 Jan 1; 32(1): 126-132. 


\section{Abstract}

Background: Calcific uraemic arteriolopathy (CUA, calciphylaxis) is a rare disease predominantly in dialysis patients and associated with high mortality. Painful skin ulcerations and calcification of cutaneous arterioles characterize calciphylaxis.

Methods: We established an observational, Internet-based registry allowing online notification for all German CUA cases. The registry recorded data about patient characteristics, biochemistry and therapies. Blood samples were stored in a central biobank.

Results: Between 2006 and 2015, 253 CUA patients were recorded: median age 70 [interquartile range (IQR) 61-76] years, 60\% females and $86 \%(n=207)$ dialysis patients, translating into an estimated annual incidence rate of $0.04 \%$ in German dialysis patients. Fifty-two per cent received vitamin $\mathrm{K}$ antagonists (VKAs) prior to CUA. Skin lesions were localized in $71 \%$ on the legs or gluteal region. In dialysis CUA patients median total serum calcium was 2.20 (IQR 2.06-2.37) mmol/L, phosphorus 1.67 (IQR 1.35-2.03) mmol/L, intact parathyroid hormone 147 (IQR 72-276) pg/ml and fetuin-A 0.21 (IQR 0.16-0.26) g/L (normal range 0.35-0.95). Median sclerostin, osteoprotegerin, TRAP5b, bone-specific alkaline phosphatase and c-terminal FGF23 levelswere all elevated.Themost frequently recorded therapeutic procedures in dialysis CUA patients were as follows: wound debridement (29\% of cases), stopping VKA (25\%), lowering calcium supply (24\%), sodium thiosulphate (22\%), application of vitamin $\mathrm{K}(18 \%)$, increase of dialysis duration/frequency $(17 \%)$ and stoping active vitamin $D(16 \%)$.

Conclusions: Approximately 50\% of CUA patients used VKA. Our data suggest that uncontrolled hyperparathyroidism is not the key determinant of calciphylaxis. Therapeutic strategies were heterogeneous. The experience of the German registry will help substantially to initiate a large-scale multinational CUA registry. Keywords: anticoagulation, calcification, calciphylaxis, cardiovascular, ESRD 


\section{Introduction}

Calcific uraemic arteriolopathy (CUA), also known as calciphylaxis, is a rare disease (ORPHA292147) predominantly affecting patients with end-stage renal disease (ESRD) on dialysis. ${ }^{1,2}$ The exact incidence and prevalence are unknown. Although rare, two clinical and aetiological aspects qualify CUA as an exceptional research target in chronic kidney diseasemineral and bone disorder (CKD-MBD). ${ }^{3}$ First, the unmet clinical need of how to prevent and how to treat calciphylaxis is urgent since the condition is clinically devastating: debilitating pain, potentially large areas of skin ulcerations and markedly reduced quality of life dominate the clinical picture. Moreover, CUA is associated with a massive reduction in longterm survival. ${ }^{1,2,4}$ Second, CUA might serve as a potential 'high-speed' template for general cardiovascular calcification processes in CKD involving larger arteries or heart valves.

Therefore, CUA research might add valuable insights into the causative pathways of accelerated uraemic calcifying arteriosclerosis, since circumferential calcification in themedial layer of (in this case small cutaneous) arteries is also the histological hallmark of CUA. ${ }^{5}$ Unfortunately, CUA treatment options are not evidencebased since prospective randomized controlled trials are barely possible in such a devastating, rare disease. ${ }^{1,2}$ Overcoming these limitations is not easy since centralizing clinical as well as research expertise in the field of CUA is difficult: the severe clinical condition and the high degree of comorbidities in the often elderly CUA patients complicate establishing tertiary referral centres (centres of expertise), requiring frequent long-distance travel. As an alternative, we established an Internet-based registry in 2006 (http://www.calciphylaxie.de). Within this online registry, we invited treating physicians to register all cases of established or suspected CUA. The registry consists of a comprehensive database of various parameters, including patient characteristics, laboratory data, clinical background and presentation as well as therapeutic strategies. The aimof the registry was to collect data on potential risk factors and good clinical practice as well as the creation of a biobank allowing research biomarker analyses in the core facility [University Hospital Rheinisch-Westfälische Technische Hochschule (RWTH) Aachen].The aim of the present analyses is to provide a detailed and comprehensive summary of the first 9 years of data collection ithin the German calciphylaxis registry.

\section{Methods}

The German calciphylaxis registry is accessible at www.calciphylaxie.de. It was established in December 2006 (first atient in). The nature of the registry is non-interventional and purely observational. For study participation, written informed consent of the patient is required. The storage of patient data is anonymous. The registry activity was approved by the University ospital RWTH Aachen ethical committee (vote no. 10-024). Most of the query items allow simple selection via dropdown menus. In contrast, the field with the question about applied treatment strategies allows a free text answer, since drop-down list might incompletely reflect the real-world situation. Moreover, such a pre-selection may have created the impression of plausibility or a preference for a certain intervention. 
Incoming data underwent centralized plausibility checking and quality control. Numerical outliers were double checked with the peripheral centre, and in case of doubts, ambiguous data, implausible data or incomplete data, such issues were discussed with the peripheral centre and the treating physician locally in charge. In case such a request could not clarify implausible data, such data or the entire data set was deleted from the database. Whenever possible, photo documentation and transfer of the images to the registry centre in Aachen was requested to allow second-opinion evaluation. The registry team at the Aachen University Hospital requested full blood, plasma and serum sampling of the patients according to standard procedures and asked for immediate freezing at the peripheral study site. Long-term storage was done at $-80^{\circ} \mathrm{C}$ immediately after arrival at the University Hospital Aachen. The registry activities were supported by an unrestricted grant from Amgen (2006 until present) and Sanofi (2012 until present). The registry is under the patronage of the German National Society of Nephrology (DGFN) and the European Renal Association-European Dialysis and Transplant Association (ERA-EDTA) CKD-MBD Scientific Working Group. Marketing activities were undertaken by the study team to increase awareness of the registry and to increase motivation for participation. At the start of the registry, Amgen field staff distributed flyers about the aims and scope of the registry to virtually all German nephrologists. Since then, the study team has regularly presented data summaries at annual national as well as international nephrology congresses.

\subsection{Laboratory measurements}

The registry recorded online levels of serum albumin, total calcium, alkaline phosphatase, haemoglobin, serum creatinine, inorganic phosphate, intact parathyroid hormone (iPTH), 25-hydroxyvitamin D [25(OH)D, calcidiol] and total protein. For those parameters, standard procedures were applied according to the laboratory routine in the peripheral centres. Total serum calcium was corrected for albumin content. In order to increase comparability between biochemistry results, centralized laboratory analysis was performed using Aachen biobank samples for the following CKD-MBD parameters: iPTH, C-reactive protein (CRP) and calcidiol $[25(\mathrm{OH})]$. Additionally, non-routine (research) CKD-MBD parameters were measured from the same biobank samples: fetuin-A, osteoprotegerin (OPG), sclerostin, tartrate-resistant alkaline phosphatase 5b (TRAP5b), bone-specific alkaline phosphatase (BSAP) and c-terminal fibroblast growth factor 23 (c-FGF23). Commercially available enzyme-linked immunosorbent assays (ELISAs) were used to determine levels of fetuin-A, OPG and BAP (TECOmedical AG, Sissach, Switzerland). PTH was measured as IPTH by an assay provided by Biomerica (Irvine, CA, USA). Serum sclerostin was assessed by the TECO Sclerostin EIA Kit, which is a 96-well imunocapture ELISA product. TRAP5b was assessed via ELISA (Quidel, San Diego, CA, USA). C-FGF23 was measured in plasma by an assay from Immutopics (San Clemente, CA, USA). CRP was measured by ELISA (Biomerica).

\subsection{Statistical analysis}

Descriptive statistics were performed for the entire cohort as well as for subgroups of patients: separate analyses were done for dialysis patients, for peritoneal dialysis (PD) patients and for haemodialysis (HD)/haemodiafiltration (HDF) patients stratified for gender. Results are expressed as number (\%) for categorical variables, as mean \pm SD for normally distributed continuous variables and as median [interquartile range (IQR)] for continuous 
Brandenburg VM, Kramann R, Rothe $\mathrm{H}$ et al. High-Dose Calcific uraemic arteriolopathy (calciphylaxis): data from a large nationwide registry. Nephrol Dial Transplant. 2017 Jan 1; 32(1): 126-132.

variables with skewed distribution. For differences between groups, Student's t-test and the Mann-Whitney $U$ test were performed for normally and non-normally distributed variables, respectively. The statistical analysis was performed with SPSS 21 (IBM, Armonk, NY, USA).

\section{Results}

3.1. The entire registry cohort: clinical data

From December 2006 to March 2015 (100 months), 265 patients were recorded. Twelve patients were deleted from the database after negative plausibility control and feedback discussion with the referring physician revealing low probability of CUA or after an alternative diagnosis was established. Overall, 253 patients were finally classified as calciphylaxis. The median age of the CUA patients was 70 years (IQR 61-76; minimum 21 and maximum 88 ). The male/female ratio was $40-60 \%$. Most $(n=252)$ patients were Caucasian, and one patient was Asian. The median annual notification rate in the complete years 2007-2014 was 30 cases per year [ranging from 24 (2012) to 35 (2009) per year]. In 210 cases (83\%), a date for the occurrence of first symptoms was recorded, hence allowing calculation of days between onset of the disease and online notification to the registry. The median time interval was 28 days (IQR 13-60). Overall, 19 centres recorded more than one patient into the registry. The maximum of registered patients per centre was five patients (period from 2008 to 2015). A skin biopsy was performed in $45 \%$ of patients, whereas in $55 \%$ the diagnosis was established without histological examination of the specimen. In $88 \%(n=222$ ) of cases, the treating physician stated the predominant anatomic site of cutaneous CUA manifestation. The dominant lesions were located on the legs in $179(71 \%)$ cases. In the vast majority of these cases, the thighs were affected either alone or in combination with the lower legs. The trunk was the predominant location in 45 (18\%) cases, with the abdominal wall and the hips being the most frequent locations. In $12 \%$ of cases, a dominant anatomic location was not recorded. The character of the skin lesions was described as ulcerative in 63\% versus non-ulcerative in 37\% [rate of return $n=199(79 \%)$ ]. In 66 (26\%) cases, the referring physician speculated about the presence of an acute triggering event prior to calciphylaxis development. Physical trauma (e.g. fall, subcutaneous injections, injury, surgical wound, compression trauma and haematoma) was the single most recorded triggering event

$(n=27)$. The referring physician was asked to classify the presence/absence and degree of kidney disease prior to CUA development into categories (Table 1). 
Status of kidney disease prior to CUA development $(n=253) \quad n(\%)$

Normal or mildly impaired renal function

CKD, non-dialysis

Functioning kidney graft

PD

Dialysis (HD + HDF)

ESRD (dialysis + transplantation)

Table 1: Stage of kidney disease at the time of CUA development

The majority of patients were ESRD patients. Cardiovascular comorbidities at baseline are listed in Supplementary data, Table S1, among which arterial hypertension, diabetes mellitus and coronary heart disease were most frequently recorded. In 250 patients, data on previous or ongoing vitamin $\mathrm{K}$ antagonist (VKA) use at the time of CUA development were available. The overall proportion of patients on VKA was 130 (52\%) versus 120 (48\%) without previous VKA use (Supplementary data, Table S2). The patients were stratified according to the VKA prescription 'yes' versus 'no'. Those two groups did not reveal statistically significant differences in terms of anthropomorphic data, clinical data or biochemistry (data not shown).

\begin{tabular}{lcc}
\hline Comorbidity (n=253) & yes, $\mathbf{n}(\%)$ & no, $\mathbf{n}(\%)$ \\
\hline Arterial hypertension & $224(89 \%)$ & $26(10 \%)$ \\
Diabetes mellitus (type 1/2) & $137(55 \%)$ & $115(45 \%)$ \\
Coronary heart disease & $123(49 \%)$ & $78(31 \%)$ \\
Peripheral vascular disease & $99(39 \%)$ & $111(44 \%)$ \\
Cerebrovascular disease & $50(20 \%)$ & $182(72 \%)$ \\
History of myocardial infarction & $48(19 \%)$ & $192(76 \%)$ \\
Any bone fractures & $26(10 \%)$ & $221(87 \%)$
\end{tabular}

Table S1: Overview about the prevalence of comorbidities (\% related to $n=253$ pts; in the remaining patients the question was not answered or answered with "unknown") 


\begin{tabular}{lcc}
$\begin{array}{l}\text { VKA usage in subgroups of CUA patients } \\
(\mathbf{n}=\mathbf{2 5 0})\end{array}$ & VKA: yes & VKA: no \\
\hline & $n(\%)$ & $n(\%)$ \\
Total & $130(52 \%)$ & $120(48 \%)$ \\
Chronic kidney disease, non-dialysis & $8(44 \%)$ & $10(56 \%)$ \\
Normal or mildly impaired renal function & $3(43 \%)$ & $4(57 \%)$ \\
Functioning kidney graft & $6(60 \%)$ & $4(40 \%)$ \\
Peritoneal dialysis (PD) & $15(62.5 \%)$ & $9(37.5 \%)$ \\
Dialysis (HD + HDF), male ( $=$ & $33(46 \%)$ & $38(54 \%)$ \\
Dialysis (HD + HDF), female ( $\mathrm{n}=120)$ & $65(54 \%)$ & $55(46 \%)$
\end{tabular}

Table 2S: Proportion of VKA users in the entire CUA population (*data missing for 3 patients)

\subsection{The subgroup of CUA dialysis patients}

For further analysis, especially regarding laboratory values and background medication usage, we focussed on dialysis patients. The group of dialysis patients was defined as HD/HDF patients $(n=193)$ and PD patients $(n=25)$ [ $n=218(86 \%$ of the entire cohort]. The HD/HDF patient group was split into males and females for further analysis. Table 2 provides an overview of the clinical data for the group of dialysis patients. We also recorded prescription of prototypic nephrology medication. Table 3 gives an overview of medication prescriptions in the dialysis subgroup of the entire cohort. The laboratory values of the dialysis CUA patients are depicted according to the place of measurement, either in a peripheral treatment centre (Table 4) or results were obtained from the central biobank after measurement in the core lab (Table 5). In 180 dialysis patients, both albumin and total calcium levels were available, allowing for calculation of albumin-corrected calcium. Biochemistry data regarding calcium, phosphate and IPTH were stratified according to target ranges defined in the Kidney Disease Outcomes Quality Initiative (KDOQI) or Kidney Disease: Improving Global Outcomes (KDIGO) guidelines (Supplementary data, Table S3 and Table 6). We analysed the recorded data from the free text field regarding therapeutic strategies in the questionnaire. Data were recorded in 165 cases (76\%; in the other $24 \%$ of patients no data were recorded) (Table 7). 


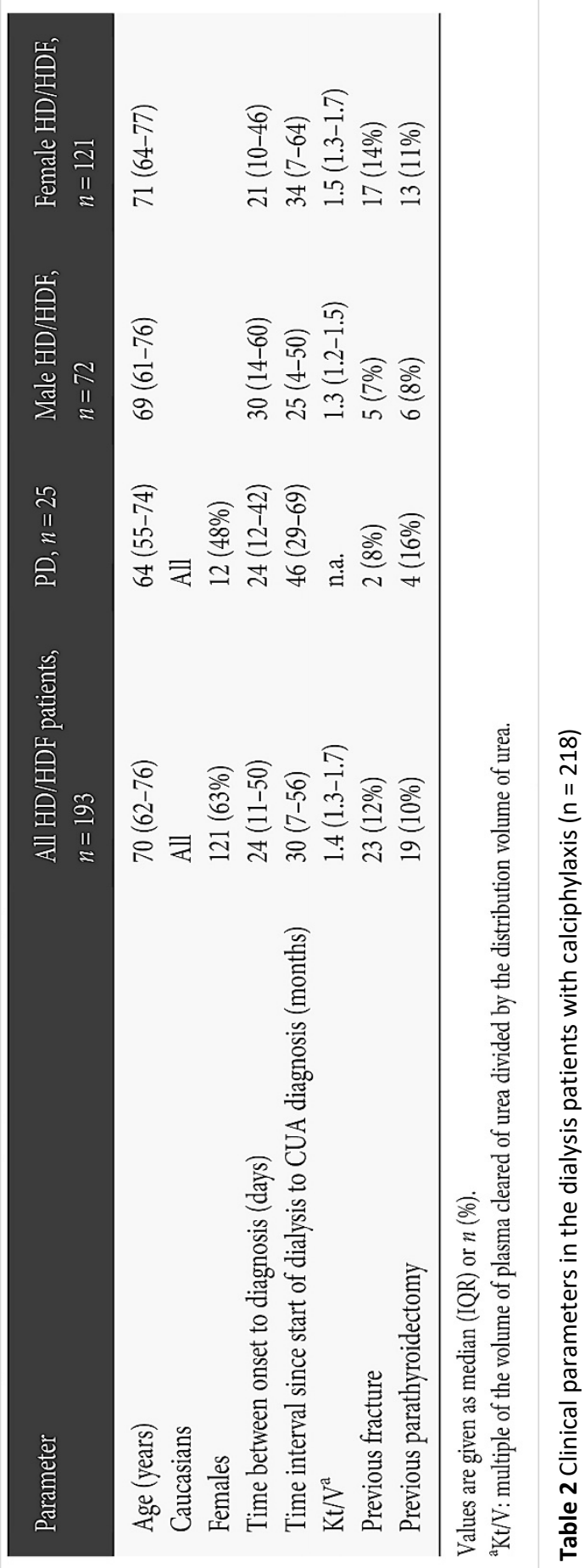




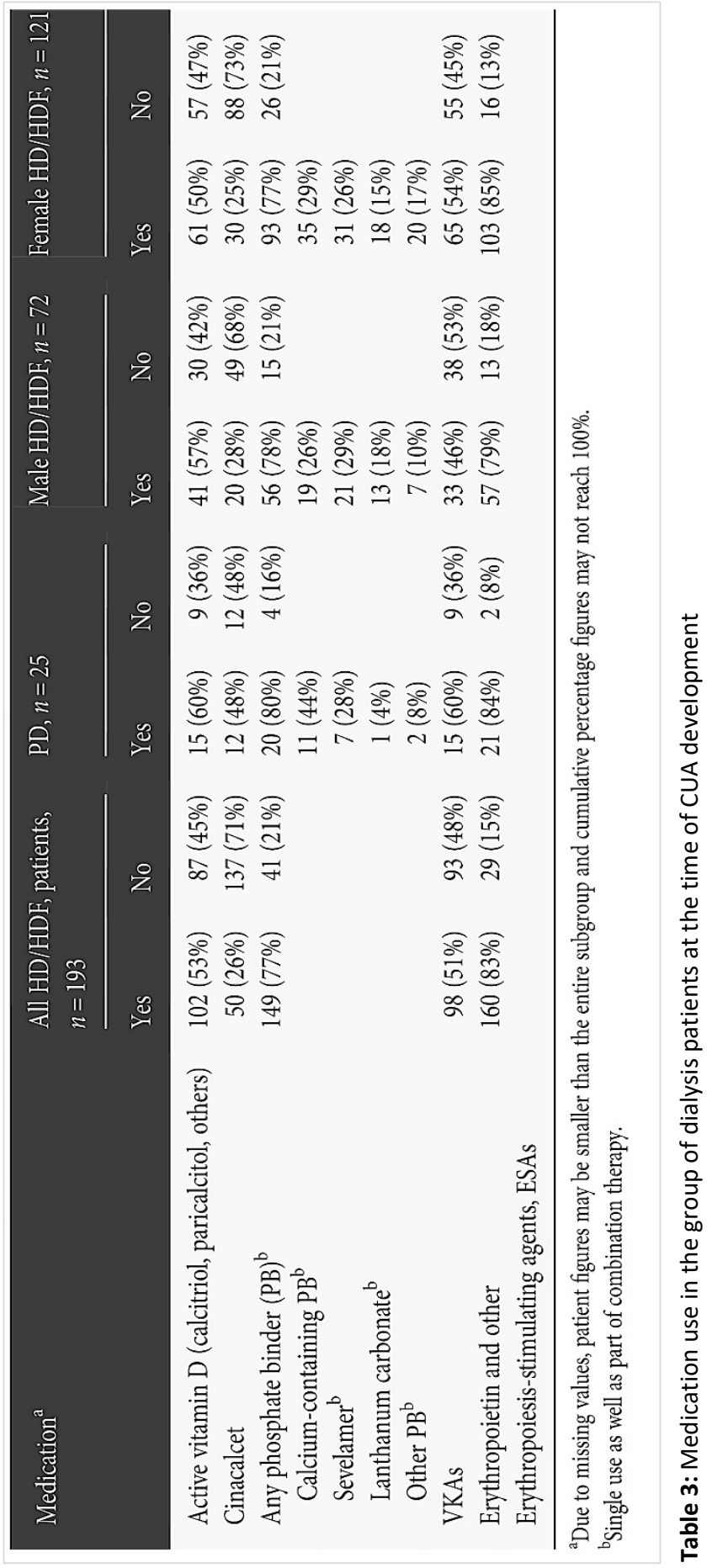




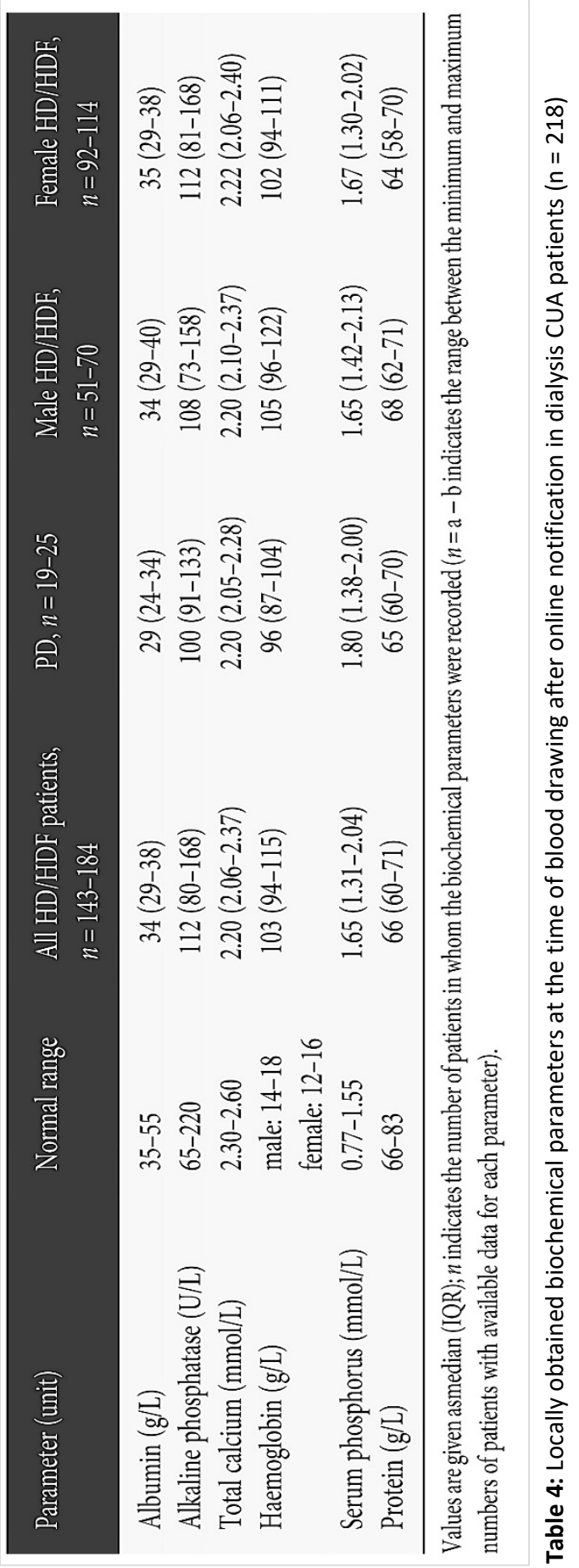




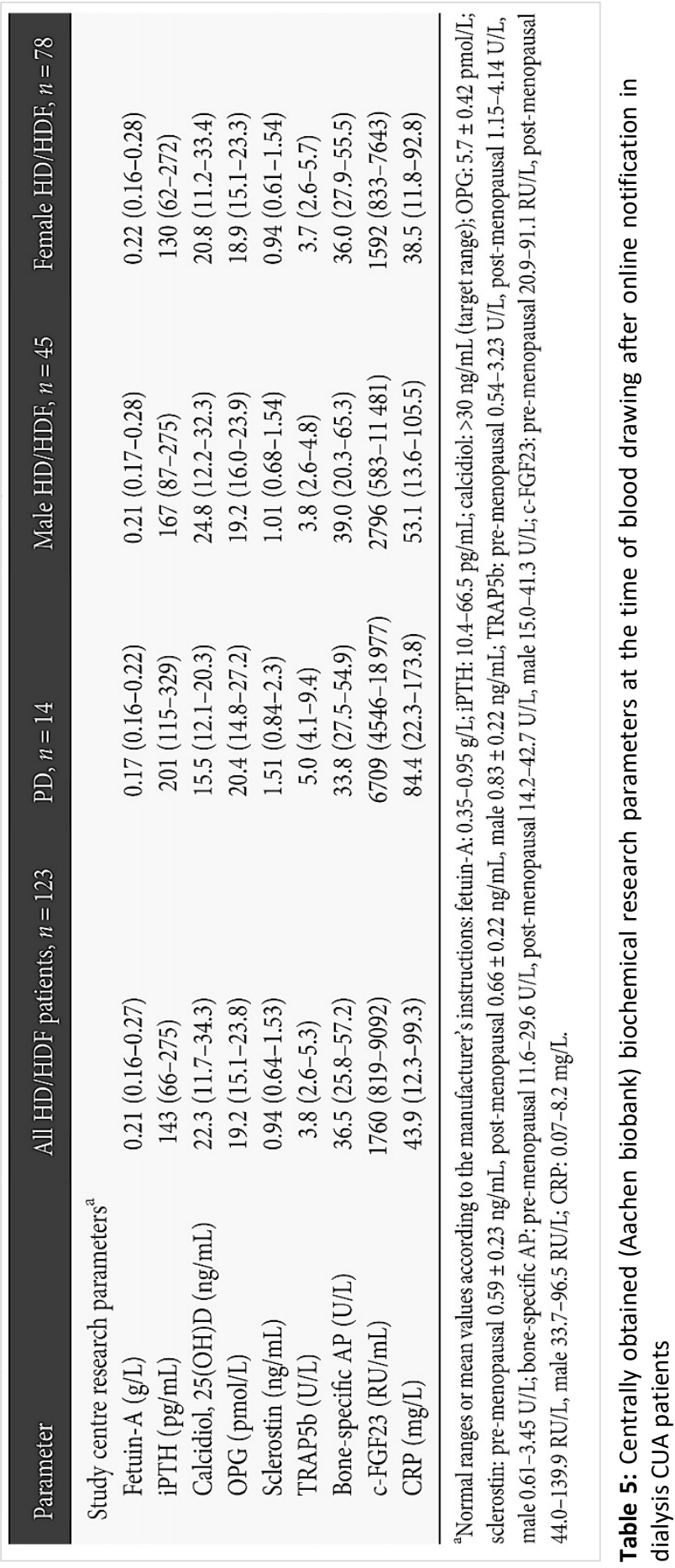



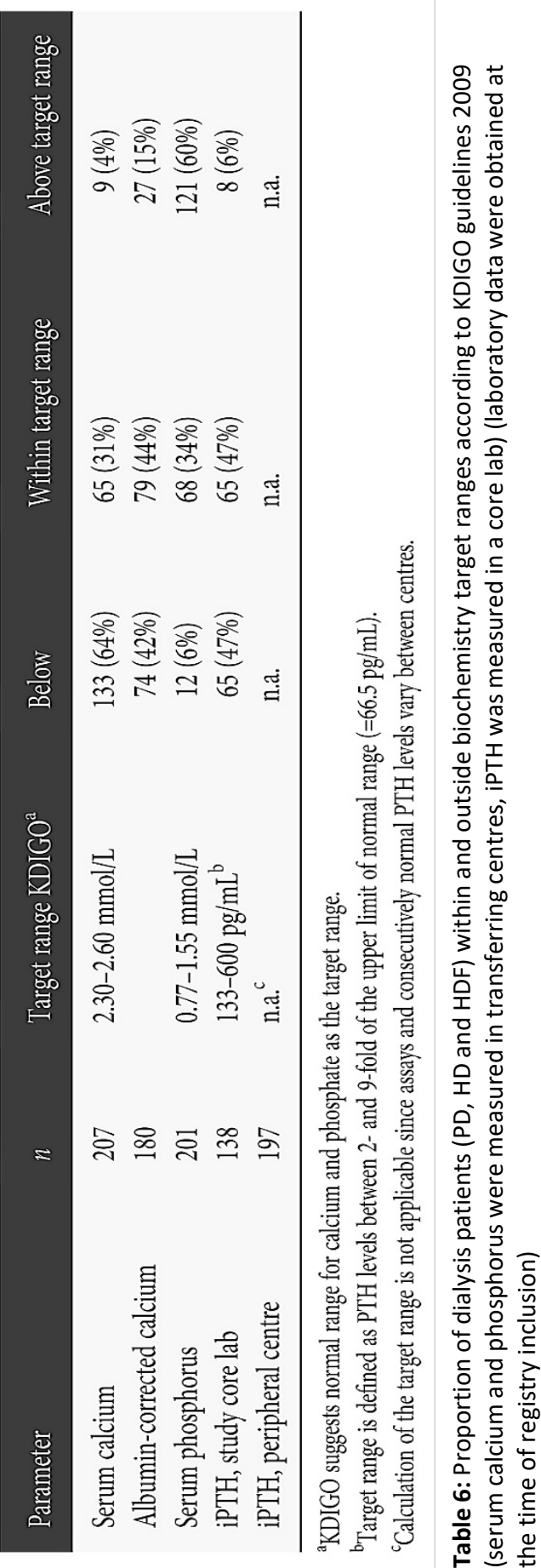
Intensifying dialysis therapy

Increase of dialysis duration and/or frequency

$16.9 \%$

Switch from haemodialysis to haemodiafiltration

$0.8 \%$

Switch from PD to HD

$1.5 \%$

Reduction of calcium supply/intake

Lowering/stopping of calcium-containing PB

$23.8 \%$

Lowering dialysis bath calcium concentration

$1.5 \%$

Reduction/stop active vitamin D treatment including VDRA

$16.2 \%$

Vitamin K metabolism

Stop VKA treatment

$25.4 \%$

Give vitamin K

Secondary hyperparathyroidism

Initiate cinacalcet

$10.8 \%$

Stop cinacalcet

$2.3 \%$

Parathyroidectomy

$2.3 \%$

Initiate native vitamin $\mathrm{D}$

$2.3 \%$

Calcification inhibition

Apply STS

$21.5 \%$

Give bisphosphonates

$2.3 \%$

Fresh frozen plasma

$1.7 \%$

Tissue oxygen supply

Revascularization (surgical and angioplasty)

$3.8 \%$

Antibiotics

$16.1 \%$

Surgical wound management

Including necrosectomy, debridement and skin transplantation

$29.2 \%$

Others
Application of glucocorticoids
$3.1 \%$
Prostaglandin infusion
$0.7 \%$

Table 7: Recorded therapeutic strategies in 165 CUA dialysis patients (76\% of the entire dialysis CUA cohort) [multiple answers possible; single answers in $n=16$ (10\%) cases]

\section{Discussion}

We report data from a long-term nationwide online CUA registry that represents the largest CUA cohort documented so far. Overall, the German CUA registry allows presentation of far-reaching data regarding the clinical picture, additional background data, comprehensive data on biomarkers (CKD-MBD standard as well as research biomarkers) as well as applied therapeutic strategies. We recorded a stable notification rate of about 30 dialysis patients per year, which equals an annual incidence of about $0.04 \%$, assuming that the number of German dialysis patients has been about 70000 during the registry period. Thus, our data do not support estimated incidence figures as high as $4-5 \%$ among dialysis 
patients. ${ }^{6}$ Also, we need to acknowledge that we have to accept a potentially high estimated number of unreported cases. Our cohort of CUA patients is characterized by a striking predominance of dialysis patients. It is generally accepted that non-renal CUA is even rarer than dialysis-related CUA. ${ }^{7}$ We acknowledge that our registry and our scientific activities primarily address the German nephrology community, and therefore we might have missed cases seen by other medical specialists. Additionally, lack of awareness of the disease might have contributed to a difficult to quantify number of hidden cases. On the other hand, our registry approach might carry the risk of including a few false-positive cases, which cannot be excluded completely due to the absence of systematic diagnostic standards for calciphylaxis and decentralized patient care within the registry. All available data, including the present registry, indicate that ESRD predisposes patients to develop CUA. The registry allows comprehensive analyses of CKD-MBD parameters; at the time of CUA diagnosis, serum calcium levels in affected dialysis individuals were clinically unremarkable. Total serum calcium levels were indeed quite low, looking at the distribution of calcium levels according to the historical KDOQI target ranges or according to the current KDIGO target ranges. Hypercalcaemia above the upper limit of normal (2.60 $\mathrm{mmol} / \mathrm{l})$ was present in only $15 \%$ of CUA dialysis patients in terms of albumin-corrected calcium. In contrast, serum phosphate levels were more often above target ranges (42\% for the KDOQI range and $60 \%$ for the KDIGOrange), reflecting the well-documented prevalence of hyperphosphatemia in dialysis patients. Of note, these laboratory data were obtained about 1 month after CUA development. Hence, the current disease burden and nutritional status may have influenced the recorded calcium and phosphate levels. More strikingly, the PTH levels in our dialysis CUA cohort were unexpectedly low, which deserves thorough comments and further evaluation. Relatively low PTH levels are in line with previous case-control series, which could not document uncontrolled hyperparathyroidism being a risk factor for CUA development. ${ }^{1}$ The fact that our CUA cohort exhibited low PTH levels is also reflected by the low rate of co-medication with cinacalcet in our cohort: $71 \%$ of our patients did not receive cinacalcet at the time of CUA diagnosis. Adynamic bone disease might predispose to CUA development since the buffering capacity for an excess of circulating minerals is thought to be impaired [8]. One potential reason for low PTH levels in dialysis patients is oversuppression of hyperparathyroidism prior to CUA development. However, such a discussion about iatrogenic adynamic bone disease remains speculative in the absence of bone histomorphometry and serial bone metabolism data. Both BSAP and TRAP5b markedly exceeded the normal range in our cohort, but such levels cannot reliably exclude the presence of localized transient osteoporosis. Our notion of overall predominantly 'low' PTH levels in the CUA cohort is not in contrast with findings from the Evaluation of Cinacalcet Hydrochloride Therapy to Lower Cardiovascular Events (EVOLVE) trial, ${ }^{9}$ indicating that cinacalcet treatment was associated with a significant decrease of CUA incidence compared with the control arm. In the EVOLVE trial, the median PTH levels prior to CUA development were $796 \mathrm{pg} / \mathrm{ml}$ in the placebo arm and $410 \mathrm{pg} / \mathrm{ml}$ in the cinacalcet arm. Of note, the EVOLVE trial included preselected patients with advanced hyperparathyroidism at baseline, while a nationwide approach such as the registry is unlimited by any exclusion criteria. So, the EVOLVE design presumably missed the predominant PTH range for calciphylaxis development and fuels speculation about an 
optimal intermediate (protective) PTH range. Taken together, for all classical CKD-MBD parameters (calcium, phosphate, calcium-phosphate product and PTH), further CUA studies should investigate the time course (trend analysis) in the months prior to CUA. Interpretation of the innovative research biomarkers is limited due to the absence of a control group. Remarkably, fetuin-Alevels were much below the normal range in our CUA dialysis patients. Deficiency of fetuin-A may be expected in a dialysis cohort with high CRP levels and overall low protein and albumin levels. Cause or effect of low fetuin-A levels cannot be established from our data, and both interpretations are possible. Interestingly, we also observed median sclerostin levels above the normal range in our CUA patients. The potential role of sclerostin as a marker or mediator of vascular calcification is a matter of ongoing debate. ${ }^{10}$ If sclerostin alone or in combination with the various alternative bone markers, which proved to be above the normal range in our calciphylaxis cohort (OPG, BSAP and TRAP5b), might help in identifying patients at particular risk for developing calciphylaxis remains undetermined.

The high prevalence of VKA treatment is striking. Vitamin $\mathrm{K}$ activates matrix Gla protein (MGP) via gamma-carboxylation. ${ }^{1}$ Fully active MGP is a prerequisite for maintaining vascular wall integrity by avoiding calcification. Hence, the application of a VKA such as warfarin and phenprocoumon (most often Marcumar ${ }^{\circledast}$ in Germany) is thought to interfere with calcification defence mechanisms and promote vascular wall calcification. ${ }^{11}$ There are no confirmed data available about the exact prevalence of a VKA application in dialysis patients in Germany, but valid estimates point towards about $10 \%$ of patients. This suggests that our 50\% VKA treatment prevalence might be a factor of 5-fold increased prevalence of VKA in CUA patients compared with non-CUA dialysis patients. This finding is in line with a previous report from Japan that calculated a factor (hazard ratio) of 10 according to a case-control approach. ${ }^{12}$ We should point out that the assumption of VKA being causally linked to CUA development has already influenced treatment strategies (see below). A recent state-of-the-art review by Nigwekar et al. ${ }^{13}$ nicely summarized current treatment strategies in CUA patients, showing several analogies, but also discrepancies, with our registry data-the latter reflecting the real-world treatment situation in Germany. Overall, our data confirm the clinical experience that treatment is multimodal. In terms of homologies, wound care (noninvasively and surgically) is amainstay of therapy, accompanied by systemic antibiotic therapy. Real-world care considers a reduction in calcium supply via reduced oral intake, less active vitamin dosages and lowering dialysis bath calcium as effective. PTH-lowering interventions (cinacalcet and parathyroidectomy) are a rarely used treatment option in Germany. German nephrologists increased the frequency and duration of dialysis sessions in a substantial proportion of cases, although CKD-MBD parameters were formally 'controlled' (with the exception of highly prevalent hyperphosphatemia). Modification of the anticoagulation regime by stopping VKA and/or vitamin $\mathrm{K}$ replenishment was a common treatment option. ${ }^{14}$ Pain management and other supportive care measures such as nutritional consulting have not been regularly recorded in the German registry. We speculate about 'false-negative' results here because physicians might not have regarded this as specific CUA interventions.

The issue of sodium thiosulphate (STS) application warrants some additional comments. Case series published, e.g. by Nigwekar et al., ${ }^{15}$ have fuelled the discussion about 
potentially positive effects of STS in CUA patients. Accordingly, STS is part of the treatment summary provided by Nigwekar et al.. ${ }^{13}$ However, evidence regarding a positive risk: benefit ratio of STS in CUA is low, given the fact that no controlled, prospective data are available. ${ }^{1}$ STS is indeed applied in about a fifth of patients in Germany. We speculate that this percentage is a reliable estimate of the real-world situation (meaning a low number of false-negative recordings), as physicians might be especially prepared and motivated to communicate STS as specific CUA treatment. Regarding CUA treatment, we cannot draw conclusions about any therapeutic effect of any intervention, since systematic follow-up visits were not part of the registry protocol. Hence, it remains speculative if any single intervention (such as the application of STS) or any multimodal treatment approach influences outcomes in these patients. A relevant limitation of our registry is the crosssectional nature with single-spot recording of data-so, we cannot comment on biomarker trends and upcoming warning signs prior to CUA outbreak. The latter is of particular interest in terms of average low PTH levels, which we recorded at the time of diagnosis. Moreover, the registry did not record long-term outcomes in terms of potential treatment effects or survival. The international European Calciphylaxis Network initiative (http://www.eucalnet.net)-a multinational European calciphylaxis registry-is aimed at biochemistry trend analyses and outcome assessment to overcome this limitation [16]. In summary, we consider three issues raised by the registry as important. Our data confirm that CUA qualifies as a truly rare disease. A novel finding is that median PTH levels among dialysis patients are low. VKA usage is highly prevalent in CUA patients, pointing towards the need to investigate the potential beneficial effects of early VKA withdrawal and vitamin $\mathrm{K}$ replenishment.

\section{Supplementary data}

Supplementary data are available online at http://ndt.oxfordjournals.org. 


\section{References}

1. Brandenburg VM, Sinha S, Specht $P$ et al. Calcific uraemic arteriolopathy: a rare disease with a potentially high impact on chronic kidney diseasemineral and bone disorder. Pediatr Nephrol 2014; 29: 2289-2298

2. Nigwekar SU, Solid CA, Ankers E et al.Quantifying a rare disease in administrative data: the example of calciphylaxis. J Gen Intern Med 2014; 29: S724-S731

3. Brandenburg VM, Cozzolino M, Ketteler M. Calciphylaxis: a still unmet challenge. J Nephrol 2011; 24: 142-148

4. Weenig RH, Sewell LD, Davis MD et al. Calciphylaxis: natural history, risk factor analysis, and outcome. J Am Acad Dermatol 2007; 56: 569-579

5. Kramann R, Brandenburg VM, Schurgers LJ et al. Novel insights into osteogenesis and matrix remodelling associated with calcific uraemic arteriolopathy. Nephrol Dial Transplant 2012; 28: 856-868

6. Angelis M, Wong LL, Myers SA et al. Calciphylaxis in patients on hemodialysis: a prevalence study. Surgery 1997; 122: 1083-1089

7. Nigwekar SU, Wolf $\mathrm{M}$, Sterns $\mathrm{RH}$ et al. Calciphylaxis from nonuremic causes: a systematic review. Clin J Am Soc Nephrol 2008; 3: 1139-11438. Mawad HW, Sawaya BP, Sarin R et al. Calcific uremic arteriolopathy in association with low turnover uremic bone disease. Clin Nephrol 1999; 52: 160-166

8. Floege J, Kubo $Y$, Floege $A$ et al. The effect of cinacalcet on calcific uremic arteriolopathy events in patients receiving hemodialysis: the EVOLVE trial. Clin J Am Soc Nephrol 2015; 10: 800-807

9. Evenepoel P, D'Haese P, Brandenburg V. Sclerostin and DKK1: new players in renal bone and vascular disease. Kidney Int 2015; 88: 235-240

10. Brandenburg VM, Schurgers LJ, KaeslerNet al. Prevention of vasculopathy by vitamin K supplementation: can we turn fiction into fact? Atherosclerosis 2015; 240: 10-16

11. Hayashi M, Takamatsu I, Kanno $\mathrm{Y}$ et al. A case-control study of calciphylaxis in Japanese end-stage renal disease patients. Nephrol Dial Transplant 2011; 27: 15801584

12. Nigwekar SU, Kroshinsky D, Nazarian RM et al. Calciphylaxis: risk factors, diagnosis, and treatment. Am J Kidney Dis 2015; 66: 133-146

13. Kruger T, BrandenburgV, SchlieperGet al. Sailing between Scylla and Charybdis: oral long-term anticoagulation in dialysis patients. Nephrol Dial Transplant 2013; 28: 534541

14. Nigwekar SU, Brunelli SM, Meade D et al. Sodium thiosulfate therapy for calcific uremic arteriolopathy. Clin J Am Soc Nephrol 2013; 8: 1162-1170

15. Brandenburg V, Adragao T, van Dam B et al. Blueprint for a European calciphylaxis registry initiative: the European Calciphylaxis Network (EuCalNet). Clin Kidney J 2015; 8: $567-571$ 



\section{b) \\ Calciphylaxis (IF 55)}

Calciphylaxis.

Nigwekar SU, Thadhani R, Brandenburg VM. N EngI J Med. 2018 May 3; 378(18): 1704-1714. 
Calciphylaxis is a rare, life-threatening syndrome of vascular calcification characterized by occlusion of microvessels in the subcutaneous adipose tissue and dermis that results in intensely painful, ischemic skin lesions. Once calciphylaxis has been diagnosed, the prognosis is generally poor (survival, $<1$ year). ${ }^{1-3}$ The disorder, which is underrecognized, ${ }^{4}$ typically affects patients with end-stage renal disease (ESRD), ${ }^{2,5}$ a population with a high prevalence of extraskeletal calcifications. A clear majority of such calcifications do not represent calciphylaxis, which cannot be placed on a simple continuum of vascular calcification. However, an improved understanding of vascular calcification has helped to elucidate the pathogenesis of calciphylaxis and promising approaches to reatment. Calciphylaxis also occurs in patients with earlier stages of chronic kidney disease, ${ }^{2,5}$ acute kidney injury, ${ }^{6}$ or prior receipt of a kidney transplant, 7 and in rare cases, it occurs in patients with normal kidney function. ${ }^{2,5,8,9}$ We therefore prefer the name calciphylaxis to calcific uremic arteriolopathy, which is another name for this entity. 10 This review presents the current understanding of calciphylaxis and provides a framework for its interdisciplinary management.

\section{Clinical Manifestations}

Calciphylaxis causes painful skin lesions (Figures $1 \mathrm{~A}$ through $1 \mathrm{H}$ ). The pain is somatic and may precede the appearance of skin lesions. ${ }^{11}$ Although the pain may initially fluctuate in intensity, $^{12}$ it characteristically remains severe during the course of the disease and is frequently accompanied by tactile hyperesthesia. ${ }^{11}$ The initial skin manifestations may include induration, plaques, nodules, livedo, or purpura. ${ }^{12,13}$ A dusky discoloration of the skin indicates an area of imminent necrosis. Because an arteriole supplies a 1-to-3-cm conical area of microvasculature in a funnel shape, there are frequently reticulate (netlike) areas of erythema (Figure $1 \mathrm{C}$ ) and livedo. Patients typically have multiple, bilateral lesions, with surrounding skin showing a leatherlike texture. The initial lesions rapidly progress to stellate, malodorous ulcers with black eschars. ${ }^{12,13}$ Sepsis originating from the resultant wounds is considered the most common cause of death. ${ }^{8,14,15}$ Approximately $50 \%$ of patients are bedridden or wheelchair-bound, and more than $70 \%$ require hospitalization for severe ulcers. ${ }^{14}$ Ongoing pain, anorexia, insomnia, and depression further compromise the quality of life. ${ }^{16}$ Extraskeletal calcifications (Figures $1 \mathrm{l}$ and $1 \mathrm{~J}$ ) are often found on imaging studies, but the sequelae of cutaneous involvement are the predominant clinical manifestations. On rare occasions, extracutaneous vascular calcifications lead to skeletal myopathy, intestinal bleeding, or visual impairment. ${ }^{17}$ 


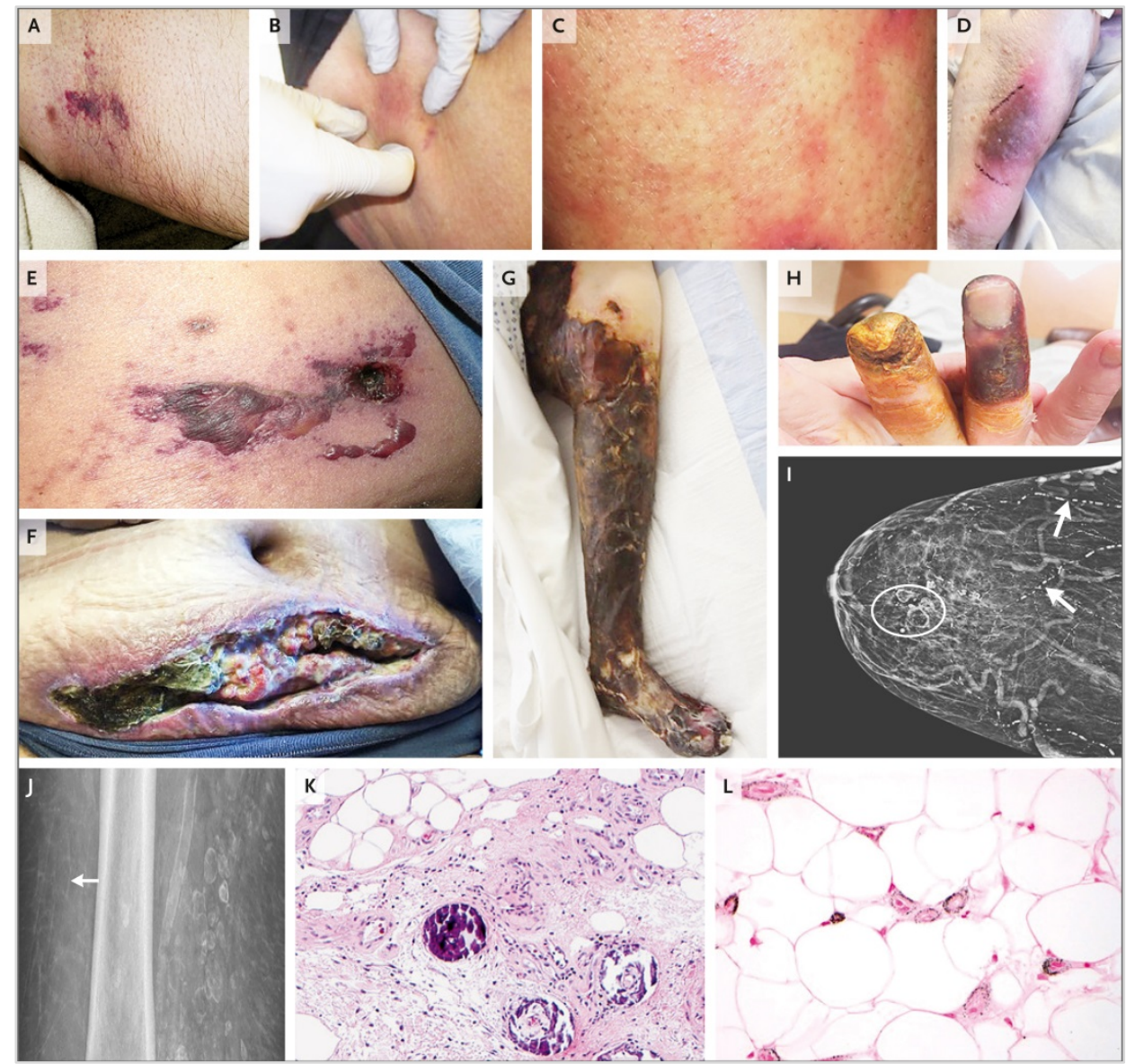

Figure 1: Clinical Manifestations, Radiographic Features, and Histologic Characteristics of Calciphylaxis. Panels A through E show the early manifestations of calciphylaxis: a violaceous patch with surrounding retiform purpura (Panel A), a palpable subcutaneous nodule with overlying erythema (Panel B), a reticulate pattern of erythema (Panel C), an induration with dusky discoloration (Panel D), and multiple plaques with livedo (Panel E). Panels F, G, and $\mathrm{H}$ show late manifestations: a necrotic ulcer partially covered with a black eschar (Panel F), a leg with a mummified appearance (Panel $G$ ), and gangrenous fingers (Panel $H$ ). Panels $A, B, E$, and $F$ show central involvement, and Panels C, D, G, and $\mathrm{H}$ show peripheral involvement. In Panel I, a mammogram from a patient with calciphylaxis involving the breast shows microvascular calcifications (arrows) and fat necrosis (oval). In Panel J, microvascular calcifications in a netlike pattern (arrow), subcutaneous extravascular calcifications, and a calcified femoral artery are evident on a radiograph from a patient with ulcerated calciphylaxis involving the thigh. A skin-biopsy section stained with hematoxylin and eosin (Panel K) shows coarse basophilic calcification, fibrointimal hyperplasia, and fibrin thrombus in dermal and subcutaneous microvessels with septal panniculitis. A skin-biopsy section with von Kossa stain (Panel L) shows fine arteriolar and interstitial calcifications. Pathological and radiographic findings by themselves are not diagnostic of calciphylaxis and should be clinically correlated. 


\section{Clinical Classification}

Calciphylaxis can be classified as uremic (in patients with ESRD) or nonuremic (in patients with normal renal function or earlier stages of chronic kidney disease). The lesions in affected patients can be classified as central (involving central areas within subcutaneous adipose tissue such as the abdomen or thighs) or peripheral (restricted to peripheral sites that have limited adipose tissue, such as the digits). In addition, lesions can be nonulcerated (in the earlier stages of the disease) or ulcerated (in later stages). The lesions are similar whether or not patients have kidney disease; however, 70 to $80 \%$ of lesions in patients with ESRD have a central distribution, ${ }^{1,14}$ as compared with approximately $50 \%$ of lesions in patients who do not have ESRD. ${ }^{8,14}$ Patients without ESRD have a better prognosis (1-year mortality, 25 to $45 \%)^{8,9}$ than those who have ESRD (1-year mortality, 45 to $\left.80 \%\right)^{1-3}$, probably because of the differences in coexisting conditions and the location of lesions. Patients with central lesions are more likely to have a high body-mass index than patients without central lesions, ${ }^{1}$ are more likely to be women, ${ }^{1}$ and have a higher risk of death. ${ }^{18}$ The presence of ulcerated (late) lesions reduces the 6 -month survival rate to $20 \%{ }^{3}$ Histopathological Features Characteristic histologic features of calciphylaxis (Figures $1 \mathrm{~K}$ and $1 \mathrm{~L}$ ) include calcification, fibrointimal hyperplasia, and thrombosis in microvessels in the subcutaneous adipose tissue and dermis, often accompanied by necrosis of epidermal and adipose tissue, dermal-epidermal separation, panniculitis, proliferation of dermal endothelial cells, and extravascular calcifications. ${ }^{19,20}$ The mean diameter of the involved microvessels is $100 \mu \mathrm{m}$ (range, 40 to 600 ). ${ }^{15}$ Calcified lesions consist of calcium and phosphate in a molar ratio of 1.7 , which matches that of hydroxyapatite. ${ }^{21}$

\section{Epidemiology}

Calciphylaxis, although rare, has been reported worldwide, with an estimated annualized incidence of 35 cases per 10,000 patients undergoing hemodialysis in the United States, ${ }^{1} 4$ per 10,000 in Germany, ${ }^{5}$ and less than 1 per 10,000 in Japan. ${ }^{22}$ A report from the United States suggests an increasing incidence, ${ }^{23}$ which may be due to an actual increase, heightened awareness of the disorder, or both. The interval from the initiation of dialysis to the appearance of calciphylaxis ranges from 30 months in the United States1 and Germany5 to 105 months in Japan. ${ }^{24}$ Patients treated with peritoneal dialysis have a higher incidence of calciphylaxis than those treated with hemodialysis; ${ }^{25,26}$ however, the underlying mechanisms are unclear. The incidence in kidney-transplant recipients and in patients with earlier stages of chronic kidney disease is unknown. Several reports suggest that the mean age at the time of diagnosis is 50 to 70 years; ${ }^{2,5,14,25}$ very few patients are children. ${ }^{27}$ Approximately 60 to $70 \%$ of patients with calciphylaxis are women. ${ }^{3,5,14}$ In a U.S. study involving 1030 patients with calciphylaxis who were dependent on hemodialysis, $49 \%$ were white and $28 \%$ were black, ${ }^{1}$ a racial distribution approximating that of patients undergoing hemodialysis in the United States. 


\section{Risk Factors}

Table 1 lists risk factors for calciphylaxis, 1,8,17,25,28-31 which include obesity, diabetes mellitus, female sex, and dependence on dialysis for more than 2 years. Obesity and diabetes mellitus are also risk factors for calciphylaxis in patients without ESRD. ${ }^{8,9}$ Elevations in phosphate and calcium levels increase the risk of subsequent calciphylaxis in patients undergoing dialysis. ${ }^{1}$ Patients with calciphylaxis have high parathyroid hormone (PTH) levels at the start of treatment with dialysis, ${ }^{1}$ and primary hyperparathyroidism ${ }^{8}$ and administration of recombinant $\mathrm{PTH}^{31}$ are risk factors for calciphylaxis in patients who do not have ESRD. At clinical presentation, however, approximately $45 \%$ of dialysis-dependent patients with calciphylaxis have PTH levels below the recommended target range. ${ }^{5}$ These observations suggest overuse of calcium and vitamin D supplements, leading to PTH suppression and adynamic bone (low bone turnover), which may exacerbate extraskeletal calcium depositions. ${ }^{32}$ Fibroblast growth factor 23 (FGF-23), a phosphaturic hormone, is increased in patients with ESRD and calciphylaxis; ${ }^{5}$ however, the role of FGF-23 in vascular calcification remains controversial. ${ }^{33,34}$ The use of warfarin, a vitamin $\mathrm{K}$ antagonist, increases the risk of calciphylaxis by a factor of 3 to $13.1,24,25,35$ About 40 to $50 \%$ of patients with ESRD and calciphylaxis ${ }^{5,36}$ and $25 \%$ of those with calciphylaxis in the absence of ESRD have been treated with warfarin, ${ }^{8}$ and warfarin use is also linked with increased mortality among patients with this disease. ${ }^{36}$ Even in the absence of warfarin use, vitamin $\mathrm{K}$ deficiency from malabsorption or other causes develops in $80 \%$ of patients with ESRD and calciphylaxis. ${ }^{37}$ Most patients with one or even multiple risk factors do not have calciphylaxis. A triggering event in patients with underlying risk factors probably induces calciphylaxis. Cutaneous calcifications develop in rats that have been sensitized with PTH extract, high-dose vitamin D, a high-phosphate diet, or nephrotoxic insults and then challenged with physical trauma or metal injections. ${ }^{38}$ Repetitive trauma from subcutaneous injections is an example of a trigger reported in some cases of human calciphylaxis. ${ }^{1}$ Most often, however, no obvious trigger is identified. 


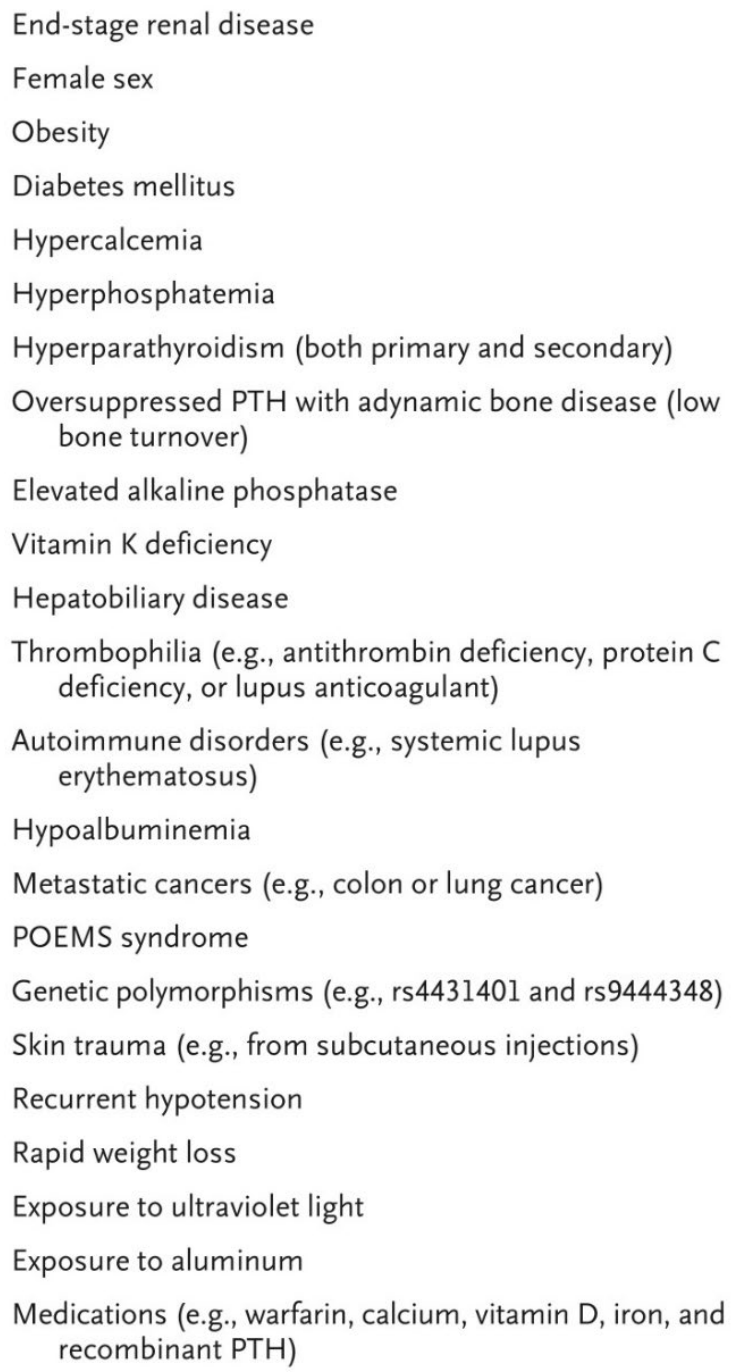

Table 1: Risk Factors for Calciphylaxis.*

\section{Pathogenesis}

The pathogenesis of calciphylaxis is uncertain. Histologic analysis suggests that calcified, narrowed microvessels lead to chronic, low-grade ischemia, and further occlusion of vessels induced by endothelial injury and microthrombosis results in infarction. ${ }^{20,21}$ Thrombosis could be due to a local prothrombotic state, ${ }^{21}$ with or without systemic hypercoagulability. ${ }^{39}$ The similarity of histologic features in patients with calciphylaxis, irrespective of their status with respect to ESRD, suggests a common final pathway. ${ }^{20}$ The development of microvascular calcifications in patients with calciphylaxis (and in patients with other vascular calcifications) is likely to be an active, cell-mediated process that 
depends on the balance between the promoters and inhibitors of calcification (Figure 2). ${ }^{21,40,41}$ Serum samples from patients with calciphylaxis show impaired inhibition of calcium phosphate precipitation, ${ }^{42}$ which is probably the result of a deficiency of calcification inhibitors. Matrix Gla protein (MGP) is an extracellular matrix protein synthesized by vascular smooth-muscle and endothelial cells. Carboxylated MGP is a potent inhibitor of calcification, with carboxylation dependent on vitamin $\mathrm{K} .{ }^{43} \mathrm{~A}$ deficiency of carboxylated MGP accelerates spontaneous arterial calcifications in mice. ${ }^{43}$ Calciphylaxis in humans is characterized by relative reductions of carboxylated MGP in cutaneous tissue $^{21}$ and the circulation. ${ }^{37}$ Moreover, reduced circulating levels predict more extensive lesions and ulcer formation. ${ }^{37}$ Carboxylated MGP, in addition to being a direct calcification inhibitor, inhibits the procalcifying factors bone morphogenetic protein 2 (BMP-2) and bone morphogenetic protein 4 (BMP-4). ${ }^{44}$ As shown in Figure 2, in calciphylaxis, the deficiency of car-boxylated MGP probably promotes increased cutaneous expression of BMP-2 ${ }^{21}$ and BMP $-4{ }^{45}$ and further osteogenic transcription, as evidenced by increased runtrelated transcription factor 2 (RUNX2). ${ }^{21,46}$ Another calcification inhibitor is fetuin-A, which is involved in the formation of calciprotein particles that transport mineral nanocrystals. ${ }^{42}$ Fetuin-A is down-regulated in chronic inflammatory conditions, including chronic kidney disease. ${ }^{42,47}$ Calciphylaxis is characterized by a pronounced burden of circulating calciprotein particles, indicative of severe, functional fetuin-A deficiency. ${ }^{47,48}$ The discovery of causal genes for mendelian traits with extensive calcifications may provide clues to the pathogenesis of calciphylaxis. Mutations of $\mathrm{NT}^{2} \mathrm{E}^{49}$ and the gene encoding ectonucleotide pyrophosphatase and phosphodiesterase (ENPP1), ${ }^{50}$ which are involved in the pathways that regulate the metabolism of pyrophosphate (a critical inhibitor of calcification), ${ }^{51}$ lead to arterial calcifications in humans. Polymorphisms in NT5E (rs4431401 and rs9444348) are overrepresented in patients with calciphylaxis. ${ }^{30}$ In murine models, administration of an ENPP1-Fc fusion protein50 or a small-molecule ENPP1 inhibitor ${ }^{52}$ prevents cardiovascular calcifications - findings that highlight a promising pathway for the treatment of calcification disorders, including calciphylaxis. Calcifications of the aorta, coronary artery, and femoral artery are common in patients with ESRD. ${ }^{34}$ Nonetheless, cutaneous microvascular calcifications leading to clinical manifestations of calciphylaxis remain rare. Why calciphylaxis occurs primarily in the cutaneous microcirculation is unclear. Predominant involvement of subcutaneous panniculus and aggregation of lesions in body areas with abundant adipose tissue, such as the abdomen and thighs, suggest a role of adipocytes in the pathogenesis of calciphylaxis. Mature adipocytes exposed to high phosphate levels calcify and unidirectionally induce calcification of vascular smooth-muscle cells, probably through the release of adipokines. ${ }^{53}$ Vascular endothelial growth factor $A$ (VEGF-A) is a potential adipokine that has been shown to produce a procalcific response through BMP-4. ${ }^{54}$ The relatively high prevalence of calciphylaxis (4\%) among patients with the polyneuropathy, organomegaly, endocrinopathy, $M$ component, and skin changes (POEMS) syndrome underscores the possible role of VEGF-A in calciphylaxis, since the POEMS syndrome is characterized by marked elevations in VEGF-A. ${ }^{55}$ Adipocytes also secrete $M G P,{ }^{56}$ which may be inadequate or ineffective in patients with calciphylaxis. Whether differences in susceptibility to calciphylaxis are due to genetic or environmental variations in adipose tissue is unknown. 


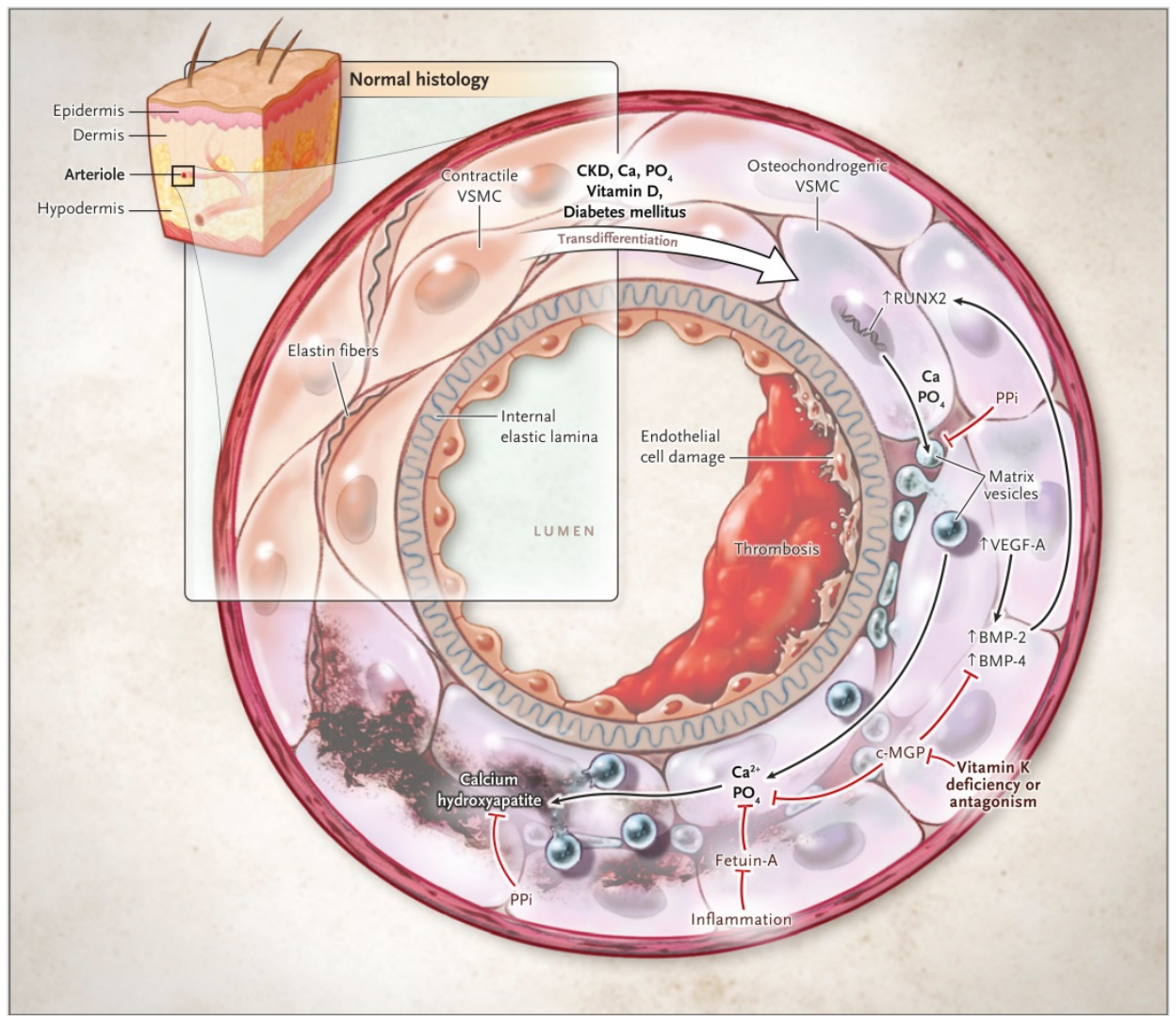

Figure 2: Proposed Pathogenesis of Calciphylaxis. A representative arteriole from a skin section is magnified. The top left quarter of the arteriole represents normal histologic features, including an intact endothelial lining, internal elastic lamina, vascular smooth-muscle cells (VSMCs), and elastin fibers. In the presence of chronic kidney disease (CKD) and toxins from other sources, VSMCs are probably transdifferentiated from a contractile phenotype to an osteochondrogenic phenotype with up-regulated transcription factors such as runt-related transcription factor 2 (RUNX2). The transdifferentiated cells elaborate matrix vesicles containing calcium ( $\mathrm{Ca}$ ) and phosphate (PO4), which nucleate crystalline hydroxyapatite in the extracellular matrix. Eventually, the balance between calcification promoters (e.g., bone morphogenetic protein 2 and 4 [BMP-2 and BMP-4]) and inhibitors (e.g., carboxylated matrix Gla protein [c-MGP], fetuin-A, and inorganic pyrophosphate [PPi]) determines whether the arteriole will calcify. Carboxylated MGP inhibits BMP-driven VSMC transdifferentiation and, by loading into matrix vesicles, prevents mineralization. Vitamin $\mathrm{K}$ deficiency or antagonism blocks MGP carboxylation, which then promotes VSMC transdifferentiation and matrix mineralization. The transdifferentiated VSMCs produce less MGP, resulting in a cascade effect. Adipocytes may influence this process by releasing vascular endothelial growth factor A (VEGF-A). Arteriolar calcification combined with endothelial destruction and thrombosis ultimately leads to clinical manifestations. 
$\underline{\text { Interdisciplinary Management }}$

Although there is no approved therapy for calciphylaxis, several approaches may be effective (see Table S1 in the Supplementary Appendix, available with the full text of this article at NEJM.org). However, the evidence in support of these approaches comes from uncontrolled, observational studies and case reports; for this reason, prospective clinical trials of repurposed and novel therapies are now under way (Table S2 in the Supplementary Appendix). Nonetheless, on the basis of expert opinion, we recommend an interdisciplinary approach (including specialists in dermatology, nephrology, nutrition, pain and palliative medicine, plastic surgery, and wound care) with the aim of expediting the diagnosis and treatment (Figure 3).

\begin{tabular}{l|}
\hline Sodium thiosulfate \\
\hline Bisphosphonate \\
\hline Non-calcium based phosphate binder \\
\hline Calcimimetic agent \\
\hline 35 \\
\hline Opioid analgesic \\
\hline Neuropathic analgesic \\
\hline Spinal anesthetic \\
\hline Non-vitamin K anticoagulant $^{37}$ \\
\hline Tissue plasminogen activator \\
\hline High flow oxygen \\
\hline Vitamin K \\
\hline Pentoxifylline \\
\hline Intensification of dialysis duration and or frequency \\
\hline Transition from hemodialysis to peritoneal dialysis \\
\hline LDL-apheresis \\
\hline Sterile maggot therapy \\
\hline Recombinant platelet-derived growth factor \\
\hline
\end{tabular}

Table S1: Examples of the reported medical therapies for calciphylaxis 


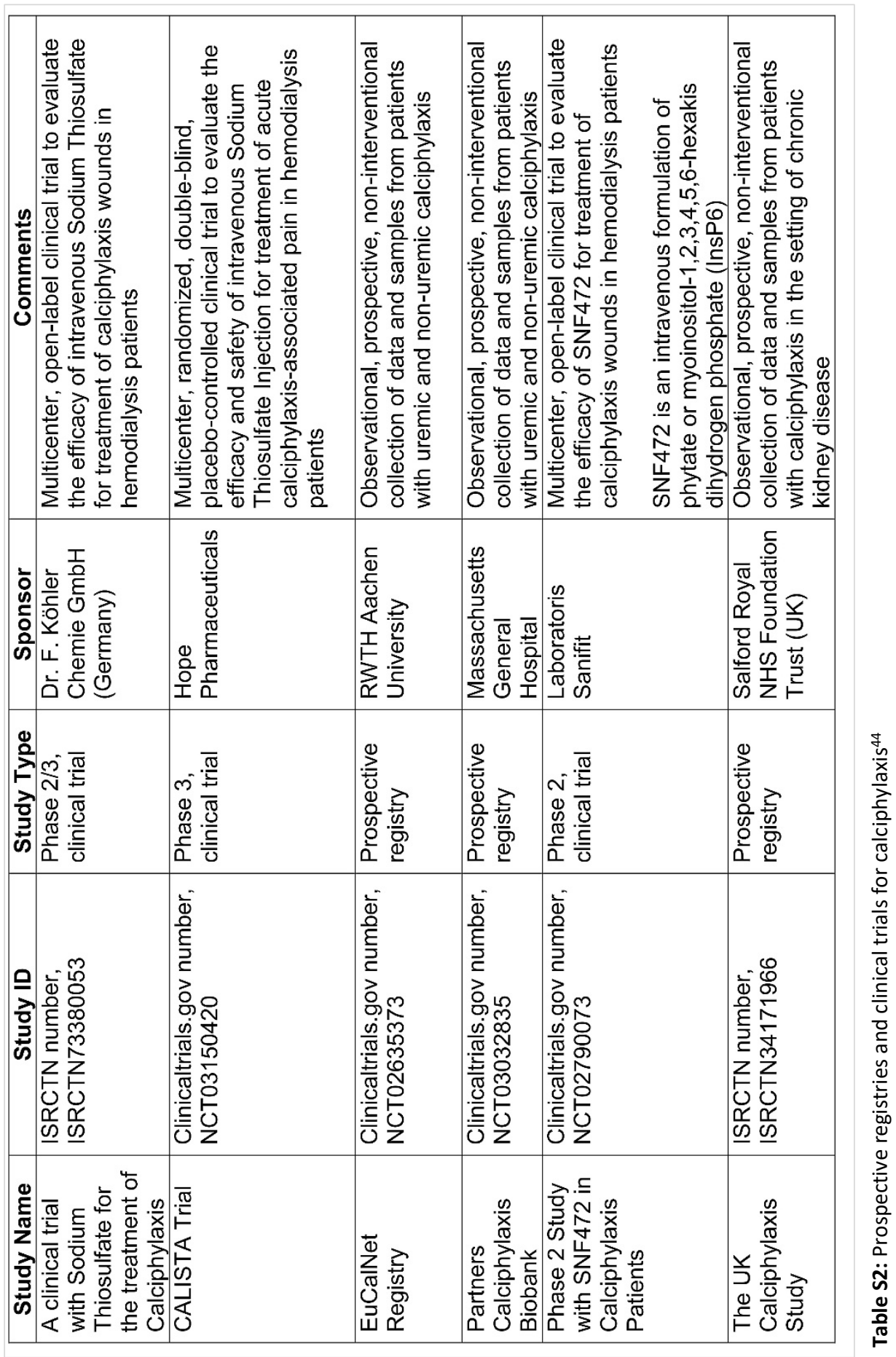




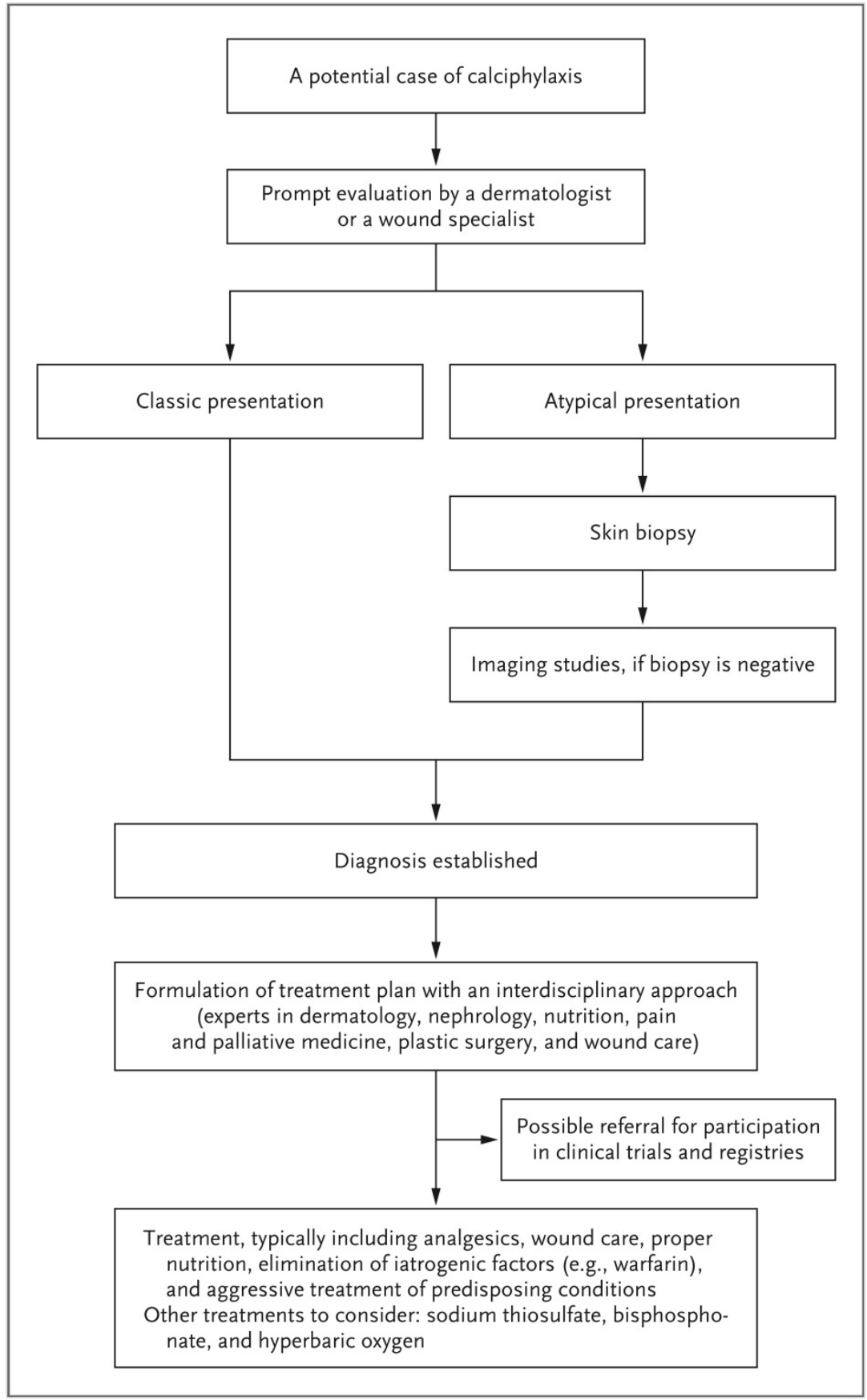

Figure 3: An Interdisciplinary Approach to the Management of Calciphylaxis. A stepwise process for the diagnosis and therapy of calciphylaxis underscores the potential benefits of interdisciplinary collaboration. 


\section{Diagnosis}

Clinical suspicion is important for an early diagnosis. Elevations in serum calcium or phosphate levels are not specific. A recent analysis of data from the German Calciphylaxis Registry showed that $86 \%$ of dialysis-dependent patients with calciphylaxis had either normal or low plasma calcium levels, and $40 \%$ had either normal or low plasma phosphate levels. ${ }^{5}$ Many disorders mimic calciphylaxis (Table 2). These diagnoses can be eliminated by performing a meticulous clinical examination and evaluating histopathological features, laboratory findings, and imaging results (Table S3 in the Supplementary Appendix). Skin biopsy is the standard method for confirmation of clinically suspected calciphylaxis; however, its role in practice is debated, given the risk of provoking new, nonhealing ulcers and infection. ${ }^{4} \mathrm{~A}$ biopsy is not needed for a patient with ESRD and the classic presentation of a painful necrotic ulcer covered with a black eschar. However, a biopsy should be strongly considered if a patient has early, atypical lesions or if calciphylaxis is suspected in a patient without ESRD. A biopsy is contraindicated for acral, penile, or infected lesions. A punch biopsy is safer than a large, excisional biopsy but has limited depth and can be nondiagnostic. The yield on biopsy can be improved with a double-punch technique, wherein a second punch is inserted through the center of the first to retrieve deeper subcutaneous tissue, and by biopsy of an active lesion margin rather than a central or necrotic area. Specialized stains (e.g., the von Kossa stain, which uncovers phosphate within hydroxyapatite) are necessary to avoid missing subtle calcifications. Patients with ESRD may have cutaneous microvascular calcifications from causes other than calciphylaxis (e.g., metastatic calcinosis cutis or Mönckeberg's arteriosclerosis). ${ }^{19,20,57}$ The following features, combined with clinical manifestations, help to establish the diagnosis of calciphylaxis: a stippled appearance of calcifications, involvement of capillaries, internal elastic lamina or perieccrine glands, or the presence of fibrointimal hyperplasia or thrombosis. ${ }^{15,19,20,57}$ Although imaging studies (e.g., plain radiography, mammography, or nuclear bone scanning) are not routinely recommended for the diagnosis, they may support the diagnosis when a biopsy is inconclusive or contraindicated. In small, retrospective studies, a netlike pattern of subcutaneous calcification on plain radiographs (Figure 1J) and increased heterogeneous radiotracer uptake in soft tissues on nuclear bone scanning have robust specificity (Figure S1 in the Supplementary Appendix). ${ }^{58,59}$ 


\section{Warfarin-induced skin necrosis}

\section{Atherosclerotic vascular disease}

\section{Venous stasis ulcer}

\section{Cellulitis}

\section{Cholesterol embolization}

\section{Dystrophic calcinosis cutis}

\section{Livedoid vasculopathy}

\section{Nephrogenic systemic fibrosis}

\section{Oxalosis}

\section{Pyoderma gangrenosum}

\section{Purpura fulminans}

\section{Necrotizing vasculitis}

\section{Martorell's ulcer}

Table 2: Differential Diagnosis of Calciphylaxis.

\section{Analgesia and Wound Management}

A clinician should first consider analgesic agents to address the severe pain that accompanies calciphylaxis. Adequate pain relief can be challenging because the pain may be unresponsive to high-dose opioids, and opioid toxicity may develop. ${ }^{11}$ Concomitant treatment with gabapentin, ketamine, or the application of spinal anesthetic agents is used in refractory cases. ${ }^{11}$ The primary goals of wound care are to remove exudate and necrotic tissue and prevent infection. Calciphylaxis wounds are particularly complicated because the ischemic tissue bed often heals poorly. Moreover, the lesions are extremely painful, making débridement difficult; thus, collaboration with a plastic surgeon and a pain specialist is beneficial. Retrospective studies have suggested improved survival among patients who underwent operative débridement. ${ }^{2,14}$ However, patients who can tolerate débridement may be healthier than those who cannot, possibly accounting for the difference in survival. Corroborating data from prospective, controlled studies are lacking. Operative débridement accompanied by negative-pressure wound therapy is recommended for infected wounds and large necrotic areas with drainage, but such therapy can result in defective soft tissue lined by marginally viable tissue, requiring further excision. Once the wound has stabilized and granulation tissue is present, split-thickness 
skin grafting may be performed to close the wound. Transcutaneous oxygen tension is reduced at lesion sites. ${ }^{60}$ In a retrospective study involving 34 patients with predominantly peripheral disease, hyperbaric oxygen therapy was associated with complete healing in half the patients after 44 sessions of therapy administered over a period of 2 months. ${ }^{61}$ These findings provide support for the use of hyperbaric oxygen, particularly in patients with peripheral lesions.61 Attention to nutritional status is necessary to prevent or treat protein-energy wasting. ${ }^{62}$ There is no indication for prophylactic use of antibiotics.

\section{Elimination of Risk Factors}

Hypercalcemia and hyperphosphatemia should be corrected. Intake of vitamin D and calcium (including calcium-based phosphate binders) should be eliminated, and high levels of dialysate calcium should be avoided. The optimal PTH level for patients with calciphylaxis is unknown; however, extreme values (high and low) should be avoided. In a randomized trial involving more than 3500 patients being treated with hemodialysis, the administration of cinacalcet (a calcimimetic agent) decreased the median PTH level from approximately $690 \mathrm{pg}$ per milliliter to $300 \mathrm{pg}$ per milliliter. ${ }^{63}$ Adverse-event analyses in that trial showed a reduced incidence of calciphylaxis (unadjusted relative hazard, 0.31 ; $95 \%$ confidence interval, 0.13 to 0.79 ) in the cinacalcet group. The low event rate for calciphylaxis in both study groups $(0.3 \%$ [ 6 patients] in the cinacalcet group and $0.9 \%$ [18 patients] in the placebo group) precluded detailed analyses; furthermore, this trial did not address the role of cinacalcet once calciphylaxis phylaxis is present. However, the possibility that a calcimimetic agent is helpful warrants further prospective examination in both preventive and treatment studies. Considering the risks associated with parathyroidectomy, including irreversible reduction of PTH levels and the hungry bone syndrome, requiring calcium and calcitriol, a calcimimetic agent is preferable to parathyroidectomy, the latter being reserved for refractory cases. ${ }^{64}$ In patients with ESRD, increasing the length or frequency of dialysis sessions may accelerate wound healing. ${ }^{65}$ Intensified hemodialysis (beyond the regular regimen of 4-hour sessions three times weekly) is warranted for treating bone and mineral abnormalities, including severe hyperphosphatemia, hypercalcemia, and hyperparathyroidism. A transition to hemodialysis is recommended for patients being treated with peritoneal dialysis, since hemodialysis may accelerate wound healing, presumably through better control of mineral metabolism. ${ }^{26} \mathrm{~A}$ complete resolution of calciphylaxis in patients with ESRD has been achieved with kidney transplantation; ${ }^{66}$ however, transplantation is not a feasible treatment option for all such patients. latrogenic factors, including treatment with warfarin, should be identified and discontinued, and best practices for the treatment of predisposing conditions should be instituted. If subcutaneous injections cannot be avoided, injection sites should be rotated to minimize repetitive trauma to one location.

\section{Pharmacotherapeutic Agents}

Sodium thiosulfate is an agent with antioxidant and vasodilatory properties that also inhibits adipocyte calcification and blocks the ability of adipocytes to induce calcification of vascular smooth-muscle cells. ${ }^{48,53}$ In a study involving 53 hemodialysis-dependent patients with calciphylaxis who were treated with intravenous sodium thiosulfate (three times per week [with each dialysis session] for approximately 3 months), calciphylaxis completely 
resolved in $26 \%$ of the patients, and $19 \%$ had marked improvement in skin lesions. ${ }^{67}$ In another study, involving 27 patients being treated with dialysis, complete remission was observed in $52 \%$ of the patients and partial remission in $19 \%$ after treatment with intravenous sodium thiosulfate. ${ }^{18}$ Lack of a control group and the retrospective nature of the study preclude definitive conclusions regarding the effectiveness of sodium thiosulfate. Although successful use of sodium thiosulfate for the treatment of calciphylaxis was first reported more than a decade ago, only now are two ongoing trials investigating its safety and efficacy (Current Controlled Trials number, ISRCTN73380053; and ClinicalTrials.gov number, NCT03150420). Nevertheless, sodium thiosulfate is frequently used to treat calciphylaxis. A typical dose is $25 \mathrm{~g}$ in $100 \mathrm{ml}$ of solution given intravenously three times a week during the last 30 to 60 minutes of hemodialysis. The optimal duration of the treatment course is unclear. Pharmacokinetic simulations may be used to estimate the dose for hemodialysis at various levels of intensity. ${ }^{68}$ The dosing for patients undergoing peritoneal dialysis, patients who are not being treated with dialysis, and children is less standardized. Adverse effects include volume overload, hypocalcemia, QT-interval prolongation, hypotension, and metabolic acidosis. These adverse effects can be avoided with intralesional administration, which may be an alternative approach for patients with early and limited disease. ${ }^{69}$ Bisphosphonates are pyrophosphate analogues that have been used successfully to treat patients with genetic ENPP1 deficiency. ${ }^{70}$ In a prospective series of 11 patients, bisphosphonates halted the progression of lesions in all the patients starting at 2 to 4 weeks after treatment initiation. ${ }^{71}$ Further investigation of bone-vascular crosstalk is needed to understand the role of bisphosphonates and other agents that modify bone (e.g., receptor activator of nuclear factor-kB ligand inhibitor and antisclerostin antibody). Decisions regarding anticoagulation therapy should be individualized after an assessment of the risk of bleeding versus the risk of thrombosis. If ongoing anticoagulation therapy is favored, the selection of an agent should be based on the patient's kidney function and the indication for anticoagulation. ${ }^{72}$ In a study involving patients 60 to 80 years of age, vitamin K1 supplementation (phylloquinone at a dose of $500 \mu \mathrm{g}$ per day) slowed the progression of preexisting coronary-artery calcification by $6 \%$ at 3 years of follow-up. ${ }^{73}$ In healthy postmenopausal menopausal women, vitamin K2 supplementation (menaquinone-7 administered at a dose of $180 \mu \mathrm{g}$ daily for 3 years) reduced aortic stiffness (measured as carotid-femoral pulse wave velocity with the use of mechanotransducers) and common carotid-artery stiffness (measured according to the stiffness index $\beta$ with the use of echotracking and oscillometry). ${ }^{74}$ Moreover, vitamin K1 supplementation (phytonadione administered at a dose of $2 \mathrm{mg}$ daily for 12 months) slowed the progress of aortic-valve calcification (measured by means of computed tomography) by $57 \%$, as compared with placebo, in patients with mild-to-moderate aortic stenosis. ${ }^{75}$ The efficacy of vitamin $\mathrm{K}$ supplementation for calciphylaxis, however, is unclear, with no support for the superiority of a specific form of vitamin K (K1 or K2). A proof-of-concept study of vitamin $\mathrm{K} 1$ supplementation (10 $\mathrm{mg}$ administered orally three times weekly after hemodialysis) is currently under way (NCT02278692). 


\section{Summary and Future Directions}

Calciphylaxis is a complex disorder of microvascular calcification that is typically manifested as painful cutaneous lesions and results in poor outcomes. Currently, there are no approved therapies for calciphylaxis; however, ongoing trials are examining end points that include pain intensity and lesion characteristics. Although some risk factors for calciphylaxis are now better understood, animal models that recapitulate this rare human condition would be helpful to gain a better understanding of pathogenesis and to test novel therapeutic agents. 


\section{References}

1. Nigwekar SU, Zhao S, Wenger J, et al. A nationally representative study of calcific uremic arteriolopathy risk factors. J Am Soc Nephrol 2016; 27: 3421-9.

2. McCarthy JT, El-Azhary RA, Patzelt MT, et al. Survival, risk factors, and effect of treatment in 101 patients with calciphylaxis. Mayo Clin Proc 2016; 91: 1384-94.

3. Fine A, Zacharias J. Calciphylaxis is usually non-ulcerating: risk factors, outcome and therapy. Kidney Int 2002; 61: 2210-7.

4. Brandenburg VM, Evenepoel P, Floege J, et al. Lack of evidence does not justify neglect: how can we address unmet medical needs in calciphylaxis? Nephrol Dial Transplant 2016; 31: 1211-9.

5. Brandenburg VM, Kramann $\mathrm{R}$, Rothe $\mathrm{H}$, et al. Calcific uraemic arteriolopathy (calciphylaxis): data from a large nationwide registry. Nephrol Dial Transplant 2017; 32: 126-32.

6. Honda $\mathrm{Y}$, Endo $\mathrm{Y}$, Tanizaki $\mathrm{H}$, et al. Calciphylaxis associated with acute renal failure in multicentric Castleman's disease. Eur J Dermatol 2015; 25: 497-9.

7. Vanparys J, Sprangers B, Sagaert X, Kuypers DR. Chronic wounds in a kidney transplant recipient with moderate renal impairment. Acta Clin Belg 2013; 68: 128-31.

8. Nigwekar SU, Wolf M, Sterns RH, Hix JK. Calciphylaxis from nonuremic causes: a systematic review. Clin J Am Soc Nephrol 2008; 3: 1139-43.

9. Kalajian AH, Malhotra PS, Callen JP, Parker LP. Calciphylaxis with normal renal and parathyroid function: not as rare as previously believed. Arch Dermatol 2009; 145: 451-8.

10. Coates T, Kirkland GS, Dymock RB, et al. Cutaneous necrosis from calcific uremic arteriolopathy. Am J Kidney Dis 1998; 32: 384-91.

11. Polizzotto MN, Bryan T, Ashby MA, Martin P. Symptomatic management of calciphylaxis: a case series and review of the literature. J Pain Symptom Manage 2006; 32: 186-90.

12. Ghosh T, Winchester DS, Davis MDP, El-Azhary R, Comfere NI. Early clinical presentations and progression of calciphylaxis. Int J Dermatol 2017; 56: 856-61.

13. Daudén E, Oñate MJ. Calciphylaxis. Dermatol Clin 2008; 26: 557-68. 14. Weenig RH, Sewell LD, Davis MD, McCarthy JT, Pittelkow MR. Calciphylaxis: natural history, risk factor analysis, and outcome. J Am Acad Dermatol 2007; 56: 569-79.

15. Case Records of the Massachusetts General Hospital (Case 7-2007). N Engl J Med 2007; 356: 1049-57.

16. Riemer CA, El-Azhary RA, Wu KL, Strand JJ, Lehman JS. Underreported use of palliative care and patient-reported outcome measures to address reduced quality of life in patients with calciphylaxis: a systematic review. Br J Dermatol 2017; 177: 1510-8.

17. Nigwekar SU. Calciphylaxis. Curr Opin Nephrol Hypertens 2017; 26: 276-81.

18. Zitt $E$, König $M, V y c h y t i l ~ A$, et al. Use of sodium thiosulphate in a multi-interventional setting for the treatment of calciphylaxis in dialysis patients. Nephrol Dial Transplant 2013; 28: 1232-40. 
19. Mochel MC, Arakaki RY, Wang G, Kroshinsky D, Hoang MP. Cutaneous calciphylaxis: a retrospective histopathologic evaluation. Am J Dermatopathol 2013; 35: 582-6.

20. Chen TY, Lehman JS, Gibson LE, Lohse CM, El-Azhary RA. Histopathology of calciphylaxis: cohort study with clinical correlations. Am J Dermatopathol 2017; 39: 795-802.

21. Kramann R, Brandenburg VM, Schurgers $L$, et al. Novel insights into osteogenesis and matrix remodelling associated with calcific uraemic arteriolopathy. Nephrol Dial Transplant 2013; 28: 856-68.

22. Hayashi M. Calciphylaxis: diagnosis and clinical features. Clin Exp Nephrol 2013; 17: 498-503.

23. Nigwekar SU, Solid CA, Ankers E, et al. Quantifying a rare disease in administrative data: the example of calciphylaxis. J Gen Intern Med 2014; 29: Suppl 3: S724-S731.

24. Hayashi M, Takamatsu I, Kanno Y, Yoshida T, Abe T, Sato Y. A case-control study of calciphylaxis in Japanese endstage renal disease patients. Nephrol Dial Transplant 2012; 27: 1580-4.

25. Zhang Y, Corapi KM, Luongo M, Thadhani R, Nigwekar SU. Calciphylaxis in peritoneal dialysis patients: a single center cohort study. Int J Nephrol Renovasc Dis 2016; 9: 23541.

26. Sprague SM. Painful skin ulcers in a hemodialysis patient. Clin J Am Soc Nephrol 2014; 9: 166-73.

27. Araya CE, Fennell RS, Neiberger RE, Dharnidharka VR. Sodium thiosulfate treatment for calcific uremic arteriolopathy in children and young adults. Clin J Am Soc Nephrol 2006; 1: 1161-6.

28. James LR, Lajoie G, Prajapati D, Gan BS, Bargman JM. Calciphylaxis precipitated by ultraviolet light in a patient with end-stage renal disease secondary to systemic lupus erythematosus. Am J Kidney Dis 1999; 34: 932-6.

29. Amuluru L, High W, Hiatt KM, et al. Metal deposition in calcific uremic arteriolopathy. J Am Acad Dermatol 2009; 61: 73-9.

30. Rothe $H$, Brandenburg V, Haun M, et al. Ecto-5'-nucleotidase CD73 (NT5E), vitamin D receptor and FGF23 gene polymorphisms may play a role in the development of calcific uremic arteriolopathy in dialysis patients - data from the German Calciphylaxis Registry. PLoS One 2017; 12(2): e0172407.

31. Spanakis EK, Sellmeyer DE. Nonuremic calciphylaxis precipitated by teriparatide [rhPTH(1-34)] therapy in the setting of chronic warfarin and glucocorticoid treatment. Osteoporos Int 2014; 25: 1411-4.

32. Mawad HW, Sawaya BP, Sarin R, Malluche HH. Calcific uremic arteriolopathy in association with low turnover uremic bone disease. Clin Nephrol 1999; 52: 160-6.

33. Scialla JJ, Lau WL, Reilly MP, et al. Fibroblast growth factor 23 is not associated with and does not induce arterial calcification. Kidney Int 2013; 83: 1159-68.

34. Yamada S, Giachelli CM. Vascular calcification in CKD-MBD: roles for phosphate, FGF23, and Klotho. Bone 2017; 100: 87-93. 
35. Nigwekar SU, Bhan I, Turchin A, et al. Statin use and calcific uremic arteriolopathy: a matched case-control study. Am J Nephrol 2013; 37: 325-32.

36. Santos PW, He J, Tuffaha A, Wetmore JB. Clinical characteristics and risk factors associated with mortality in calcific uremic arteriolopathy. Int Urol Nephrol 2017; 49: 2247-56.

37. Nigwekar SU, Bloch DB, Nazarian RM, et al. Vitamin K-dependent carboxylation of matrix Gla protein influences the risk of calciphylaxis. J Am Soc Nephrol 2017; 28: 1717-22.

38. Selye H, Gentile G, Prioreschi P. Cutaneous molt induced by calciphylaxis in the rat. Science 1961; 134: 1876-7.

39. Dobry AS, Ko LN, St John J, Sloan JM, Nigwekar S, Kroshinsky D. Association between hypercoagulable conditions and calciphylaxis in patients with renal disease: a casecontrol study. JAMA Dermatol 2018; 154: 182-7.

40. Moe SM, Chen NX. Calciphylaxis and vascular calcification: a continuum of extraskeletal osteogenesis. Pediatr Nephrol 2003; 18: 969-75.

41. Shroff R, Long DA, Shanahan C. Mechanistic insights into vascular calcification in CKD. J Am Soc Nephrol 2013; 24: 179-89.

42. Schafer $C$, Heiss $A$, Schwarz A, et al. The serum protein alpha 2-Heremans-Schmid glycoprotein/fetuin-A is a systemically acting inhibitor of ectopic calcification. J Clin Invest 2003; 112: 357-66.

43. Luo G, Ducy $P$, McKee MD, et al. Spontaneous calcification of arteries and cartilage in mice lacking matrix GLA protein. Nature 1997; 386: 78-81.

44. Schurgers L, Uitto J, Reutelingsperger CP. Vitamin K-dependent carboxylation of matrix Gla-protein: a crucial switch to control ectopic mineralization. Trends Mol Med 2013; 19: 217-26.

45. Griethe W, Schmitt R, Jurgensen JS, Bachmann S, Eckardt KU, Schindler R. Bone morphogenic protein-4 expression in vascular lesions of calciphylaxis. J Nephrol 2003; 16: 728-32.

46. Nigwekar SU, Jiramongkolchai $P$, Wunderer $F$, et al. Increased bone morphogenetic protein signaling in the cutaneous vasculature of patients with calciphylaxis. Am J Nephrol 2017; 46: 429-38.

47. Smith ER, Cai MM, McMahon LP, et al. Serum fetuin-A concentration and fetuin-Acontaining calciprotein particles in patients with chronic inflammatory disease and renal failure. Nephrology (Carlton) 2013; 18: 215-21.

48. Sowers KM, Hayden MR. Calcific uremic arteriolopathy: pathophysiology, reactive oxygen species and therapeutic approaches. Oxid Med Cell Longev 2010; 3: 109-21.

49. St Hilaire C, Ziegler SG, Markello TC, et al. NT5E mutations and arterial calcifications. N Engl J Med 2011; 364: 432-42.

50. Albright RA, Stabach P, Cao W, et al. ENPP1-Fc prevents mortality and vascular calcifications in rodent model of generalized arterial calcification of infancy. Nat Commun 2015; 6: 10006. 
51. Lomashvili KA, Narisawa S, Millán JL, O’Neill WC. Vascular calcification is dependent on plasma levels of pyrophosphate. Kidney Int 2014; 85: 1351-6.

52. Pillai ICL, Li S, Romay M, et al. Cardiac fibroblasts adopt osteogenic fates and can be targeted to attenuate pathological heart calcification. Cell Stem Cell 2017; 20(2): 218232.e5.

53. Chen NX, O'Neill K, AkI NK, Moe SM. Adipocyte induced arterial calcification is prevented with sodium thiosulfate. Biochem Biophys Res Commun 2014; 449: 151-6.

54. Mikhaylova L, Malmquist J, Nurminskaya M. Regulation of in vitro vascular calcification by BMP4, VEGF and Wnt3a. Calcif Tissue Int 2007; 81: 372-81.

55. Araki N, Misawa S, Shibuya K, et al. POEMS syndrome and calciphylaxis: an unrecognized cause of abnormal small vessel calcification. Orphanet J Rare Dis 2016; 11: 35.

56. Mutch DM, Rouault $C$, Keophiphath $M$, Lacasa D, Clément K. Using gene expression to predict the secretome of differentiating human preadipocytes. Int J Obes (Lond) 2009; 33: 354-63.

57. Cassius C, Moguelet $\mathrm{P}$, Monfort JB, et al. Calciphylaxis in haemodialysed patients: diagnostic value of calcifications in cutaneous biopsy. Br J Dermatol 2018; 178: 292-3.

58. Paul S, Rabito CA, Vedak P, Nigwekar SU, Kroshinsky D. The role of bone scintigraphy in the diagnosis of calciphylaxis. JAMA Dermatol 2017; 153: 101-3.

59. Shmidt E, Murthy NS, Knudsen JM, et al. Net-like pattern of calcification on plain softtissue radiographs in patients with calciphylaxis. J Am Acad Dermatol 2012; 67: 1296301.

60. Wilmer WA, Voroshilova O, Singh I, Middendorf DF, Cosio FG. Transcutaneous oxygen tension in patients with calciphylaxis. Am J Kidney Dis 2001; 37: 797- 806.

61. An J, Devaney B, Ooi KY, Ford S, Frawley G, Menahem S. Hyperbaric oxygen in the treatment of calciphylaxis: a case series and literature review. Nephrology (Carlton) 2015; 20: 444-50.

62. Fouque D, Kalantar-Zadeh K, Kopple J, et al. A proposed nomenclature and diagnostic criteria for protein-energy wasting in acute and chronic kidney disease. Kidney Int 2008; 73: 391-8.

63. The EVOLVE Trial Investigators. Effect of cinacalcet on cardiovascular disease in patients undergoing dialysis. N Engl J Med 2012; 367: 2482-94.

64. Nigwekar SU, Sprague SM. We do too many parathyroidectomies for calciphylaxis. Semin Dial 2016; 29: 312-4.

65. Baldwin $C$, Farah $M$, Leung $M$, et al. Multi-intervention management of calciphylaxis: a report of 7 cases. Am J Kidney Dis 2011; 58: 988-91.

66. Nordheim E, Dahle DO, Syse IM, Åsberg A, Reisæter AV, Hartmann A. Resolution lution of calciphylaxis after urgent kidney transplantation in 3 patients with endstage kidney failure. Transplant Direct 2016; 2(11): e113.

67. Nigwekar SU, Brunelli SM, Meade D, Wang W, Hymes J, Lacson E Jr. Sodium thiosulfate therapy for calcific uremic arteriolopathy. Clin J Am Soc Nephrol 2013; 8: 1162-70. 
68. Singh RP, Derendorf $H$, Ross EA. Simulation- based sodium thiosulfate dosing strategies for the treatment of calciphylaxis. Clin J Am Soc Nephrol 2011; 6: 1155- 9.

69. Strazzula L, Nigwekar SU, Steele D, et al. Intralesional sodium thiosulfate for the treatment of calciphylaxis. JAMA Dermatol 2013; 149: 946-9.

70. Ramjan KA, Roscioli T, Rutsch F, Sillence D, Munns CF. Generalized arterial calcification of infancy: treatment with bisphosphonates. Nat Clin Pract Endocrinol Metab 2009; 5: 167-72.

71. Torregrosa JV, Sánchez-Escuredo A, Barros X, Blasco M, Campistol JM. Clinical management of calcific uremic arteriolopathy before and after therapeutic inclusion of bisphosphonates. Clin Nephrol 2015; 83: 231-4.

72. King BJ, El-Azhary RA, McEvoy MT, et al. Direct oral anticoagulant medications in calciphylaxis. Int J Dermatol 2017; 56: 1065-70.

73. Shea MK, O'Donnell CJ, Hoffmann U, et al. Vitamin $K$ supplementation and progression of coronary artery calcium in older men and women. Am J Clin Nutr 2009; 89: 1799-807.

74. Knapen MH, Braam LA, Drummen NE, Bekers O, Hoeks AP, Vermeer C. Menaquinone7 supplementation improves arterial stiffness in healthy postmenopausal women: a double-blind randomised clinical trial. Thromb Haemost 2015; 113: 1135-44.

75. Brandenburg VM, Reinartz $\mathrm{S}$, Kaesler $\mathrm{N}$, et al. Slower progress of aortic valve calcification with vitamin $\mathrm{K}$ supplementation: results from a prospective interventional proof-of-concept study. Circulation 2017; 135: 2081-3. 



\section{c)}

Slower Progress of Aortic Valve Calcification With Vitamin K Supplementation: Results From a Prospective Interventional Proof-of-Concept Study (IF 19)

Slower Progress of Aortic Valve Calcification With Vitamin K Supplementation: Results From a Prospective Interventional Proof-of-Concept Study.

Brandenburg VM, Reinartz $\mathrm{S}$, Kaesler N, Krüger $\mathrm{T}$, Dirrichs $\mathrm{T}$, Kramann R, Peeters F, Floege J, Keszei A, Marx N, Schurgers L, Koos R. Circulation. 2017 May 23; 135(21): 2081-2083. 


\section{Results}

Calcific aortic stenosis is a common degenerative disease characterized by progressive aortic valve calcification (AVC). ${ }^{1}$ Effective medical treatment options to retard the progression of AVC are sparse. ${ }^{1}$ Epidemiological data point to vitamin $\mathrm{K}$ as a potential protective factor for cardiovascular health, particularly for protection against vascular calcification. 2,3 Matrix Gla-protein (MGP), a potent inhibitor of cardiovascular calcification, requires vitamin $\mathrm{K}$ for posttranslational carboxylation and hence full bioactivity. ${ }^{4}$ Thus, vitamin $\mathrm{K}$ supplementation might retard the progression of AVC. ${ }^{1,2}$ Dephosphorylated undercarboxylated MGP (dp-ucMGP) serves as a circulating marker for vitamin $\mathrm{K}$ deficiency. ${ }^{2,3}$ We performed a 12-month prospective, single-center, open-label, randomized interventional trial in patients with asymptomatic or mildly symptomatic AVC. Written informed consent was obtained before inclusion in the trial (URL: http://www.clinicaltrials.gov. Unique identifier: NCT00785109; RWTH Aachen Institutional Review Board No. 165/08). Inclusion criterion was a peak flow velocity exceeding $2 \mathrm{~m} / \mathrm{s}$. The main exclusion criteria were chronic kidney disease (estimated glomerular filtration rate $<60 \mathrm{ml} \cdot \mathrm{min}^{-1} \cdot 1.73 \mathrm{~m}^{-2}$ ), expected valve replacement within the next year, and anticoagulation with vitamin $\mathrm{K}$ antagonists. Patients were randomized 1:1 to receive $2 \mathrm{mg}$ phytomenadione (vitamin K1, Ka-vit, INFECTOPHARM Arzneimittel CONSILIUM GmbH, Heppenheim, Germany) or matching placebo once daily orally. Patients underwent a baseline and end-of-study cardiac computed tomography (CT) scan for AVC quantification (volume calcification score). All CT examinations were performed on a 128-slice dualsource CT scanner (SOMATOM Definition Flash, Siemens, Germany) and were reanalyzed in a blinded fashion by 2 radiologists experienced in cardiac CT. The primary end point was the difference in progression of AVC volume score between vitamin $\mathrm{K}$ and placebo. We also assessed changes of dp-ucMGP plasma levels (IDS, Boldon, UK) as a secondary end point. Linear regression models for AVC change with treatment effect and baseline measures were used as independent variables, and 95\% confidence intervals for treatment effects were calculated. The trial cohort included 99 patients $(82 \%$ male; $35 \%$ with aortic sclerosis [ $\leq 2.5 \mathrm{~m} / \mathrm{s}$ ], $38 \%$ with mild aortic stenosis [2.6-2.9 m/s], and $27 \%$ with moderate aortic stenosis [3.0-4.0 m/s]; $71 \%$ of each group received statins). Seventy-two participants also underwent an end-of-study cardiac CT scan (representing the per-protocol analysis cohort: $\mathrm{n}=38$ vitamin $\mathrm{K}, \mathrm{n}=34$ placebo). Twenty-seven patients (12 vitamin $\mathrm{K}, 15$ placebo) dropped out of the study. Reasons for discontinuation were initiation of oral anticoagulant treatment ( $n=3$ placebo, $n=4$ vitamin $K$ ), loss to follow-up, withdrawal of consent ( $n=6$ placebo, $n=3$ vitamin K), cardiac surgery ( $n=2$ each), death ( $n=1$ each), or other reasons ( $n$ $=3$ placebo, $n=2$ vitamin $\mathrm{K}$ ). Over the 12-month period, the AVC volume score progressed by $10.0 \%$ in patients in the vitamin $\mathrm{K}$ group compared with $22.0 \%$ in the placebo group (Table), representing a significant attenuation of AVC progression by vitamin $\mathrm{K}$ compared with placebo. Linear regression with treatment group and baseline AVC as independent variables revealed an estimated difference in the change in AVC volume score between the vitamin $\mathrm{K}$ and placebo groups of $-101 \mathrm{ml}$ (95\% confidence interval, -194 to $-8.3 ; \mathrm{p}=0.03$, adjusted $R^{2}=0.08$ ). Adding age to the model did not improve the model or change the 
Brandenburg VM, Reinartz S, Kaesler $N$ et al. Slower Progress of Aortic Valve Calcification With Vitamin $K$ Supplementation: Results From a Prospective Interventional Proof-of-Concept Study. Circulation. 2017 May 23; 135(21): 2081-2083.

estimated difference. Baseline mean gradient and peak flow velocity were highly correlated $(r=0.88)$. After adjustment for mean gradient, the estimated difference in AVC volume progression was -65 (95\% confidence interval, -147 to $17 ; p=0.12$; adjusted $R^{2}=$ 0.26). Similar results were obtained after AVC was indexed to body surface area. Plasma dpucMGP concentration significantly decreased in the vitamin $\mathrm{K}$ group by $45 \%$ ( $p<0.001$; Table). Statistically, the change in peak flow velocity was not significantly different between the 2 groups. No thromboembolic events occurred. The present study is the first randomized controlled trial in men to demonstrate that vitamin $\mathrm{K}$ supplementation might decelerate the progression of AVC. Our findings are clinically meaningful because a strong, significant correlation exists between the AVC volume score and functional valvular parameters such as mean gradient or peak flow velocity. ${ }^{5}$ Hence, deceleration of AVC progression, a direct precursor of hemodynamic impairment, might finally translate into a stabilization of valvular functionality in calcific aortic stenosis and a slowing of cardiac and clinical deterioration. In parallel, vitamin $\mathrm{K}$ treatment induced a marked reduction of plasma dpucMGP, indicating increased vitamin K bioactivity. We consider the present study results to represent the first proof of concept in the evaluation of the potential anticalcification effects of vitamin $\mathrm{K}$ treatment in human calcific aortic valvular disease. We acknowledge that our results need to be confirmed and should therefore be interpreted with caution. Limitations of our trial are the relatively small study size and the additional high dropout rate, resulting in missing data for primary end-point interpretation, as well as the short duration of follow-up, the open-label design, and the broad spectrum of severity of valvular disease at baseline. Moreover, the study was not powered to assess valve functionality using echocardiography, an important determinant for clinical end points. Despite these limitations, our data lay the basis for future intervention trials to investigate valvular hemodynamic parameters or patient outcomes in parallel to calcification parameters. In summary, vitamin K supplementation may represent an effective and safe therapy in cardiovascular disease related to ectopic calcification such as calcific aortic stenosis. 


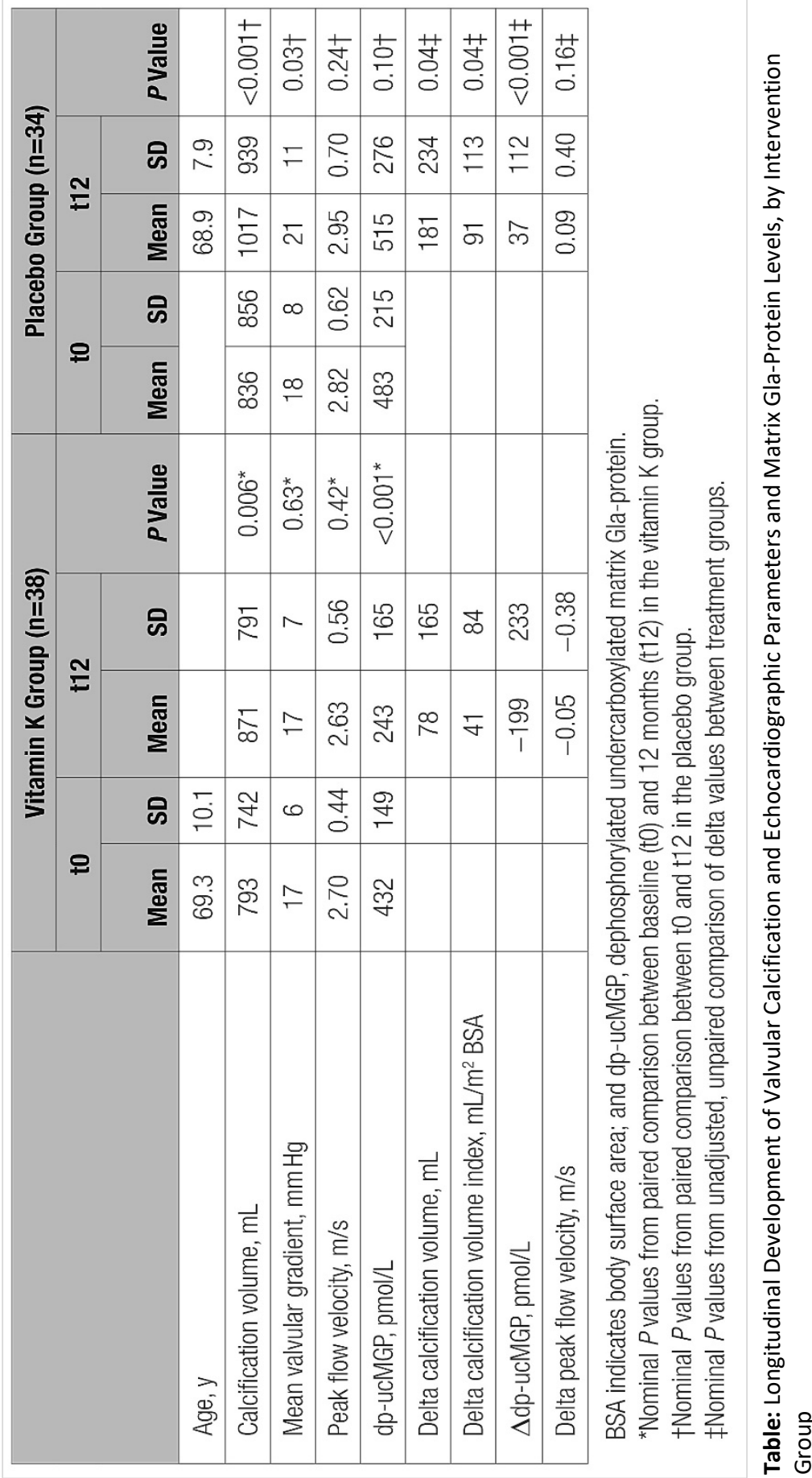




\section{Acknowledgments}

The authors thank Mhammed Bougoussa (IDS, Liege, Belgium) and Pierre Lukas (Department of Clinical Chemistry, University of Liège, Belgium) for technical assistance. Assay kits for the measurement of dephosphorylated undercarboxylated matrix Glaprotein were kindly donated by Immunodiagnostic Systems (IDS, UK).

\section{Sources of funding}

The present study was funded by a grant from the Else-Kroener Fresenius Stiftung (Foundation), Germany.

\section{Disclosures}

Drs Koos and Brandenburg received a grant from the Else-Kroener Fresenius Foundation. The other authors report no conflicts.

\section{References}

1. Marquis-Gravel G, Redfors $B$, Leon MB, Généreux $P$. Medical treatment of aortic stenosis. Circulation. 2016; 134: 1766-1784. doi: 10.1161/CIRCULATION AHA. 116.023997.

2. Brandenburg VM, Schurgers LJ, Kaesler N, Püsche K, van Gorp RH, Leftheriotis G, Reinartz S, Koos $R$, Krüger $T$. Prevention of vasculopathy by vitamin $K$ supplementation: can we turn fiction into fact? Atherosclerosis. 2015; 240: 10-16. doi: 0.1016/ j.atherosclerosis.2015.02.040.

3. Willems BA, Vermeer C, Reutelingsperger CP, Schurgers LJ. The realm of vitamin $\mathrm{K}$ dependent proteins: shifting from coagulation toward calcification. Mol Nutr Food Res. 2014; 58: 1620-1635. doi: 10.1002/mnfr.201300743.

4. Cranenburg EC, Vermeer C, Koos R, Boumans ML, Hackeng TM, Bouwman FG, Kwaijtaal M, Brandenburg VM, Ketteler M, Schurgers LJ. The circulating inactive form of matrix Gla Protein (uc-MGP) as a biomarker for cardiovascular calcification. J Vasc Res. 2008; 45: 427-436. doi: 10.1159/000124863.

5. Koos R, Mahnken AH, Sinha AM, Wildberger JE, Hoffmann R, Kühl HP. Aortic valve calcification as a marker for aortic stenosis severity: assessment on 16-MDCT. AJR Am J Roentgenol. 2004; 183: 1813-1818. doi: 10.2214/ajr.183.6.01831813. 



\section{SECTION: \\ Additional documents}




\section{a) \\ Summary}

The scientific work summarized in the present thesis was performed in order to improve our understanding of how CKD influences cardiovascular risk and ascertain which treatment options potentially exist to modify this risk. Two major CKD-related cardiovascular risk factors and biomarkers were specifically selected as research targets for the present thesis, i.e. FGF23 excess and vitamin K deficiency - the latter was presented as closely linked to the calcification disorder calciphylaxis.

The major results of the work are as follows:

We analyzed the potency to predict outcome of the FGF23-klotho axis in the LURIC cohort, a prospective observational cohort consisting of patients undergoing coronary angiography for acute coronary syndrome. Regarding FGF23, the present work confirms that FGF23 (in this case c-term FGF23) is an independent predictor of mortality and morbidity in patients undergoing coronary angiography. Hence, our work investigated the previously welldescribed association between FGF23 serum levels and outcome, now in a novel type of patient cohort. Interestingly, a closely associated second publication denied such an association for soluble klotho levels, which is important in order to establish a hierarchy within the biomarkers of the FGF23-klotho axis in terms of risk prediction. Our data clearly showed that soluble klotho serum levels failed as risk prediction tool, at least in the LURIC cohort.

On top of these cross-sectional data, we also investigated the influence of i.v. iron (specifically ferric carboxymaltose) on FGF23 and phosphate metabolism in a prospective interventional trial. Results from our study show that ferric carboxymaltose modifies levels of intact as well as c-terminal FGF23 substantially. Noteworthy, ferric carboxymaltose leads to the development of FGF23 serum levels in opposing directions (increase in iFGF23 and decrease in c-term FGF23). Most importantly, these first-in-man data clearly indicate that hypophosphatemia development due to transient increases in intact FGF23 needs to be taken into account when discussing the pros and cons of i.v. iron therapy in heart failure. Further studies are required to evaluate the pathophysiology behind this finding, e.g. down-regulation of the splicing process of intact FGF23. It is currently also unclear, if and to what extent this transient iFGF23 increase might impair myocardial function.

A second key aspect of the thesis is vitamin $\mathrm{K}$ deficiency and its clinical consequences with a specific focus on calciphylaxis. Regarding calciphylaxis, the present thesis summarizes ground-breaking clinical work in the area of calciphylaxis, which led to a better understanding of the disease and provided the basis to introduce this rare disease to a broader audience. For this reason, we collected and analyzed data from the German calciphylaxis registry. Noteworthy, our data underline the close link between vitamin $\mathrm{K}$ deficiency and the subsequent risk for vascular calcification induced by vitamin $\mathrm{K}$ 
antagonist treatment. The presented study contributed significantly to the introduction of preventive measures, such as avoidance of VKA treatment in ESRD patients whenever alternaties appear appropriate. In consequence, the Aachen calciphylaxis team was involved in a recent state-of-the-art review about calciphylaxis with a specific focus on treatment options. Moreover, we support these descriptive data about potential benefits of vitamin $\mathrm{K}$ in cardiovascular health by publishing results from a randomized, controlled vitamin $\mathrm{K}$ interventional pilot study in patients with calcific aortic stenosis. This trial opens up a promising treatment area by showing that vitamin $\mathrm{K}$ replenishment slows the progression of valvular calcification in patients with calcific aortic stenosis compared to placebo. 


\section{b) \\ Samenvatting}

De onderzoekprojecten die samengevat zijn in deze promotie gaan enerzijds over de invloed van chronische nierziekte (CKD) op het cardiovasculaire risico en anderzijds over de vraag in hoeverre er potentiële behandelopties zijn om dit risico te verminderen. Twee zeer belangrijke CKD gerelateerde risicofactoren en biomarkers werden gekozen om nader te onderzoeken middels deze promotie: FGF23 exces en vitamine K deficiëntie (ook ivm de verkalkingsstoornis calcifylaxie).

De meest belangrijke bevindingen zijn:

1) We onderzochten het vermogen van de FGF23-klotho om de prognose te voorspellen in het LURIC cohort. Dat is een prospectief, observationeel cohort m.b.t. patiënten, die een katheterisatie ondergingen voor diagnostiek i.v.m. een acuut coronair syndroom. In feite was deze studie bedoeld om het bekend verband van FGF23 serum spiegel en uitkomst in een verdere patiëntenpopulatie te onderzoeken. Inderdaad kon het onderzoek bevestigen dat FGF23 (in dit geval c-term FGF23) een onafhankelijke voorspeller van mortaliteit en morbiditeit was. In het verleden was er geen associatie gezien tussen de soluble klotho spiegel wat belangrijk is om meer inzicht te hebben in het hiërarchische verband tussen de FGF23-klotho als risico voorspelling. Uiteindelijk was er geen risicoschatting mogelijk in de LURIC studie o.b.v. soluble klotho spiegel.

Vervolgens werd de invloed van i.v. ijzer (namelijk ferric carboxymaltose) op FGF23 en het fosfaat metabolisme in een prospectieve studie onderzocht. Wij konden aantonen dat ferric carboxymaltose een duidelijke invloed op zowel het intacte alsook het c-terminale FGF23 heeft. Bovendien werd duidelijk dat het toedienen van ferric carboxymaltose tot averechtse effecten namelijk verhoging van iFGF23 en afname van het c-term FGF23 leidde. Het is belangrijk om te benadrukken dat deze eerste resultanten in patiënten duidelijk laten zien dat een hypofosfatemie zich kan ontwikkelen vanwege een passagère afname van het intacte FGF23. Deze bevindingen moeten afgewogen worden ten opzichte van de voordelen van een i.v. ijzerbehandelingen. Hoe dan ook, er zijn meer studies nodig om de pathofysiologie (bijvoorbeeld down-regulatie van het splicing proces van het intacte FGF23) beter boven water te halen. Tot op heden is het niet duidelijk in hoeverre het passagère intacte FGF23 de cardiale functie belemmert.

2) Het tweede aspect van de promotie was het onderzoek naar de klinische consequenties van een vitamine $\mathrm{K}$ deficiëntie met een klemtoon op calcifylaxie. Vooral m.b.t. calcifylaxie vat deze promotie baanbrekend klinisch werk samen wat 
tot betere inzichten in deze zeldzame aandoening geleidt en tegelijkertijd deze ziekte in een groter publiek van artsen geïntroduceerd heeft. Data uit het Duitse calcifylaxie register was voor deze analyses toegankelijk. Onze resultaten laten duidelijk het verband tussen vitamine $K$ deficiëntie en het risico op vasculaire verkalkingen o.b.v. behandeling met vitamine $\mathrm{K}$ antagonisten zien. Ons onderzoek heeft een belangrijke bijdrage geleverd om alternatieve strategieën en preventieve maatregelen te implementeren (bijvoorbeeld vermijden van vitamine $\mathrm{K}$ antagonisten in patiënten met eindstadium nierfalen). Vervolgens werd het calcifylaxie team uit Aken uitgenodigd om een state-of-the-art review over calcifylaxie en de behandelopties van dien te schrijven.

Bovendien hebben wij een prospectieve, gerandomiseerde studie gedaan om de positieve effecten van vitamine $\mathrm{K}$ m.b.t. cardiovasculaire gezondheid bij patiënten met een verkalkte aortaklepstenose te onderzoeken. Omdat er een afname van de snelheid van progressie van klepverkalking door de suppletie van vitamine $\mathrm{K}$ te zien was, wijzen deze resultaten op nieuwe, potentiele behandelopties. 


\section{c) \\ Discussion}

\section{$\underline{\text { Role of FGF23 as cardiorenal biomarker and risk factor }}$}

The canonical role of the osteocyte-derived circulating hormone fibroblast growth factor 23 (FGF23) is to augment renal phosphate excretion via blockade of tubular reabsorption and the down-regulation of 1,25 dihydroxyvitamin $D$ synthesis (62). In states of primary FGF23 excess, such as oncogenic osteomalacia or x-linked hypophosphatemic rickets, where the overproduction or oversupply of FGF23 hits a normally functioning tubular system, a dramatic hypophosphatemia may occur (63). Longstanding hypophosphatemia poses a substantial risk to the skeleton due to the induction of demineralization which may lead to the well-known entity hypophosphatemic (vitamin D resistant) rickets (osteomalacia in the adult population). However, the so-called off-target (specifically cardiac) effects of FGF23 have reached a significant level of interest $(39 ; 64-66)$ and prompted FGF23 to leave the bone-niche more than a decade ago.

Numerous cohort and observational studies have been published, all pointing in the same direction. They all describe the association between increasing circulating levels of FGF23 in serum and the dismal outcome and prognosis in various patient populations, e.g. in patients with chronic kidney disease, heart failure, critically ill patients, and in the general population (45;67-78). These data have homogeneously postulated an independent association between increasing serum FGF23 levels and the risk of increased cardiovascular morbidity events (such as hospitalization for heart failure) and risk of mortality in all the investigated cohorts (46). Notebly, this association was stable despite thorough adjustements to competing standard risk factors. Noteworthy, the link between FGF23 and heart failure-associated endpoints was reported to be especially strong, while the association to atherosclerosis-related cardiovascular endpoints such as myocardial infarction was modest (79). In other words, the myocardium rather than the arterial wall structures (endothelial or medial layer) is apparanetly the primary target for off-target effects of FGF23. After years of collecting such associative observational data, experimental data finally seemed to prove causality: Experimental in vivo data have supported these human cohort data by attributing a direct, independent and causal role for FGF23 to leftventricular hypertrophy and dysfunction (47;80;81). FGF23 caused pathological hypertrophy of isolated rat cardiomyocytes via FGF receptor-dependent activation of the calcineurin-NFAT signaling pathway. Intramyocardial or intravenous injection of FGF23 in wild-type mice induced increases in left ventricular mass. On the other side, the authors showed that FGF23 blockade is preventive and helps to reduce hypertrophy development. In an established animal model of CKD, treatment with an FGF receptor blocker attenuated 
LVH (47). Taken together, these findings point towards FGF23 as a promising candidate as a biomarker in heart failure and / or chronic kidney disease. In this respect, our findings, obtained from the LURIC cohort, pertaining to FGF23 as a risk factor also in patients with acute coronary syndrome, support a strong and independent predictive power for FGF23 and are in line with the vast majority of previous reports (49). Our data are of particular interest in this respect since the LURIC patients were representative for an all-comer study in a typical cardiology setting, i.e. with an average burden of CKD and a large variety of underlying diseases and comorbidities. Of note, the independent association between cterm FGf23 and mortality in LURIC remained stable even after adjustemt for brain natriuretuc peptide (BNP), a potent biomarker for heart failure (49). As a next step we sought to investigate whether soluble klotho, as the obligatory teamplayer for FGF23, exhibited comparable associations to the outcome in the same cohort. Our data, also obtained from the LURIC cohort, do not indicate that a comparably strong role in risk prediction can be attributed to soluble klotho (50). This negative finding might in part be attributable to an unclear reliability of the currently available soluble klotho assay (46).

As previously mentioned, FGF23 serum levels associate primarily with clinical signs of heart failure and finally with mortality rather than vascular disease end-points such as myocardial infarction (82). Accordingly, it is worth analyzing if differences can be detected between various subtypes of heart failure. The term heart failure summarizes a large variety of enteties with e.g. substantial differences in terms left-ventricular ejection fraction. In a follow-up study of our LURIC analysis, we were able to analyze for the first time potential differences regarding FGF23's role as a biomarker in patients with heart failure with reduced ejection fraction versus those with preserved ejection fraction (83). Indeed, such differences apparently exist since FGF-23 was independently associated with an increased risk of mortality only in patients with heart failure with reduced ejection fraction but not in those with $\mathrm{HF}$ with preserved ejection fraction, suggesting a different pathophysiological role for both entities (83).

\section{Novel aspects regarding FGF23 as a biomarker}

However, a critical reappraisal is necessary, since novel and very recent findings challenge the probably over-simplified view that extra-cardiac FGF23 damnifies the heart and does so only in a mono-directional way (66).

The vast majority of previous studies investigating the association of serum FGF23 with outcome relied upon measuring c-terminal (c-term) FGF23. ELISAs measuring c-term FGF23 identify both the biologically active hormone (intact FGF23, iFGF23) as well as degradation products. Early analysis performed in dialysis patients attributed a comparable value regarding risk assessment to both iFGF23 and c-term FGF23 (44), and a small cohort study in 100 heart failure patients recently confirmed this assumption (75). However, the biological role of iFGF23 differs substantially from that of c-term FGF23 (84) and actually counteracts some of the iFGF23 effects. Hence, relevant differences in the potency as biomarkers and risk predictors between the two forms are likely. Additionally, the 
independent role of FGF23 as myocardial noxa has been put into question. Causality must clearly be questioned in case two biomarkers with biological divergent or even opposite modes of action point in the same direction of association. Moreover, while Faul reported a klotho-independent effect of FGF-23 on cardiomyocytes (47), other groups suggested that klotho deficiency rather than FGF23 excess causes cardiac hypertrophy (85). The major finding of the latter study was that in heterozygous klotho-deficient CKD mice, the development of LVH was not modified by interventions normalizing FGF23 and phosphate levels, but only via exogenous klotho application (85). In humans, it is currently impossible to separate clearly the effects of CKD-induced klotho deficiency, phosphate load, and FGF2 rise.

\section{Is FGF23 really the bad guy?}

While some of the above-mentioned epidemiological data and experimental findings convincingly accuse FGF23 (presumably from skeletal origin) of being directly noxious to myocardial cells and a causative agent for LVH induction and myocardial damage, some data point in a different or even opposite direction. Two major unsolved issues emerge in this respect: First, does the FGF23 that finally acts upon the myocardium originate only from the bone, and second, are these actions only deleterious?

Noteworthy, also some beneficial cardiovascular effects have been attributed to FGF23, which raises the hypothesis about the existence of a U-curve-shaped association between FGF23 and myocardial disease. Remarkably, acute elevations of FGF23 were shown to have positive inotropic: FGF23 induced acute elevations of intracellular calcium of primary cardiomyocytes, an effect that could be abrogated by the calcium channel blocker Verapamil. FGF23 treatment of a ventricular muscle strip led to increased contractility, which was blocked by inhibition of FGF receptors (86). Hypothetically, this finding allows speculation about a potential physiological role of FGF23 elevations in situations of acute cardiomyocyte stress, such as ischemia and myocardial infaction, when sudden realease of FGf23 can support preservation of myocardial contractility. It appears counterintuitive that skeletal FGF23 is the sole source for such favorable cardiac actions, because this would require a fast myocardial-skeletal messenger.

In fact, recently Richter el al. found cultured cardiomyocytes to express FGF23 (87). In subsequent clinical studies, FGF23 was shown to be present in the explanted hearts of patients with ischemic or dilated cardiomyopathy undergoing heart transplantation, but not in healthy hearts (87). In another set of experiments, Andhrukova et al. found that, in the setting of experimental myocardial infarction in mice, circulating FGF23 is increased in the circulation (88). Additionally to increased FGF23 production in the bone, myocardial FGF23 was also increased on a protein and mRNA level, suggesting that increased circulating FGF23 post-myocardial infarction is at least partly derived from the myocardium itself (88). 
Some clinical data also fuel the hypothesis that FGF23 release and myocardial damage is not a one-way route from the skeleton to the myocardium. Cross-sectional data derived from patients with acute cardiogenic shock or the need to undergo mechanical assist device implantation promote the hypothesis that the heart is an active player - not only a recipient - in FGF23 metabolism $(89 ; 90)$. In patients with acute myocardial infarction complicated by cardiogenic shock, increased levels of FGF23 on admission correlated with increased mortality at 30 days and 1 year (90). However, when stratifying patients according to their baseline creatinine levels, the negative prognostic association of increased FGF23 only held true for patients whose serum creatinine was above the median (90), suggesting that FGF23 may not cause cardiac damage but rather is an indicator for it. Considering the speed and magnitude of the FGF-23 rise, the authors speculated that the myocardial damage per se induces FGF23 (be it heart derived and/or bone derived). Hence, these researchers challenged the mono-directional hypothesis that external factors stimulate bone FGF23 release which in turn induces myocardial damage $(89 ; 90)$. Instead, the FGF23 signaling pathway is increasingly recognized as having a paracrine component with myocardial FGF23 production and release acting directly locally within the heart (66).

\section{FGF23 participates in i.v. iron-induced hypophosphatemia}

The articles in this thesis also addressed a very recent discussion in heart failure patients, i.e. the link between iron deficiency, iron replenishment and hypophosphatemia induction. Iron deficiency has been identified as a relevant comorbidity in patients with heart failure with reduced ejection fraction (59). Novel iron formulations allow single-shot high dosage iron infusions, which permit a long interval (several months) between applications. This fact together with a clear recommendation to fill iron stores adequatetly in heart failure patients led to a substantial recent increase in i.v. iron usage in this setting. However, a novel disease entity emerged, the i.v. iron-related osteomalacia (57). Speculations pointed towards a causal relationship between the application of some (not all) i.v. iron formulations and the occurenec of a transient hypophosphatemia. Preliminary work in this area attributed this hypophosphatemia induction to a potential transient rise in iFGF23 (91). In our work presented in this thesis, we present a very important extension to these preliminary data (61). We performed the first controlled prospective interventional study in the field of heart failure. We investigated for the first time whether the hyphosphatemia induction is also present in heart failure patients after i.v. iron and if this increase is indeed attributable to increases in iFGF23. Additionally, we addressed the issue of whether underlying CKD in heart failure (the so-called cardio-renal syndrome) modifies the induction of hypophosphatemia. The major results of our pilot trial were (Figure 3) that $1000 \mathrm{mg} \mathrm{FCM}$ in heart failure patients with reduced ejection fraction induced a transient decrease in serum phosphorus (Figure 3), which was more pronounced in heart failure patients with reduced ejection fraction without concomitant CKD.

These biochemical changes emerged $<1$ week after infusion and lasted 2-3 weeks. Most strinkingly, in heart failure with reduced ejection fraction patients without CKD, 5 out of 11 
patients developed severe hypophosphatemia (defined as serum phosphate $<0.65 \mathrm{~mol} / \mathrm{L}$ ) at least once after 1000 i.v. FCM.

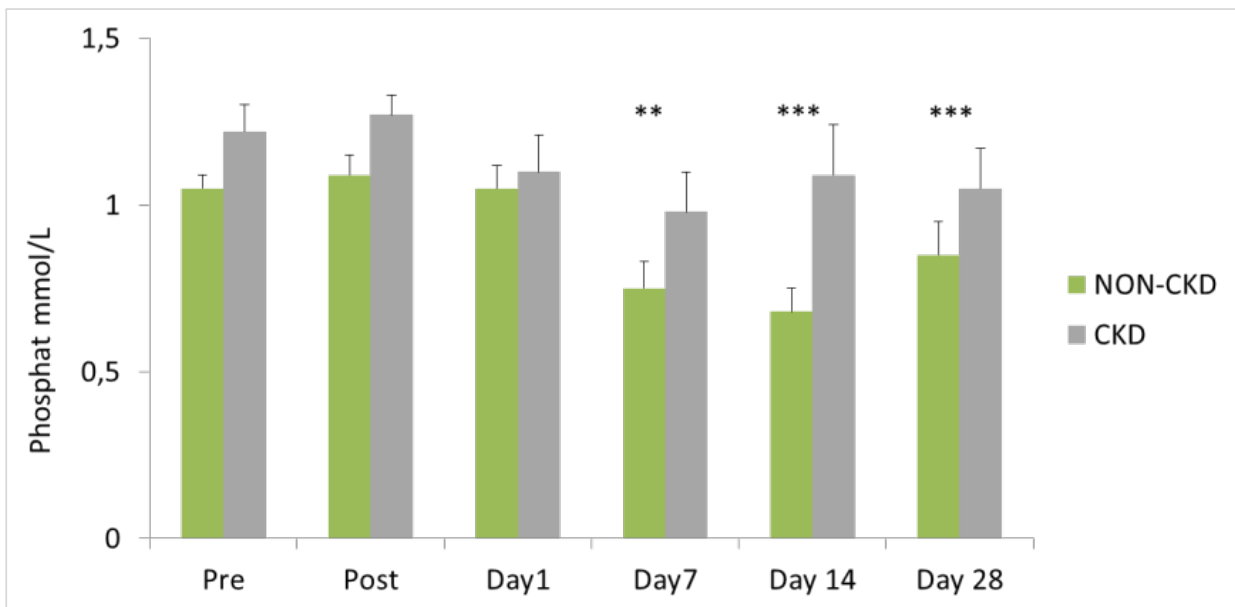

Figure 3: Mean serum phosphate levels after $1000 \mathrm{mg}$ FCM (V. Brandenburg, R. Stöhr, data on file)

These findings have highly relevant implications for heart failure therapy in serval ways: Physicians must determine if the observed derangements in FGF-23-phosphate metabolism may partly outweigh the beneficial effects of iron infusion in heart failure patients, particularly with repetitive dosing. These negative effects might emerge from noxious effects of high levels of intact FGF23 upon the myocardium (in the same way as hypothezied by Faul and coworkers (47)) and also from phosphate depletion which might impair energy metabolism via impaired ATP supply. Potential negative skeletal effects should also be assessed in case repetitive dosing has subsequent comparable effects. Based on our findings (61), we recommend monitoring of serum phosphate for 2 to 3 weeks after high-dosage FCM infusion in heart failure patients. 


\section{Vitamin K, calcification and calciphylaxis}

A second core area of the present thesis was the issue of vitamin $\mathrm{K}$ and its role in vascular calcification with unique insights into the rare disease calciphylaxis and first-in-man controlled prospective data on the ability of vitamin $\mathrm{K}$ to decrease vascular calcification progression.

The rationale of vitamin $\mathrm{K}$ science in cardiovascular disease emerges fom early genetic studies about MGP deficiency. The genetic deficiency modell of the MGP null-mouse clearly shows how important a functioning matrix-Gla protein system is for the integrety of the arterial wall (20). The MGP deficiency results in an ultra-fast vascular calcification phenotype which ends up in premature, early death due to fracturing of the aorta (20). This very dominant phenotype points towards the overwhelming importance of MGP for the integrity of the arterial wall and prevention of vascular calcification (20). This phenotype can be mimicked by the titrated application of vitamin $\mathrm{K}$ antagonists in rodents (13) and potentially also in humans (92). However, the application of VKA might actually even induce further consequences since additional proteins have been identified as being vitamin $\mathrm{K}$ depenendent such as osteocalcin, GAS6 or "Gla-rich protein“ (GRP, also known as cartilage matrix-associated protein (UCMA)) (93). There is obviously an important difference between the cogulation system and MGP in terms of amount of vitamin $\mathrm{K}$ needed to sufficiently activate these two systems. While bleeding disorders in adults virtually never occur due to a nutritional mal-supply of vitamin $\mathrm{K}$ (instead the most important causal factor for hemorrhage in adults is treatment with VKA) the MGP system is more susceptible. There is always a substantial amount of MGP circulating measurably in an un-carboxylated subfraction (ucMGP). This subfration is suggestive of a suboptimal natural (nutritional) supply in patients since it can be easily diminished with oral vitamin $K$ supply $(23 ; 37)$. This subfraction of UcMGP correlates positively with the amount of vascular calcification (94) fueling the hypothesis that circulating ucMGP levels actually reflect suboptimal local vitamin $\mathrm{K}$ activity in the vascular wall. In the last approximately 10 years, there has been growing evidence from animal experiments and human epidemiological and associative studies that vitamin $\mathrm{K}$ is important for vascular health (23). However, none of these studies could clearly prove causality in humans. Such proof can only be delivered by prospective interventional and randomized trials. It had previously been shown that vitamin $\mathrm{K}$ application can reduce the concentration of undercarboxylated MGP in the circulation (95), but the biological consequences had not yet been assessed. We were able to close this obvious gap in evidence via a prospective randomized trial. The study presented in this thesis assessed for the first time the potential biological consequences of vitamin $\mathrm{K}$ replenishment in humans (37). The study performed serial CT quantification of valvular calcification in patients with calcific aortic stenosis (37). This study can be considered the pilot first-in-man proof-of-concept study since it showed that the application of vitamin $\mathrm{K}$ over 12 months ( $2 \mathrm{mg}$ phytomedadione per day) significantly slowed the progression of valvular calcification in patients with calcific aortic stenosis (37). 
Figure 4 depicts the different progression of calcification levels in patients with vitamin $\mathrm{K}$ supply versus those with placebo.

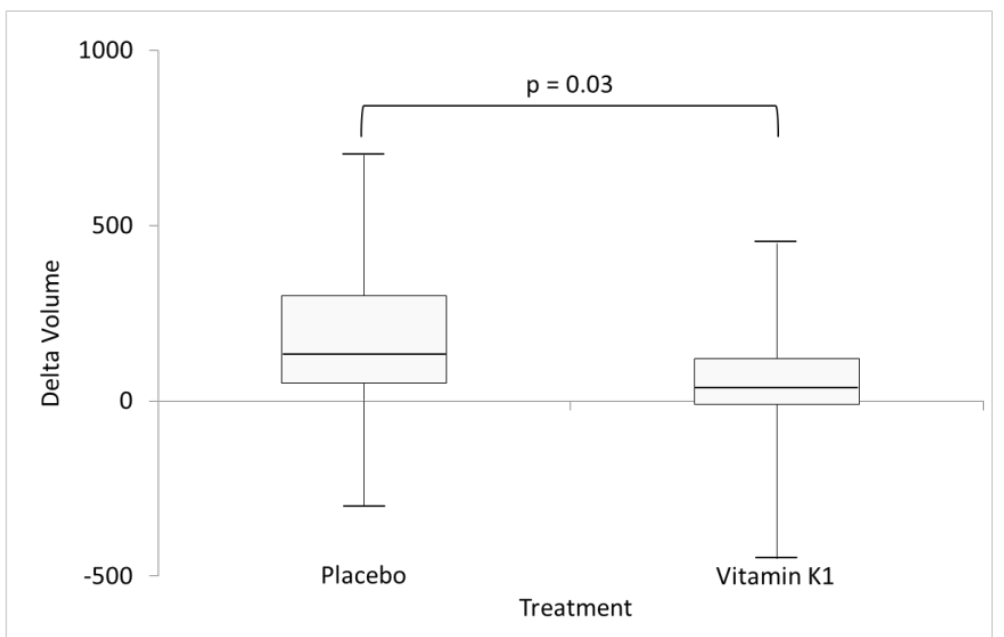

Figure 4: Calcification progression in patients with $2 \mathrm{mg}$ vitamin $\mathrm{K}$ daily versus placebo over 12 months (data from (37))

This result is of specifc interest since the severity of stenosis in the aortic valve is directly correlated to the amount of calcification, meaning that a rapid progression of calcification translates directly into a progressive hemodynamic impairment (96).

\section{Calciphylaxis}

Our better understanding of the association between vitamin $\mathrm{K}$ deficiency and the development of vascular calcification has a direct clinical impact in the rare disease calciphylaxis. Calciphylaxis primarily occurs in patients with severe or end-stage renal failure. As such, prospective and systematic data collection is difficult since the occurrence in patients is unpredictable. Hence, it is of utmost importance to consider alternative mezhods of data collection, which we accomplished through the German internet-based online registry which was later transferred to a European registry "EucalNet" (14). In the field of vascular calcification research, calciphylaxis can be considered as a high-speed template for calcification processes, which also tend to occur in the elderly, diabetic, or CKD population. Due to the rapid occurrence of calciphylaxis, it is tempting to speculate that analysis of risk factors underlying caliphylaxis might ultimately lead to the identification of risk factors involved in other vascular calcification diseases. Indeed, our results from calciphylaxis research point in this direction. Based on data obtained from the German registry, we could identify two important key messages: the potential role of disturbances in bone metabolism and the deleterious role of VKA treatment regarding the induction of vascular calcification (16). An appropriate bone metabolism is crucial for providing a sufficient mineral buffering capacity in the skeleton. If mineral deposition or 
release processes are deeply disturbed, such a buffering capacity might become inadequate, which renders the soft tissue susceptible for ectopic calcification. This is the theory behind the hypothesis that states of low bone turnover (a major portion of which are called adynamic bone disease) play a critical role in vascular calcification (9). Indeed, the German registry data point in the same direction. PTH levels were on average much lower in dialysis calciphylaxis patients than current dialysis patient guidelines recommend. Such low PTH levels might reflect suppressed bone turnover or even the co-existence of adynamic bone disease. Consequently, our recommendation, as summarized in (10), states that an intermediate PTH range $(150-300 \mathrm{pg} / \mathrm{ml})$ might be the optimal PTh range with regard to prevention of calciphylaxis.

A second dominant finding of our calciphylaxis registry is the confirmation of how strongly previous VKA usage associates with calciphylaxis. About $50 \%$ of calciphylaxis patients enlisted in our registry were on VKA prior to calciphylaxis development (16). These data underline previous findings of how prevalent VKA therapy in these patients is, and one study from Japan elaborated an odds ratio of around 10 for VKA usage inducing calciphylaxis compared to non-usage (97). In summary, merely observationally obtained calciphylaxis data strongly support experimental findings on the deleterious role of VKA and opposing beneficial effects of vitamin $\mathrm{K}$ in vascular calcification. These clinical and observational fingings represent the rationale for ongoing controlled interventional trials in calciphylaxis patients testing the hypothesis that vitamin $\mathrm{K}$ application can support a viable cure for the disease (see above in (10)). 


\section{d) \\ Dankwoord}

Science is nothing without teamplay. Numerous collaborators have supported my scientific efforts in the past with their valuable expertise and friendly support. Regarding the topics of this thesis, I'd like to thank especially those friends and collaborators who contributed to the projects in terms of planning, initiation and execution. I feel honored and pleased to have them all as co-authors in the corresponding publications!

Iris, you made it possible for me to spend endless hours with scientific work. I dedicate this thesis to you and our three wonderful children Franca, Lorenz, and Thea. 


\section{e) \\ Currciculum vitae}

Vincent Brandenburg was born in 1970 in Monschau Germany.

He is nephrologist and head of the department of nephrology at the Rhein-Maas Klinikum in Würselen, Germany. He was associate professor and senior consultant at the Department of Cardiology, University Hospital of the RWTH Aachen, Germany until 2018. In this position he was Consultant for the Intermediate Care Unit and Heart Failure outpatient clinic. He gained his medical degree in 1998 at the RWTH Aachen and the Ludwig-Maximilians University Munich, Germany. In 2005, he completed a two-year postdoctoral research period at the IZKF BioMAT, also at the University Hospital Aachen on the subject of the mechanism of extraosseous calcification in uremia. Dr Brandenburg then became a nephrologist at the Department of Nephrology, University Hospital Aachen (Head: Professor Jürgen Floege, MD) until 2009 before he started completing his educational program at the cardiology department. Dr Brandenburg is conducting clinical research on the pathophysiology and treatment of renal osteodystrophy, bone disease after renal transplantation, and cardiovascular calcification in chronic kidney disease. His basic research interests are mechanisms of cardiovascular disease in uremia with particular focus on vitamin $\mathrm{K}$ and oral anticoagulation. He is currently also conducting research about the role of alkaline phosphatase, fetuin-A, FGF23, cardiovascular effects of vitamin D and Wnt/beta-catenin signaling in the bone-vascular axis in uremia.

A major research target is calciphylaxis. He was also board member of the ERA-EDTA scientific working group "CKD-MBD" until 2017. As such, he is currently initiating a multinational European calciphylaxis registry "EuCalNet" for which he is principal investigator (www.calciphylaxis.net). Prof. Brandenburg is also principal investigator in several prospective human intervention trials investigating interventions against cardiovascular calcification progression. The clinical focus is the chronic cardio-renal syndrome. Dr Brandenburg has authored or co-authored over 160 articles in peer-reviewed journals. He is member of the German and European societies of nephrology and cardiology. 


\section{f) \\ List of publications}

\section{Original publications with leading authorship}

1. Stöhr R, Sandstede L, Heine GH, Marx N, Brandenburg V. High-Dose Ferric Carboxymaltose in Patients With HFrEF Induces Significant Hypophosphatemia. J Am Coll Cardiol. 2018 May 15; 71(19): 2270-2271.

2. Kaesler N, Verhulst A, De Maré A, Deck A, Behets GJ, Hyusein A, Evenepoel P,Floege J, Marx N, Babler A, Kramer I, Kneissel M, Kramann R, Weis D, D'Haese PC, Brandenburg VM. Sclerostin deficiency modifies the development of CKD-MBD in mice. Bone. 2018 Feb; 107: 115-123.

3. Brandenburg VM, Reinartz S, Kaesler N, Krüger T, Dirrichs T, Kramann R, Peeters F, Floege J, Keszei A, Marx N, Schurgers LJ, Koos R. Slower Progress of Aortic Valve Calcification With Vitamin K Supplementation: Results From a Prospective Interventional Proof-of-Concept Study. Circulation. 2017 May 23; 135(21): 2081-2083.

4. Brandenburg VM, Evenepoel P, Floege J, Goldsmith D, Kramann R, Massy Z, Mazzaferro S, Schurgers LJ, Sinha S, Torregrosa V, Ureña-Torres P, Vervloet $M$, Cozzolino M; ERA-EDTA Working Group on CKD-MBD and EUCALNET. Lack of evidence does not justify neglect: how can we address unmet medical needs in calciphylaxis? Nephrol Dial Transplant. 2016 Aug; 31(8): 1211-9.

5. Brandenburg VM, Kramann R, Rothe H, Kaesler N, Korbiel J, Specht P, Schmitz S, Krüger T, Floege J, Ketteler M. Calcific uraemic arteriolopathy (calciphylaxis): data from a large nationwide registry. Nephrol Dial Transplant. 2017 Jan 1; 32(1): 126-132.

6. Brandenburg VM, Kleber ME, Vervloet MG, Larsson TE, Tomaschitz A, Pilz S, Stojakovic T, Delgado G, Grammer TB, Marx N, März W, Scharnagl H. Soluble klotho and mortality: the Ludwigshafen Risk and Cardiovascular Health Study. Atherosclerosis. 2015 Oct; 242(2): 483-9.

7. Barros X, Dirrichs T, Koos R, Reinartz S, Kaesler N, Kramann R, Gladziwa U, Ketteler M, Floege J, Marx N, Torregrosa JV, Keszei A, Brandenburg VM. Epicardial adipose tissue in long-term hemodialysis patients: its association with vascular calcification and long-term development. J Nephrol. 2016 Apr; 29(2): 241-250.

8. Burgmaier $M$, Hoppe $S$, Krüger $T$, Mahnken AH, Ketteler M, Reith S, Mühlenbruch $G$, Marx N, Brandenburg V. Serum levels of C-peptide are associated with coronary artery calcification in patients with rheumatoid arthritis. Rheumatol Int. 2015 Sep; 35(9): 1541-7.

9. Brandenburg VM, Kleber ME, Vervloet MG, Tomaschitz A, Pilz S, Stojakovic T,Delgado G, Grammer TB, Marx N, März W, Scharnagl H. Fibroblast growth factor 23 (FGF23) 
and mortality: the Ludwigshafen Risk and Cardiovascular Health Study. Atherosclerosis. 2014 Nov; 237(1): 53-9.

10. Brandenburg VM, Kramann R, Koos R, Krüger T, Schurgers L, Mühlenbruch G, Hübner S, Gladziwa U, Drechsler C, Ketteler M. Relationship between sclerostin and cardiovascular calcification in hemodialysis patients: a cross-sectional study. BMC Nephrol. 2013 Oct 10; 14 :219. doi: 10.1186/1471-2369-14-219.

11. Drechsler C, Verduijn M, Pilz S, Krediet RT, Dekker FW, Wanner C, Ketteler M, Boeschoten EW, Brandenburg V; NECOSAD Study Group. Bone alkaline phosphatase and mortality in dialysis patients. Clin J Am Soc Nephrol. 2011 Jul; 6(7): 1752-9.

12. Drechsler C, Verduijn M, Pilz S, Dekker FW, Krediet RT, Ritz E, Wanner C, Boeschoten EW, Brandenburg V; NECOSAD Study Group. Vitamin D status and clinical outcomes in incident dialysis patients: results from the NECOSAD study. Nephrol Dial Transplant. 2011 Mar; 26(3): 1024-32.

13. Brandenburg VM, Schlieper G, Heussen N, Holzmann S, Busch B, Evenepoel P, Vanholder R, Meijers B, Meert N, Fassbender WJ, Floege J, Jahnen-Dechent W, Ketteler M. Serological cardiovascular and mortality risk predictors in dialysis patients receiving sevelamer: a prospective study. Nephrol Dial Transplant. 2010 Aug; 25(8): 2672-9.

\section{Original publications with co-authorship}

1. Trummer C, Schwetz V, Pandis M, Grübler MR, Verheyen N, Gaksch M, Zittermann A, März W, Aberer F, Steinkellner J, Friedl C, Brandenburg V, Voelkl J, Alesutan I, Obermayer-Pietsch B, Pieber TR, Tomaschitz A, Pilz S. Effects of vitamin D supplementation on FGF23: a randomized-controlled trial. Eur J Nutr. 2018 Mar 30.

2. Kulikowski E, Halliday C, Johansson J, Sweeney M, Lebioda K, Wong N, Haarhaus M, Brandenburg V, Beddhu S, Tonelli M, Zoccali C, Kalantar-Zadeh K. Apabetalone Mediated Epigenetic Modulation is Associated with Favorable Kidney Function and Alkaline Phosphatase Profile in Patients with Chronic Kidney Disease. Kidney Blood Press Res. 2018; 43(2): 449-457.

3. Baldewijns K, Bektas S, Boyne J, Rohde C, De Maesschalck L, De Bleser L, Brandenburg V, Knackstedt C, Devillé A, Sanders-Van Wijk S, Brunner La Rocca HP. Improving kNowledge Transfer to Efficaciously RAise the level of Contemporary Treatment in Heart Failure (INTERACT-in-HF): Study protocol of a mixed methods study. Int J Care Coord. 2017 Dec; 20(4): 171-182.

4. Hoffmann JM, Hellwig S, Brandenburg VM, Spaderna H. Measuring Fear of Physical Activity in Patients with Heart Failure. Int J Behav Med. 2018 Jun; 25(3): 294-303

5. Gingele AJ, Brunner-la Rocca H, Ramaekers B, Gorgels A, De Weerd G, Kragten J, van Empel V, Brandenburg V, Vrijhoef H, Cleuren G, Knackstedt C, Boyne JJ. Telemonitoring in patients with heart failure: Is there a long-term effect? J Telemed Telecare. 2017 [Epub ahead of print]

6. Wetzel J, Pilz S, Grübler MR, Fahrleitner-Pammer A, Dimai HP, von Lewinski D, Kolesnik E, Perl S, Trummer C, Schwetz V, Meinitzer A, Belyavskiy E, Völkl J, Catena C, Brandenburg V, März W, Pieske B, Brussee H, Tomaschitz A, Verheyen ND. Plasma 
parathyroid hormone and cardiovascular disease in treatment-naive patients with primary hyperparathyroidism: The EPATH trial. J Clin Hypertens (Greenwich). 2017 Nov; 19(11): 1173-1180.

7. Behets GJ, Viaene L, Meijers B, Blocki F, Brandenburg VM, Verhulst A, D'Haese PC, Evenepoel P. Circulating levels of sclerostin but not DKK1 associate with laboratory parameters of CKD-MBD. PLoS One. 2017 May 11; 12(5): e0176411.

8. Verheyen N, Fahrleitner-Pammer A, Pieske B, Meinitzer A, Belyavskiy E, Wetzel J, Gaksch M, Grübler MR, Catena C, Sechi LA, Van Ballegooijen AJ, Brandenburg VM, Scharnagl H, Perl S, Brussee H, März W, Pilz S, Tomaschitz A. Parathyroid hormone, aldosterone-to-renin ratio and fibroblast growth factor-23 as determinants of nocturnal blood pressure in primary hyperparathyroidism: the eplerenone in primary hyperparathyroidism trial. J Hypertens. 2016 Sep; 34(9): 1778-86.

9. Ernst JB, Zittermann A, Pilz S, Kleber ME, Scharnagl H, Brandenburg VM, König W, Grammer TB, März W. Independent associations of vitamin D metabolites with anemia in patients referred to coronary angiography: the LURIC study. Eur J Nutr. 2017 Apr; 56(3): 1017-1024.

10. de Roij van Zuijdewijn CL, Grooteman MP, Bots ML, Blankestijn PJ, Steppan S, Büchel J, Groenwold RH, Brandenburg V, van den Dorpel MA, Ter Wee PM, Nubé MJ, Vervloet MG. Serum Magnesium and Sudden Death in European Hemodialysis Patients. PLoS One. 2015 Nov 23; 10(11): e0143104.

11. Koller $L$, Kleber ME, Brandenburg VM, Goliasch $G$, Richter $B$, Sulzgruber $P$, Scharnagl $H$, Silbernagel G, Grammer TB, Delgado G, Tomaschitz A, Pilz S, Berger R, Mörtl D, Hülsmann M, Pacher R, März W, Niessner A. Fibroblast Growth Factor 23 Is an Independent and Specific Predictor of Mortality in Patients With Heart Failure and Reduced Ejection Fraction. Circ Heart Fail. 2015 Nov; 8(6): 1059-67.

12. Tomaschitz A, Pilz S, Rus-Machan J, Meinitzer A, Brandenburg VM, Scharnagl H, Kapl M, Grammer T, Ritz E, Horina JH, Kleber ME, Pieske B, Kraigher-Krainer E, Hartaigh BÓ, Toplak H, van Ballegooijen AJ, Amrein K, Fahrleitner-Pammer A, März W. Interrelated aldosterone and parathyroid hormone mutually modify cardiovascular mortality risk. Int J Cardiol. 2015 Apr 1; 184: 710-6.

13. Kramann R, Erpenbeck J, Schneider RK, Röhl AB, Hein M, Brandenburg VM, van Diepen M, Dekker F, Marx N, Floege J, Becker M, Schlieper G. Speckle tracking echocardiography detects uremic cardiomyopathy early and predicts cardiovascular mortality in ESRD. J Am Soc Nephrol. 2014 Oct; 25(10): 2351-65.

14. Kaesler N, Magdeleyns E, Herfs M, Schettgen T, Brandenburg V, Fliser D, Vermeer C, Floege J, Schlieper G, Krüger T. Impaired vitamin K recycling in uremia is rescued by vitamin K supplementation. Kidney Int. 2014 Aug; 86(2): 286-93.

15. Koos R, Brandenburg V, Mahnken AH, Schneider R, Dohmen G, Autschbach R, Marx N, Kramann R. Sclerostin as a potential novel biomarker for aortic valve calcification: an in-vivo and ex-vivo study. J Heart Valve Dis. 2013 May; 22(3): 317-25.

16. Krüger T, Oelenberg $S$, Kaesler N, Schurgers $L$, van de Sandt AM, Boor P, Schlieper G, Brandenburg VM, Fekete BC, Veulemans V, Ketteler M, Vermeer C, Jahnen-Dechent W, Floege J, Westenfeld R. Warfarin induces cardiovascular damage in mice. Arterioscler Thromb Vasc Biol. 2013 Nov; 33(11): 2618-24. 
17. Kramann R, Brandenburg VM, Schurgers LJ, Ketteler M, Westphal S, Leisten I, Bovi M, Jahnen-Dechent W, Knüchel R, Floege J, Schneider RK. Novel insights into osteogenesis and matrix remodelling associated with calcific uraemic arteriolopathy. Nephrol Dial Transplant. 2013 Apr; 28(4): 856-68.

18. Marx N, Silbernagel G, Brandenburg V, Burgmaier M, Kleber ME, Grammer TB, Winkelmann BR, Boehm BO, März W. C-peptide levels are associated with mortality and cardiovascular mortality in patients undergoing angiography: the LURIC study. Diabetes Care. 2013 Mar; 36(3): 708-14.

19. Kramann R, Frank D, Brandenburg VM, Heussen N, Takahama J, Krüger T, Riehl J, Floege J. Prognostic impact of renal arterial resistance index upon renal allograft survival: the time point matters. Nephrol Dial Transplant. 2012 Oct; 27(10): 3958-63.

20. Westenfeld R, Schlieper G, Wöltje M, Gawlik A, Brandenburg V, Rutkowski P, Floege J, Jahnen-Dechent $W$, Ketteler $M$. Impact of sirolimus, tacrolimus and mycophenolate mofetil on osteoclastogenesis--implications for post-transplantation bone disease. Nephrol Dial Transplant. 2011 Dec; 26(12): 4115-23.

21. Schlieper G, Westenfeld R, Krüger T, Cranenburg EC, Magdeleyns EJ, Brandenburg VM, Djuric Z, Damjanovic T, Ketteler M, Vermeer C, Dimkovic N, Floege J, Schurgers LJ. Circulating nonphosphorylated carboxylated matrix gla protein predicts survival in ESRD. J Am Soc Nephrol. 2011 Feb; 22(2): 387-95.

22. Noordzij M, Cranenburg EM, Engelsman LF, Hermans MM, Boeschoten EW, Brandenburg VM, Bos WJ, Kooman JP, Dekker FW, Ketteler M, Schurgers LJ, Krediet RT, Korevaar JC; NECOSAD Study Group. Progression of aortic calcification is associated with disorders of mineral metabolism and mortality in chronic dialysis patients. Nephrol Dial Transplant. 2011 May; 26(5): 1662-9.

23. Parker BD, Schurgers LJ, Brandenburg VM, Christenson RH, Vermeer C, Ketteler $M$, Shlipak MG, Whooley MA, Ix JH. The associations of fibroblast growth factor 23 and uncarboxylated matrix Gla protein with mortality in coronary artery disease: the Heart and Soul Study. Ann Intern Med. 2010 May 18; 152(10): 640-8.

\section{Review articles, case reports, editorials with leading authorship}

1. Brandenburg VM, Verhulst A, Babler A, D'Haese PC, Evenepoel P, Kaesler N. Sclerostin in chronic kidney disease-mineral bone disorder think first before you block it! Nephrol Dial Transplant. 2018 May 24.

2. Nigwekar SU, Thadhani R, Brandenburg VM. Calciphylaxis. N Engl J Med. 2018 May 3; 378(18): 1704-1714. doi: 10.1056/NEJMra1505292. Review. PubMed PMID: 29719190.

3. Brandenburg VM, Sinha S. Calciphylaxis: Another Piece of the Puzzle. Am J Nephrol. 2017; 46(5): 427-428.

4. Vervloet MG, Brandenburg VM; CKD-MBD working group of ERA-EDTA. Circulating markers of bone turnover. J Nephrol. 2017 Oct; 30(5): 663-670. doi:10.1007/s40620017-0408-8. Epub 2017 May 13.

5. Heine GH, Brandenburg V. Anticoagulation, atrial fibrillation, and chronic kidney disease-whose side are you on? Kidney Int. 2017 Apr ;91(4): 778-780. 
6. Ketteler M, Brandenburg VM. K-alcification Protection in Dialysis Patients: The Underestimated Phenomenon of Vitamin K Deficiency. J Am Soc Nephrol. 2017 Jun; 28(6): 1667-1668.

7. Brandenburg V, Adragao $T$, van Dam B, Evenepoel $P$, Frazão JM, Ketteler $M$, Mazzaferro S, Urena Torres P, Ramos R, Torregrosa JV, Cozzolino M. Blueprint for a European calciphylaxis registry initiative: the European Calciphylaxis Network (EuCalNet). Clin Kidney J. 2015 Oct; 8(5): 567-71.

8. Evenepoel P, D'Haese P, Brandenburg V. Sclerostin and DKK1: new players in renal bone and vascular disease. Kidney Int. 2015 Aug; 88(2): 235-40.

9. Brandenburg VM, Schurgers LJ, Kaesler N, Püsche K, van Gorp RH, Leftheriotis G, Reinartz S, Koos R, Krüger $T$. Prevention of vasculopathy by vitamin $\mathrm{K}$ supplementation: can we turn fiction into fact? Atherosclerosis. 2015 May; 240(1): 10-6.

10. Brandenburg VM, D'Haese P, Deck A, Mekahli D, Meijers B, Neven E, Evenepoel P. From skeletal to cardiovascular disease in 12 steps-the evolution of sclerostin as a major player in CKD-MBD. Pediatr Nephrol. 2016 Feb; 31(2): 195-206.

11. Brandenburg VM, Martin H, Sohn CM, Ketteler M. [Calciphylaxis]. Dtsch Med Wochenschr. 2015 Mar; 140(5): 347-51.

12. Brandenburg VM, Cozzolino M, Mazzaferro S. Calcific uremic arteriolopathy: a call for action. Semin Nephrol. 2014 Nov; 34(6): 641-7.

13. Brandenburg VM, Sinha $S$, Specht $P$, Ketteler M. Calcific uraemic arteriolopathy: a rare disease with a potentially high impact on chronic kidney disease-mineral and bone disorder. Pediatr Nephrol. 2014 Dec; 29(12): 2289-98.

14. Brandenburg VM, Kruger T. Calcifediol - more than the stepchild of CKD-MBD therapy? Curr Vasc Pharmacol. 2014 Mar; 12(2): 286-93.

15. Brandenburg V, Al-Fakhri N, Nemeth K, Goettsch C, Schurgers L, Vermeer C, Hofbauer LC, Schoppet M. Calcification inhibitors in vascular calciphylaxis associated with normal renal function. Thromb Haemost. 2012 Dec; 108(6): 1241-3.

16. Kramann R, Floege J, Ketteler M, Marx N, Brandenburg VM. Medical options to fight mortality in end-stage renal disease: a review of the literature. Nephrol Dial Transplant. 2012 Dec; 27(12): 4298-307.

17. Brandenburg VM, Vervloet MG, Marx N. The role of vitamin D in cardiovascular disease: from present evidence to future perspectives. Atherosclerosis. $2012 \mathrm{Dec}$; 225(2): 253-63.

18. Brandenburg VM, Kramann R, Specht $P$, Ketteler M. Calciphylaxis in CKD and beyond. Nephrol Dial Transplant. 2012 Apr; 27(4): 1314-8.

19. Brandenburg VM, Cozzolino M, Ketteler M. Calciphylaxis: a still unmet challenge. J Nephrol. 2011 Mar-Apr; 24(2): 142-8.

20. Cozzolino M, Mazzaferro S, Brandenburg V. The treatment of hyperphosphataemia in CKD: calcium-based or calcium-free phosphate binders? Nephrol Dial Transplant. 2011 Feb; 26(2): 402-7.

21. Brandenburg VM, Jahnen-Dechent W, Ketteler M. Sevelamer and the bone-vascular axis in chronic kidney disease: bone turnover, inflammation, and calcification regulation. Kidney Int Suppl. 2009 Dec; (114): S26-33. 
22. Cozzolino M, Brandenburg V. Paricalcitol and outcome: a manual on how a vitamin D receptor activator (VDRA) can help us to get down the "U". Clin Nephrol. 2009 Jun; 71(6): 593-601. Review. Erratum in: Clin Nephrol. 2009 Jul; 72(1): 82. PubMed PMID: 19473626. 


\section{g) \\ Valorization Addendum}

The following chapter will briefly describe which impact the thesis will have in terms of novel products, processes or services that are relevant for the society.

\section{1) Relevance: What are the economical and societal implications of the}

\section{results?}

The projects mentioned in the present thesis have significant implications for the present times regarding patient care. They lay the basis for future projects (see below) that have the potential to create data with also economical as well as societal implications.

2) Target groups: Are the results of interest zo somebody beyond the medical world?

Obviously, results from medical trials do have the largest impact upon affected patients and their caregivers. However, I would like to mention specifically two issues from the thesis, where the projects itself and / or the results might influence a broader community or even societal structures. That is on one hand the issue of centralized data collection for patients with rare disease. We consider the internet-based structures implemented, tested and validated for the Germany calciphylaxis registry and later for the European Calciphylaxis netwetwork "EuCalNet" www.calciphylaxis.net as a template for other rare diseases which do not allow transferring affected patients to a central study site. Moreover, successfully addressing unmet medical needs in a prototypic rare disease such as calciphylaxis and sharing experiences about the project with other caregivers as well as societal structures might directly affect the motivation and the success to copy this approach in other rare diseases. Often patients with rare diseases suffer from a dismal lack of evidence-based treatment options since the hurdles for creating sich evidence have been overwhelming.

On the other hand I would like to mention the potential impact of evaluating health benefits of vitamin $\mathrm{K}$ for braod parts of the society. Since vitamin $\mathrm{K}$ is an easily available component of nutrition studies pinpointing cardiovascular health benefits of high vitamin $\mathrm{K}$ intake can lay the basis for future projects evaluating the rationale to use high nutritional vitamin $\mathrm{K}$ intake as primary prevention. Such data could substantially influence future recommendations about healthy nutrition facing the fact that calcifying arteriosclerosis is an endemic disease. 
3) Activities / products: Are there any specific products, processes, activities where the results are beingh applied?

The topics covered by the recent thesis have stimulated ongoing international research efforts. I would like to specifically point towards planned as well as already recruiting trials in the field of iron-induced osteomalacia (head-to-head randomized controlled trial scheduled in 2018) as well as vascular calcification (ClinicalTrials.gov Identifier: NCT02066662: "Rivaroxaban Compared to Vitamin K Antagonist Upon Development of Cardiovascular Calcification"). These trials have the potential to modify guideline recommendations regarding optimal treatment choice and need for monitoring which could increase both efficacy as well as safety.

\section{4) Innovation: to what extend are those innovative in comparison to existing} options?

In this regard the structures of "Eucalnet" can be considered as an innovative approach since the way data are collected and validated may be used a template for future activities. Such an approach can help identifying patients, establishing experts'networks and optimizing patient care for many other rare diseases. Moreover, the innovations realized with EuCalNet (ClinicalTrials.gov Identifier: NCT02635373) have laid the foundation for performing prospective trials in the field (ClinicalTrials.gov Identifier: NCT02790073) which would be virtually impossible without a sufficient network basis.

5) Planning and realization: What are the actual plans for the valirization process, what are the risks, costs and chances?

We have not yet established a roadmap for a systematic valorization process. However, above mentioned implications for future projects e.g. via providing the rationale and fascilitating the progress have the potential to add additional value. 


\section{h) \\ Literature}

(1) Go AS, Chertow GM, Fan D, McCulloch CE, Hsu CY. Chronic kidney disease and the risks of death, cardiovascular events, and hospitalization. N Engl J Med 2004; 351(13): 12961305.

(2) Foley RN, Murray AM, Li S, Herzog CA, McBean AM, Eggers PW, Collins AJ. Chronic kidney disease and the risk for cardiovascular disease, renal replacement, and death in the United States Medicare population, 1998 to 1999. J Am Soc Nephrol 2005; 16(2): 489-495.

(3) Fox CS, Matsushita K, Woodward M, Bilo HJ, Chalmers J, Heerspink HJ, Lee BJ, Perkins RM, Rossing P, Sairenchi T, Tonelli M, Vassalotti JA, Yamagishi K, Coresh J, de Jong PE, Wen $\mathrm{CP}$, Nelson RG. Associations of kidney disease measures with mortality and end-stage renal disease in individuals with and without diabetes: a meta-analysis. Lancet 2012; 380(9854): 1662-1673.

(4) Ortiz A, Covic A, Fliser D, Fouque D, Goldsmith D, Kanbay M, Mallamaci F, Massy ZA, Rossignol P, Vanholder R, Wiecek A, Zoccali C, London GM. Epidemiology, contributors to, and clinical trials of mortality risk in chronic kidney failure. Lancet 2014; 383(9931): 18311843.

(5) Cozzolino M, Urena-Torres P, Vervloet MG, Brandenburg V, Bover J, Goldsmith D, Larsson TE, Massy ZA, Mazzaferro $S$. Is chronic kidney disease-mineral bone disorder (CKDMBD) really a syndrome? Nephrol Dial Transplant 2014; 29(10): 1815-1820.

(6) Wanner C, Krane V, Marz W, Olschewski M, Mann JF, Ruf G, Ritz E. Atorvastatin in patients with type 2 diabetes mellitus undergoing hemodialysis. N Engl J Med 2005; 353(3): 238-248.

(7) Covic A, Vervloet M, Massy ZA, Torres PU, Goldsmith D, Brandenburg V, Mazzaferro S, Evenepoel P, Bover J, Apetrii M, Cozzolino M. Bone and mineral disorders in chronic kidney disease: implications for cardiovascular health and ageing in the general population. Lancet Diabetes Endocrinol 2018; 6(4): 319-331.

(8) Ketteler M, Westenfeld R, Schlieper G, Brandenburg V. Pathogenesis of vascular calcification in dialysis patients. Clin Exp Nephrol 2005; 9(4): 265-270. 
(9) Bover J, Urena P, Brandenburg V, Goldsmith D, Ruiz C, DaSilva I, Bosch RJ. Adynamic bone disease: from bone to vessels in chronic kidney disease. Semin Nephrol 2014; 34(6): 626-640.

(10) Nigwekar SU, Thadhani R, Brandenburg VM. Calciphylaxis. N Engl J Med 2018; 378(18): 1704-1714.

(11) Dobry AS, Ko LN, St John J, Sloan JM, Nigwekar S, Kroshinsky D. Association Between Hypercoagulable Conditions and Calciphylaxis in Patients With Renal Disease: A CaseControl Study. JAMA Dermatol 2018; 154(2): 182-187.

(12) Krueger T, Westenfeld R, Schurgers L, Brandenburg V. Coagulation meets calcification: the vitamin K system. Int J Artif Organs 2009; 32(2): 67-74.

(13) Kruger T, Oelenberg S, Kaesler N, Schurgers LJ, van de Sandt AM, Boor P, Schlieper G, Brandenburg VM, Fekete BC, Veulemans V, Ketteler M, Vermeer C, Jahnen-Dechent W, Floege J, Westenfeld R. Warfarin induces cardiovascular damage in mice. Arterioscler Thromb Vasc Biol 2013; 33(11): 2618-2624.

(14) Brandenburg V, Adragao T, van Dam B, Evenepoel P, Frazao JM, Ketteler M, Mazzaferro S, Urena TP, Ramos R, Torregrosa JV, Cozzolino M. Blueprint for a European calciphylaxis registry initiative: the European Calciphylaxis Network (EuCalNet). Clin Kidney J 2015; 8(5): 567-571.

(15) Brandenburg VM, Sinha S, Specht P, Ketteler M. Calcific uraemic arteriolopathy: a rare disease with a potentially high impact on chronic kidney disease-mineral and bone disorder. Pediatr Nephrol 2014.

(16) Brandenburg VM, Kramann R, Rothe H, Kaesler N, Korbiel J, Specht P, Schmitz S, Kruger T, Floege J, Ketteler M. Calcific uraemic arteriolopathy (calciphylaxis): data from a large nationwide registry. Nephrol Dial Transplant 2017; 32(1): 126-132.

(17) Schurgers LJ, Spronk HM, Skepper JN, Hackeng TM, Shanahan CM, Vermeer C, Weissberg PL, Proudfoot D. Post-translational modifications regulate matrix Gla protein function: importance for inhibition of vascular smooth muscle cell calcification. J Thromb Haemost 2007; 5(12): 2503-2511.

(18) Vermeer C. Vitamin K: the effect on health beyond coagulation - an overview. Food Nutr Res 2012; 56.

(19) Geleijnse JM, Vermeer C, Grobbee DE, Schurgers LJ, Knapen MH, van dM, I, Hofman A, Witteman JC. Dietary intake of menaquinone is associated with a reduced risk of coronary heart disease: the Rotterdam Study. J Nutr 2004; 134(11): 3100-3105. 
(20) Luo G, Ducy P, McKee MD, Pinero GJ, Loyer E, Behringer RR, Karsenty G. Spontaneous calcification of arteries and cartilage in mice lacking matrix GLA protein. Nature 1997; 386(6620): 78-81.

(21) Price PA, Faus SA, Williamson MK. Warfarin causes rapid calcification of the elastic lamellae in rat arteries and heart valves. Arterioscler Thromb Vasc Biol 1998; 18(9): 14001407.

(22) Murshed M, Schinke T, McKee MD, Karsenty G. Extracellular matrix mineralization is regulated locally; different roles of two gla-containing proteins. J Cell Biol 2004; 165(5): 625-630.

(23) Brandenburg VM, Schurgers LJ, Kaesler N, Pusche K, van Gorp RH, Leftheriotis G, Reinartz S, Koos R, Kruger T. Prevention of vasculopathy by vitamin $\mathrm{K}$ supplementation: can we turn fiction into fact? Atherosclerosis 2015; 240(1): 10-16.

(24) Schurgers LJ, Spronk HM, Soute BA, Schiffers PM, DeMey JG, Vermeer C. Regression of warfarin-induced medial elastocalcinosis by high intake of vitamin $\mathrm{K}$ in rats. Blood 2007; 109(7): 2823-2831.

(25) Rattazzi M, Faggin E, Bertacco E, Nardin C, Pagliani L, Plebani M, Cinetto F, Guidolin D, Puato M, Pauletto P. Warfarin, but not Rivaroxaban, promotes the calcification of the aortic valve in ApoE-/- mice. Cardiovasc Ther 2018; e12438.

(26) Tsai MT, Chen YY, Chang WJ, Li SY. Warfarin accelerated vascular calcification and worsened cardiac dysfunction in remnant kidney mice. J Chin Med Assoc 2018; 81(4): 324330.

(27) Andrews J, Psaltis PJ, Bartolo BAD, Nicholls SJ, Puri R. Coronary arterial calcification: A review of mechanisms, promoters and imaging. Trends Cardiovasc Med 2018.

(28) Moncada RM, Venta LA, Venta ER, Fareed J, Walenga JM, Messmore HL. Tracheal and bronchial cartilaginous rings: warfarin sodium-induced calcification. Radiology 1992; 184(2): 437-439.

(29) Weijs B, Blaauw Y, Rennenberg RJ, Schurgers LJ, Timmermans CC, Pison L, Nieuwlaat R, Hofstra L, Kroon AA, Wildberger J, Crijns HJ. Patients using vitamin K antagonists show increased levels of coronary calcification: an observational study in low-risk atrial fibrillation patients. Eur Heart J 2011; 32(20): 2555-2562.

(30) Koos R, Mahnken AH, Muhlenbruch G, Brandenburg V, Pflueger B, Wildberger JE, Kuhl HP. Relation of oral anticoagulation to cardiac valvular and coronary calcium assessed by multislice spiral computed tomography. Am J Cardiol 2005; 96(6): 747-749. 
(31) Lerner RG, Aronow WS, Sekhri A, Palaniswamy C, Ahn C, Singh T, Sandhu R, McClung JA. Warfarin use and the risk of valvular calcification. J Thromb Haemost 2009; 7(12): 20232027.

(32) Brandenburg VM, Sinha S, Specht P, Ketteler M. Calcific uraemic arteriolopathy: a rare disease with a potentially high impact on chronic kidney disease-mineral and bone disorder. Pediatr Nephrol 2014.

(33) Palaniswamy C, Aronow WS, Sekhri A, Adapa S, Ahn C, Singh T, Malhotra B, Lerner R. Warfarin use and prevalence of coronary artery calcification assessed by multislice computed tomography. Am J Ther 2014; 21(3): 148-151.

(34) Villines TC, O'Malley PG, Feuerstein IM, Thomas S, Taylor AJ. Does prolonged warfarin exposure potentiate coronary calcification in humans? Results of the warfarin and coronary calcification study. Calcif Tissue Int 2009; 85(6): 494-500.

(35) Schurgers LJ, Spronk HM. Differential cellular effects of old and new oral anticoagulants: consequences to the genesis and progression of atherosclerosis. Thromb Haemost 2014; 112(5).

(36) Schurgers LJ, Joosen IA, Laufer EM, Chatrou ML, Herfs M, Winkens MH, Westenfeld R, Veulemans V, Krueger T, Shanahan CM, Jahnen-Dechent W, Biessen E, Narula J, Vermeer C, Hofstra L, Reutelingsperger CP. Vitamin K-antagonists accelerate atherosclerotic calcification and induce a vulnerable plaque phenotype. PLoS One 2012; 7(8): e43229.

(37) Brandenburg VM, Reinartz S, Kaesler N, Kruger T, Dirrichs T, Kramann R, Peeters F, Floege J, Keszei A, Marx N, Schurgers LJ, Koos R. Slower Progress of Aortic Valve Calcification With Vitamin K Supplementation: Results From a Prospective Interventional Proof-of-Concept Study. Circulation 2017; 135(21): 2081-2083.

(38) Middleton RJ, Parfrey PS, Foley RN. Left ventricular hypertrophy in the renal patient. J Am Soc Nephrol 2001; 12(5): 1079-1084.

(39) Wolf M. Update on fibroblast growth factor 23 in chronic kidney disease. Kidney Int 2012; 82(7): 737-747.

(40) Erben RG. Physiological Actions of Fibroblast Growth Factor-23. Front Endocrinol (Lausanne) 2018; 9: 267.

(41) Richter B, Faul C. FGF23 Actions on Target Tissues-With and Without Klotho. Front Endocrinol (Lausanne) 2018; 9: 189.

(42) Jonsson KB, Zahradnik R, Larsson T, White KE, Sugimoto T, Imanishi Y, Yamamoto T, Hampson G, Koshiyama H, Ljunggren O, Oba K, Yang IM, Miyauchi A, Econs MJ, Lavigne J, 
Juppner H. Fibroblast growth factor 23 in oncogenic osteomalacia and X-linked hypophosphatemia. N Engl J Med 2003; 348(17): 1656-1663.

(43) Larsson T, Nisbeth U, Ljunggren O, Juppner H, Jonsson KB. Circulating concentration of FGF-23 increases as renal function declines in patients with chronic kidney disease, but does not change in response to variation in phosphate intake in healthy volunteers. Kidney Int 2003; 64(6):2272-2279.

(44) Gutierrez OM, Mannstadt M, Isakova T, Rauh-Hain JA, Tamez H, Shah A, Smith K, Lee $H$, Thadhani R, Juppner $H$, Wolf $M$. Fibroblast growth factor 23 and mortality among patients undergoing hemodialysis. N Engl J Med 2008; 359(6): 584-592.

(45) Parker BD, Schurgers LJ, Brandenburg VM, Christenson RH, Vermeer C, Ketteler M, Shlipak MG, Whooley MA, Ix JH. The associations of fibroblast growth factor 23 and uncarboxylated matrix Gla protein with mortality in coronary artery disease: the Heart and Soul Study. Ann Intern Med 2010; 152(10): 640-648.

(46) Olauson H, Vervloet MG, Cozzolino M, Massy ZA, Urena TP, Larsson TE. New Insights Into the FGF23-Klotho Axis. Semin Nephrol 2014; 34(6): 586-597.

(47) Faul C, Amaral AP, Oskouei B, Hu MC, Sloan A, Isakova T, Gutierrez OM, Aguillon-Prada R, Lincoln J, Hare JM, Mundel P, Morales A, Scialla J, Fischer M, Soliman EZ, Chen J, Go AS, Rosas SE, Nessel L, Townsend RR, Feldman HI, St John SM, Ojo A, Gadegbeku C, Di Marco GS, Reuter S, Kentrup D, Tiemann K, Brand M, Hill JA, Moe OW, Kuro O, Kusek JW, Keane MG, Wolf M. FGF23 induces left ventricular hypertrophy. J Clin Invest 2011; 121(11): 43934408.

(48) Andrukhova O, Slavic S, Odorfer KI, Erben RG. Experimental Myocardial Infarction Upregulates Circulating Fibroblast Growth Factor-23. J Bone Miner Res 2015; 30(10): 18311839.

(49) Brandenburg VM, Kleber ME, Vervloet MG, Tomaschitz A, Pilz S, Stojakovic T, Delgado G, Grammer TB, Marx N, Marz W, Scharnagl H. Fibroblast growth factor 23 (FGF23) and mortality: The Ludwigshafen Risk and Cardiovascular Health Study. Atherosclerosis 2014; 237(1): 53-59.

(50) Brandenburg VM, Kleber ME, Vervloet MG, Larsson TE, Tomaschitz A, Pilz S, Stojakovic T, Delgado G, Grammer TB, Marx N, Marz W, Scharnagl H. Soluble klotho and mortality: the Ludwigshafen Risk and Cardiovascular Health Study. Atherosclerosis 2015; 242(2): 483-489.

(51) Wallquist C, Mansouri L, Norrback M, Hylander B, Jacobson SH, Larsson TE, Lundahl J. Associations of Fibroblast Growth Factor 23 with Markers of Inflammation and Leukocyte Transmigration in Chronic Kidney Disease. Nephron 2018; 138(4): 287-295. 
(52) Agoro R, Montagna A, Goetz R, Aligbe O, Singh G, Coe LM, Mohammadi M, Rivella S, Sitara D. Inhibition of fibroblast growth factor 23 (FGF23) signaling rescues renal anemia. FASEB J 2018; fj201700667R.

(53) Glosse P, Fajol A, Hirche F, Feger M, Voelkl J, Lang F, Stangl GI, Foller M. A high-fat diet stimulates fibroblast growth factor 23 formation in mice through TNFalpha upregulation. Nutr Diabetes 2018; 8(1): 36.

(54) Tsai WC, Wu HY, Peng YS, Hsu SP, Chiu YL, Chen HY, Yang JY, Ko MJ, Pai MF, Tu YK, Hung KY, Chien KL. Effects of lower versus higher phosphate diets on fibroblast growth factor-23 levels in patients with chronic kidney disease: a systematic review and metaanalysis. Nephrol Dial Transplant 2018.

(55) Agoro R, Montagna A, Goetz R, Aligbe O, Singh G, Coe LM, Mohammadi M, Rivella S, Sitara D. Inhibition of fibroblast growth factor 23 (FGF23) signaling rescues renal anemia. FASEB J 2018; fj201700667R.

(56) Nam KH, Kim H, An SY, Lee M, Cha MU, Park JT, Yoo TH, Lee KB, Kim YH, Sung SA, Lee J, Kang SW, Choi KH, Ahn C, Han SH. Circulating Fibroblast Growth Factor-23 Levels are Associated with an Increased Risk of Anemia Development in Patients with Nondialysis Chronic Kidney Disease. Sci Rep 2018; 8(1): 7294.

(57) Zoller H, Schaefer B, Glodny B. Iron-induced hypophosphatemia: an emerging complication. Curr Opin Nephrol Hypertens 2017; 26(4): 266-275.

(58) Bishay RH, Ganda K, Seibel MJ. Long-term iron polymaltose infusions associated with hypophosphataemic osteomalacia: a report of two cases and review of the literature. Ther Adv Endocrinol Metab 2017; 8(1-2): 14-19.

(59) Ponikowski P, Voors AA, Anker SD, Bueno H, Cleland JG, Coats AJ, Falk V, GonzalezJuanatey JR, Harjola VP, Jankowska EA, Jessup M, Linde C, Nihoyannopoulos P, Parissis JT, Pieske B, Riley JP, Rosano GM, Ruilope LM, Ruschitzka F, Rutten FH, van der MP. 2016 ESC Guidelines for the diagnosis and treatment of acute and chronic heart failure: The Task Force for the diagnosis and treatment of acute and chronic heart failure of the European Society of Cardiology (ESC). Developed with the special contribution of the Heart Failure Association (HFA) of the ESC. Eur J Heart Fail 2016; 18(8): 891-975.

(60) Leistner DM, Seeger FH, Fischer A, Roxe T, Klotsche J, lekushi K, Seeger T, Assmus B, Honold J, Karakas M, Badenhoop K, Frantz S, Dimmeler S, Zeiher AM. Elevated levels of the mediator of catabolic bone remodeling RANKL in the bone marrow environment link chronic heart failure with osteoporosis. Circ Heart Fail 2012; 5(6): 769-777. 
(61) Stohr R, Sandstede L, Heine GH, Marx N, Brandenburg V. High-Dose Ferric Carboxymaltose in Patients With HFrEF Induces Significant Hypophosphatemia. J Am Coll Cardiol 2018; 71(19): 2270-2271.

(62) Silver J, Naveh-Many T. FGF-23 and secondary hyperparathyroidism in chronic kidney disease. Nat Rev Nephrol 2013; 9(11): 641-649.

(63) Brandenburg VM, Ketteler M, Frank RD, Schmitt H, Floege J, Behler CM, Riehl J. Bone pain with scintigraphy suggestive of widespread metastases--do not forget phosphate. Nephrol Dial Transplant 2002; 17(3): 504-507.

(64) Vervloet MG, Massy ZA, Brandenburg VM, Mazzaferro S, Cozzolino M, Urena-Torres P, Bover J, Goldsmith D. Bone: a new endocrine organ at the heart of chronic kidney disease and mineral and bone disorders. Lancet Diabetes Endocrinol 2014; 2(5): 427-436.

(65) Brandenburg VM, Vervloet MG, Marx N. The role of vitamin D in cardiovascular disease: from present evidence to future perspectives. Atherosclerosis 2012; 225(2): 253263.

(66) Leifheit-Nestler M, Haffner D. Paracrine Effects of FGF23 on the Heart. Front Endocrinol (Lausanne) 2018; 9: 278.

(67) Scialla JJ, Xie H, Rahman M, Anderson AH, Isakova T, Ojo A, Zhang X, Nessel L, Hamano T, Grunwald JE, Raj DS, Yang W, He J, Lash JP, Go AS, Kusek JW, Feldman H, Wolf M. Fibroblast Growth Factor-23 and Cardiovascular Events in CKD. J Am Soc Nephrol 2013; 25(2): 349-360.

(68) Plischke M, Neuhold S, Adlbrecht C, Bielesz B, Shayganfar S, Bieglmayer C, Szekeres T, Horl WH, Strunk G, Vavken P, Pacher R, Hulsmann M. Inorganic phosphate and FGF-23 predict outcome in stable systolic heart failure. Eur J Clin Invest 2012; 42(6): 649-656.

(69) Ix JH, Katz R, Kestenbaum BR, de Boer IH, Chonchol M, Mukamal KJ, Rifkin D, Siscovick DS, Sarnak MJ, Shlipak MG. Fibroblast growth factor-23 and death, heart failure, and cardiovascular events in community-living individuals: CHS (Cardiovascular Health Study). J Am Coll Cardiol 2012; 60(3): 200-207.

(70) Seiler S, Cremers B, Rebling NM, Hornof F, Jeken J, Kersting S, Steimle C, Ege P, Fehrenz M, Rogacev KS, Scheller B, Bohm M, Fliser D, Heine GH. The phosphatonin fibroblast growth factor 23 links calcium-phosphate metabolism with left-ventricular dysfunction and atrial fibrillation. Eur Heart J 2011; 32(21): 2688-2696.

(71) Arnlov J, Carlsson AC, Sundstrom J, Ingelsson E, Larsson A, Lind L, Larsson TE. Serum FGF23 and risk of cardiovascular events in relation to mineral metabolism and cardiovascular pathology. Clin J Am Soc Nephrol 2013; 8(5): 781-786. 
(72) Taylor EN, Rimm EB, Stampfer MJ, Curhan GC. Plasma fibroblast growth factor 23, parathyroid hormone, phosphorus, and risk of coronary heart disease. Am Heart J 2011; 161(5): 956-962.

(73) Ter Maaten JM, Voors AA, Damman K, van der MP, Anker SD, Cleland JG, Dickstein K, Filippatos G, van der HP, Hillege HL, Lang CC, Metra M, Navis G, Ng L, Ouwerkerk W, Ponikowski P, Samani NJ, van Veldhuisen DJ, Zannad F, Zwinderman AH, de Borst $\mathrm{MH}$. Fibroblast growth factor 23 is related to profiles indicating volume overload, poor therapy optimization and prognosis in patients with new-onset and worsening heart failure. Int J Cardiol 2018; 253: 84-90.

(74) Udell JA, Morrow DA, Jarolim P, Sloan S, Hoffman EB, O'Donnell TF, Vora AN, Omland T, Solomon SD, Pfeffer MA, Braunwald E, Sabatine MS. Fibroblast growth factor-23, cardiovascular prognosis, and benefit of angiotensin-converting enzyme inhibition in stable ischemic heart disease. J Am Coll Cardiol 2014; 63(22): 2421-2428.

(75) Gruson D, Ferracin B, Ahn SA, Rousseau MF. Head to head comparison of intact and Cterminal fibroblast growth factor 23 in heart failure patients with reduced ejection fraction. Int J Cardiol 2017; 248: 270-273.

(76) Poelzl G, Trenkler C, Kliebhan J, Wuertinger P, Seger C, Kaser S, Mayer G, Pirklbauer M, Ulmer $\mathrm{H}$, Griesmacher A. FGF23 is associated with disease severity and prognosis in chronic heart failure. Eur J Clin Invest 2014; 44(12): 1150-1158.

(77) Wohlfahrt P, Melenovsky V, Kotrc M, Benes J, Jabor A, Franekova J, Lemaire S, Kautzner J, Jarolim P. Association of Fibroblast Growth Factor-23 Levels and Angiotensin-Converting Enzyme Inhibition in Chronic Systolic Heart Failure. JACC Heart Fail 2015; 3(10): 829-839.

(78) Leaf DE, Siew ED, Eisenga MF, Singh K, Mc Causland FR, Srivastava A, Ikizler TA, Ware LB, Ginde AA, Kellum JA, Palevsky PM, Wolf M, Waikar SS. Fibroblast Growth Factor 23 Associates with Death in Critically III Patients. Clin J Am Soc Nephrol 2018; 13(4): 531-541.

(79) Seiler S, Rogacev KS, Roth HJ, Shafein P, Emrich I, Neuhaus S, Floege J, Fliser D, Heine $\mathrm{GH}$. Associations of FGF-23 and sKlotho with cardiovascular outcomes among patients with CKD stages 2-4. Clin J Am Soc Nephrol 2014; 9(6): 1049-1058.

(80) Grabner A, Schramm K, Silswal N, Hendrix M, Yanucil C, Czaya B, Singh S, Wolf M, Hermann S, Stypmann J, Di Marco GS, Brand M, Wacker MJ, Faul C. FGF23/FGFR4-mediated left ventricular hypertrophy is reversible. Sci Rep 2017; 7(1): 1993.

(81) Grabner A, Amaral AP, Schramm K, Singh S, Sloan A, Yanucil C, Li J, Shehadeh LA, Hare JM, David V, Martin A, Fornoni A, Di Marco GS, Kentrup D, Reuter S, Mayer AB, Pavenstadt H, Stypmann J, Kuhn C, Hille S, Frey N, Leifheit-Nestler M, Richter B, Haffner D, Abraham R, 
Bange J, Sperl B, Ullrich A, Brand M, Wolf M, Faul C. Activation of Cardiac Fibroblast Growth Factor Receptor 4 Causes Left Ventricular Hypertrophy. Cell Metab 2015; 22(6): 1020-1032.

(82) Qin Z, Liu X, Song M, Zhou Q, Yu J, Zhou B, Wu Y, He Y, Huang L. Fibroblast growth factor 23 as a predictor of cardiovascular and all-cause mortality in prospective studies. Atherosclerosis 2017; 261: 1-11.

(83) Koller L, Kleber ME, Brandenburg VM, Goliasch G, Richter B, Sulzgruber P, Scharnagl H, Silbernagel G, Grammer TB, Delgado G, Tomaschitz A, Pilz S, Berger R, Mortl D, Hulsmann M, Pacher R, Marz W, Niessner A. Fibroblast Growth Factor 23 Is an Independent and Specific Predictor of Mortality in Patients With Heart Failure and Reduced Ejection Fraction. Circ Heart Fail 2015; 8(6): 1059-1067.

(84) Goetz R, Nakada Y, Hu MC, Kurosu H, Wang L, Nakatani T, Shi M, Eliseenkova AV, Razzaque MS, Moe OW, Kuro-o M, Mohammadi M. Isolated C-terminal tail of FGF23 alleviates hypophosphatemia by inhibiting FGF23-FGFR-Klotho complex formation. Proc Natl Acad Sci U S A 2010; 107(1): 407-412.

(85) Xie J, Yoon J, An SW, Kuro O, Huang CL. Soluble Klotho Protects against Uremic Cardiomyopathy Independently of Fibroblast Growth Factor 23 and Phosphate. J Am Soc Nephrol 2015; 26(5): 1150-1160.

(86) Touchberry CD, Green TM, Tchikrizov V, Mannix JE, Mao TF, Carney BW, Girgis M, Vincent RJ, Wetmore LA, Dawn B, Bonewald LF, Stubbs JR, Wacker MJ. FGF23 is a novel regulator of intracellular calcium and cardiac contractility in addition to cardiac hypertrophy. Am J Physiol Endocrinol Metab 2013; 304(8): E863-E873.

(87) Richter M, Lautze HJ, Walther T, Braun T, Kostin S, Kubin T. The failing heart is a major source of circulating FGF23 via oncostatin M receptor activation. J Heart Lung Transplant 2015; 34(9): 1211-1214.

(88) Andrukhova O, Slavic S, Odorfer KI, Erben RG. Experimental Myocardial Infarction Upregulates Circulating Fibroblast Growth Factor-23. J Bone Miner Res 2015; 30(10): 18311839.

(89) Poss J, Mahfoud F, Seiler S, Heine GH, Fliser D, Bohm M, Link A. FGF-23 is associated with increased disease severity and early mortality in cardiogenic shock. Eur Heart J Acute Cardiovasc Care 2013; 2(3): 211-218.

(90) Fuernau G, Poss J, Denks D, Desch S, Heine GH, Eitel I, Seiler S, de Waha S, Ewen S, Link A, Schuler G, Adams V, Bohm M, Thiele H. Fibroblast growth factor 23 in acute myocardial infarction complicated by cardiogenic shock: a biomarker substudy of the Intraaortic Balloon Pump in Cardiogenic Shock II (IABP-SHOCK II) trial. Crit Care 2014; 18(6): 713. 
(91) Wolf M, Koch TA, Bregman DB. Effects of iron deficiency anemia and its treatment on fibroblast growth factor 23 and phosphate homeostasis in women. J Bone Miner Res 2013; 28(8): 1793-1803.

(92) Koos R, Mahnken AH, Muhlenbruch G, Brandenburg V, Pflueger B, Wildberger JE, Kuhl HP. Relation of oral anticoagulation to cardiac valvular and coronary calcium assessed by multislice spiral computed tomography. Am J Cardiol 2005; 96(6): 747-749.

(93) Viegas CS, Rafael MS, Enriquez JL, Teixeira A, Vitorino R, Luis IM, Costa RM, Santos S, Cavaco S, Neves J, Macedo AL, Willems BA, Vermeer C, Simes DC. Gla-rich protein acts as a calcification inhibitor in the human cardiovascular system. Arterioscler Thromb Vasc Biol 2015; 35(2): 399-408.

(94) Cranenburg EC, Vermeer C, Koos R, Boumans ML, Hackeng TM, Bouwman FG, Kwaijtaal M, Brandenburg VM, Ketteler M, Schurgers LJ. The circulating inactive form of matrix Gla Protein (ucMGP) as a biomarker for cardiovascular calcification. J Vasc Res 2008; 45(5): 427-436.

(95) Westenfeld R, Krueger T, Schlieper G, Cranenburg EC, Magdeleyns EJ, Heidenreich S, Holzmann S, Vermeer C, Jahnen-Dechent W, Ketteler M, Floege J, Schurgers LJ. Effect of vitamin K2 supplementation on functional vitamin K deficiency in hemodialysis patients: a randomized trial. Am J Kidney Dis 2012; 59(2): 186-195.

(96) Koos R, Mahnken AH, Sinha AM, Wildberger JE, Hoffmann R, Kuhl HP. Aortic valve calcification as a marker for aortic stenosis severity: assessment on 16-MDCT. AJR Am J Roentgenol 2004; 183(6): 1813-1818.

(97) Hayashi M, Takamatsu I, Kanno Y, Yoshida T, Abe T, Sato Y. A case-control study of calciphylaxis in Japanese end-stage renal disease patients. Nephrol Dial Transplant 2012; 27(4): 1580-1584. 
